\title{
Performance Assessment for Pump-and-Treat Closure or Transition
}

\section{September 2015}

\author{
M.J. Truex \\ C.D. Johnson \\ D.J. Becker \\ M.H. Lee \\ M.J. Nimmons
}




\title{
DISCLAIMER
}

This report was prepared as an account of work sponsored by an agency of the United States Government. Neither the United States Government nor any agency thereof, nor Battelle Memorial Institute, nor any of their employees, makes any warranty, express or implied, or assumes any legal liability or responsibility for the accuracy, completeness, or usefulness of any information, apparatus, product, or process disclosed, or represents that its use would not infringe privately owned rights. Reference herein to any specific commercial product, process, or service by trade name, trademark, manufacturer, or otherwise does not necessarily constitute or imply its endorsement, recommendation, or favoring by the United States Government or any agency thereof, or Battelle Memorial Institute. The views and opinions of authors expressed herein do not necessarily state or reflect those of the United States Government or any agency thereof.

\author{
PACIFIC NORTHWEST NATIONAL LABORATORY \\ operated by \\ BATTELLE \\ for the \\ UNITED STATES DEPARTMENT OF ENERGY \\ under Contract DE-AC05-76RL01830
}

Printed in the United States of America
Available to DOE and DOE contractors from the Office of Scientific and Technical Information, P.O. Box 62, Oak Ridge, TN 37831-0062; ph: (865) 576-8401 fax: $(865) 576-5728$
email: reports $a$ adonis.osti.gov
Available to the public from the National Technical Information Service 5301 Shawnee Rd., Alexandria, VA 22312 ph: (800) 553-NTIS (6847)

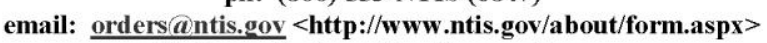 Online ordering: http://www.ntis.gov


PNNL-24696

RPT-DVZ-AFRI-029

\title{
Performance Assessment for Pump-and-Treat Closure or Transition
}

\author{
M.J. Truex ${ }^{1}$ \\ C.D. Johnson ${ }^{1}$ \\ D.J. Becker ${ }^{2}$ \\ M.H. Lee ${ }^{1}$ \\ M.J. Nimmons ${ }^{1}$
}

September 2015

\footnotetext{
${ }^{1}$ Pacific Northwest National Laboratory

${ }^{2}$ U.S. Army Corps of Engineers Environmental and Munitions Center of Expertise
}

Prepared for

the U.S. Department of Energy under Contract DE-AC05-76RL01830

Pacific Northwest National Laboratory

Richland, Washington 99352 



\begin{abstract}
A structured performance assessment approach is useful to evaluate pump-and-treat (P\&T) groundwater remediation, which has been applied at numerous sites. Consistent with the U.S. Environmental Protection Agency's Groundwater Road Map, performance assessment during remedy implementation may be needed, and should consider remedy optimization, transition to alternative remedies, or remedy closure. In addition, a recent National Research Council study examined groundwater remediation at complex contaminated sites and concluded that it may be beneficial to evaluate remedy performance and the potential need for transition to alternative approaches at these sites. The intent of this document is to provide a structured approach for assessing P\&T performance to support a decision to optimize, transition, or close a P\&T remedy. The process presented in this document for gathering information and performing evaluations to support P\&T remedy decisions includes use of decision elements to distinguish between potential outcomes of a remedy decision. Case studies are used to augment descriptions of decision elements and to illustrate each type of outcome identified in the performance assessment approach. The document provides references to resources for tools and other guidance relevant to conducting the $\mathrm{P} \& \mathrm{~T}$ assessment.
\end{abstract}





\section{Summary}

A structured performance assessment approach is useful to evaluate pump-and-treat (P\&T) groundwater remediation, which has been applied at numerous sites. Consistent with the U.S. Environmental Protection Agency's Groundwater Road Map, performance assessment during remedy implementation may be needed, and should consider remedy optimization, transition to alternative remedies, or remedy closure. In addition, a recent National Research Council study examined groundwater remediation at complex contaminated sites and concluded that it may be beneficial to evaluate remedy performance and the potential need for transition to alternative approaches at these sites. The intent of this document is to provide a structured approach for assessing P\&T performance to support a decision to optimize, transition, or close a P\&T remedy.

The performance assessment approach described in this document is organized to use a set of decision elements to help decision makers distinguish between several categories of decision outcomes associated with transition, optimization, or closure of P\&T systems. The decision elements selected for use in the P\&T performance assessment include information about:

- Contaminant concentrations and trends;

- Contaminant mass discharge from source areas or at selected plume locations;

- The attenuation capacity of the aquifer;

- Estimated future plume behavior and time to reach remedial action objectives (RAOs) for the site; and

- P\&T system design, operational, and cost information.

The categories of decision outcomes for this P\&T assessment are:

- Initiate P\&T remedy closure;

- Continue with existing or optimized P\&T;

- Transition to Monitored Natural Attenuation (MNA);

- Supplement P\&T with other treatment technologies; or

- Transition to a new remedy approach.

The performance assessment approach includes revisiting the conceptual site model (CSM), where it is important to consider the current nature of the source and plume as well as the aspects controlling contaminant transport and remedy performance. However, to effectively support the P\&T performance assessment and associated remedy decisions, efforts for updating the CSM are focused on describing the site and current conditions in terms of the decision elements defined in this document.

The decision elements from the updated CSM are applied in a decision logic framework to facilitate determining the outcome that is best supported by the performance assessment. Figure ES-1 shows the primary elements of the decision logic, highlighting the process to distinguish 
between different categories of decision outcomes. Case studies are provided in this document as examples for each of the decision outcomes. In addition, this document provides references to resources for tools and other guidance relevant to conducting the $\mathrm{P} \& \mathrm{~T}$ assessment.

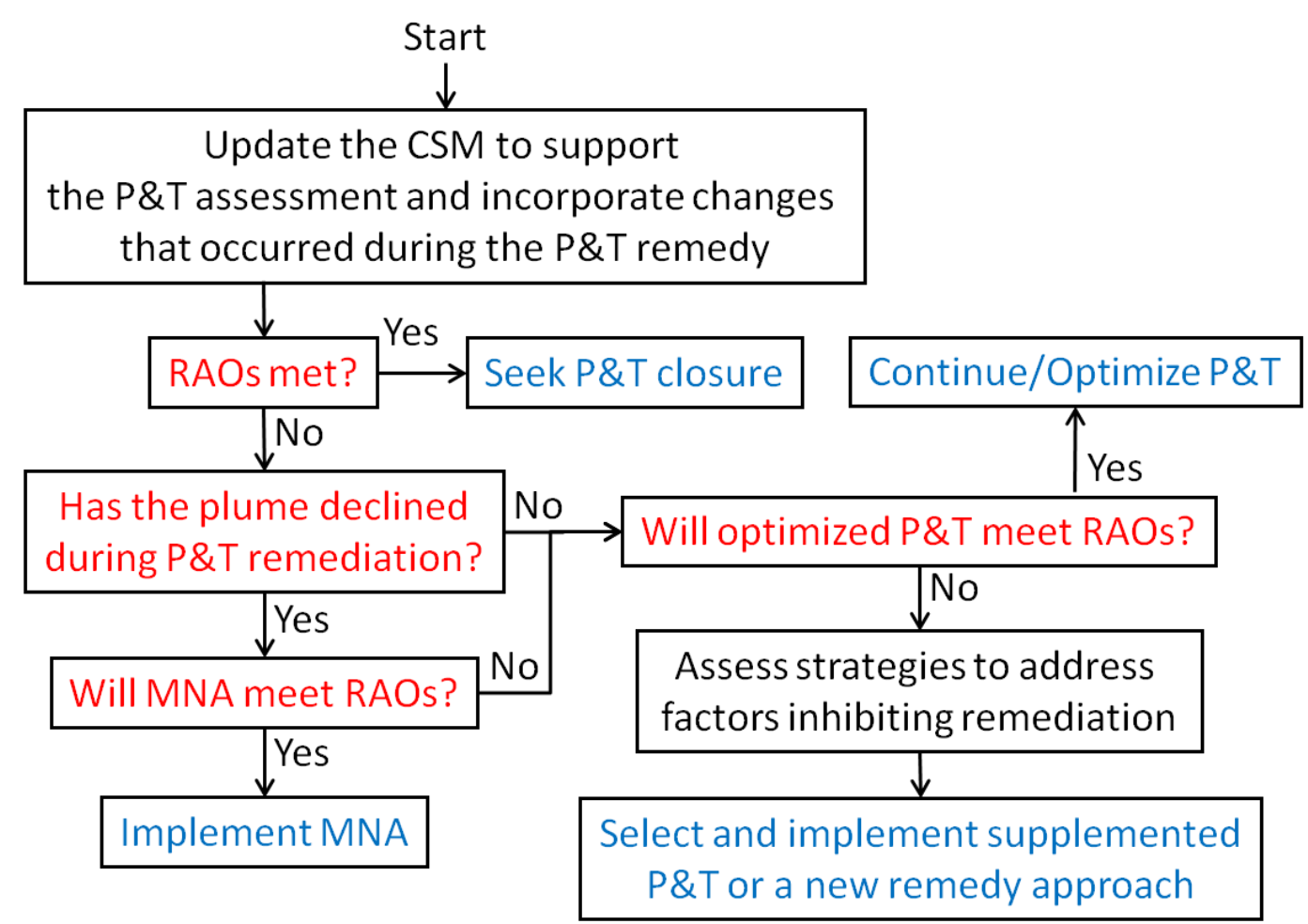

Figure ES-1. Primary elements of the decision logic used for the P\&T assessment. The full decision logic includes additional elements of the decision process, which are omitted here for brevity. 


\section{Acknowledgments}

This document was prepared by the Deep Vadose Zone - Applied Field Research Initiative at Pacific Northwest National Laboratory. Funding for this work was provided by the U.S. Department of Energy (DOE) Richland Operations Office. The Pacific Northwest National Laboratory is operated by Battelle Memorial Institute for the DOE under Contract DE-AC0576RL01830.

The following people provided case study information.

- Dave Becker, U.S. Army Corps of Engineers Environmental and Munitions Center of Expertise

- Ken Broberg, Stoller Newport News Nuclear (SN3)

- Hope Lee, Pacific Northwest National Laboratory

- Kira Lynch, EPA Region 10

- Tamzen Macbeth, CDM Smith

We also thank the following reviewers of this document.

- Kira Lynch, EPA, Region 10

- Mark Rothas, Mike Bailey, Chuck Coyle, and John Hartley, U.S. Army Corps of Engineers, Environmental and Munitions Center of Expertise

- Mike Singletary, U.S. Navy, NAVFAC Southeast

- Nancy Ruiz, U.S. Navy, Environmental Resources and Assessment Division Naval Facilities Engineering and Expeditionary Warfare Center

- Gunarti Coghlan, U.S. Navy, NAVFAC Headquarters

- Skip Chamberlain, Department of Energy, Office of Environmental Management

- Ken Broberg, Stoller Newport News Nuclear (SN3)

- Tamzen Macbeth, CDM Smith

- Mart Oostrom, Pacific Northwest National Laboratory

We also thank Bill Myers of Joint Base Lewis McChord for the use of information from site reports to provide examples for elements of the $\mathrm{P} \& \mathrm{~T}$ performance assessment process. 



\section{Acronyms and Abbreviations}

$\mathrm{AC}$

AFB

AMSL

ARAR

BB

bgs

CBA

CEC

CERCLA

CFR

CMD

$\mathrm{COC}$

CSM

DCE

DCP

DNA

DNAPL

DOE

Eh

EMD

EPA

ESD

FEPs

GMA

INL

ISCO

ISTR

ITRC

MCL

MNA

MSL

NAPL
Attenuation capacity

Air Force base

Above mean sea level

Applicable or relevant and appropriate requirements

Base Boundary (plume); pertains to Case Study 1

Below ground surface

Central Base Area (plume); pertains to Case Study 1

Cation exchange capacity

Comprehensive Environmental Response, Compensation, and Liability Act

U.S. Code of Federal Regulations

Contaminant mass discharge

Contaminant of concern

Conceptual site model

Dichloroethene (which may be the 1,1-DCE, cis-1,2-DCE, or the trans-1,2,DCE isomer)

1,2-dichloropropane

Deoxyribonucleic acid

Dense non-aqueous phase liquid

U.S. Department of Energy

Oxidation/reduction potential

Environmental molecular diagnostics

U.S. Environmental Protection Agency

Explanation of significant differences

Features, events, and processes

Great Miami Aquifer; pertains to Case Study 3

Idaho National Laboratory

In situ chemical oxidation

In situ thermal remediation

Interstate Technology \& Regulatory Council

Maximum contaminant level

Monitored natural attenuation

Mean sea level (i.e., elevation relative to mean sea level)

Non-aqueous phase liquid 


$\begin{array}{ll}\text { NPL } & \text { National Priorities List } \\ \text { NRC } & \text { National Research Council } \\ \text { ORP } & \text { Oxidation/reduction potential } \\ \text { OU } & \text { Operable unit } \\ \text { P\&T } & \text { Pump-and-treat } \\ \text { PCA } & 1,1,2,2 \text {-tetrachloroethane } \\ \text { PCE } & \text { Tetrachloroethene } \\ \text { PNNL } & \text { Pacific Northwest National Laboratory } \\ \text { POTW } & \text { Publicly owned treatment works } \\ \text { RAO } & \text { Remedial action objectives } \\ \text { RCRA } & \text { Resource Conservation and Recovery Act } \\ \text { RD/RA } & \text { Remedial design/remedial action } \\ \text { RDX } & \text { Research Department explosive (cyclotrimethylenetrinitramine) } \\ \text { RI/FS } & \text { Remedial investigation/feasibility study } \\ \text { ROD } & \text { Record of decision } \\ \text { SLA } & \text { Sea Level Aquifer } \\ \text { SVE } & \text { Soil vapor extraction } \\ \text { TAN } & \text { Test Area North (at INL) } \\ \text { TCE } & \text { Trichloroethene } \\ \text { TI } & \text { Technical impracticability (waiver) } \\ \text { TNT } & \text { Trinitrotoluene } \\ \text { UCL } & \text { Upper confidence limit } \\ \text { USACE } & \text { U.S. Army Corps of Engineers } \\ \text { USCS } & \text { Unified soil classification system } \\ \text { USGS } & \text { U.S. Geological Survey } \\ \text { UV } & \text { Ultraviolet } \\ \text { VC } & \text { Vinyl chloride } \\ \text { WDOE } & \text { Washington State Department of Ecology } \\ & \end{array}$




\section{Contents}

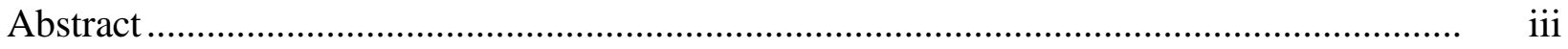

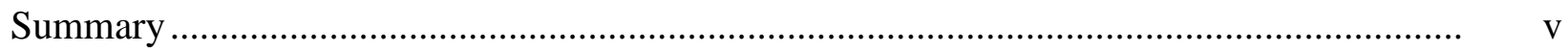

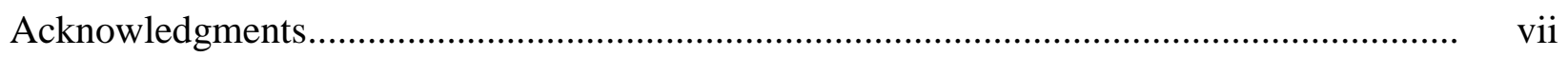

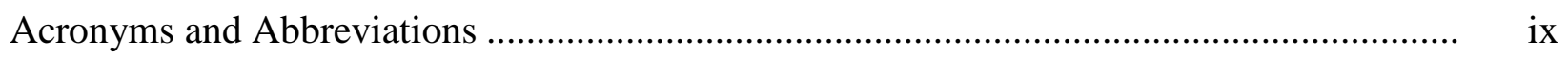

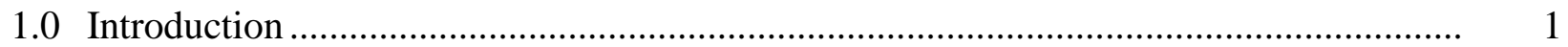

1.1 Concepts Relevant to a Pump-and-Treat Scenario ............................................ 1

1.2 Definition of Terms ................................................................................... 4

1.2.1 Contamination, Source Areas, Plumes ................................................ 4

1.2.2 Extraction Wells ................................................................................. 5

1.2.3 Monitoring, Receptors, and Goals ......................................................... 6

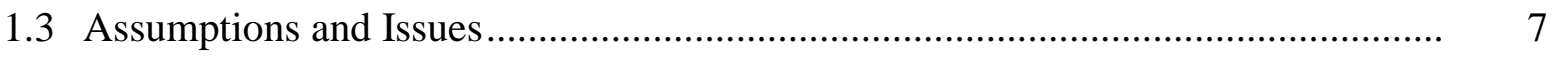

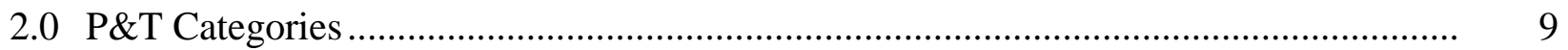

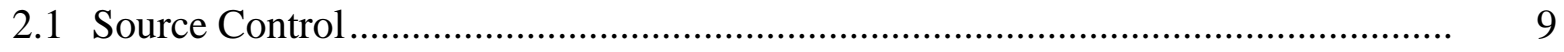

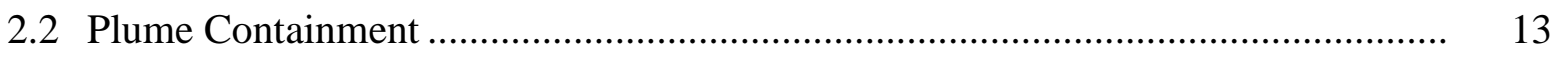

2.3 Plume Reduction ........................................................................................ 17

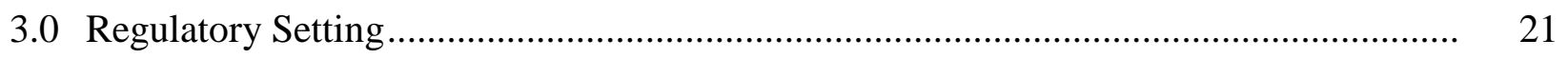

4.0 Performance Assessment Decision Logic ................................................................ 23

5.0 Conceptual Site Model Update and Approaches for Obtaining Decision Element

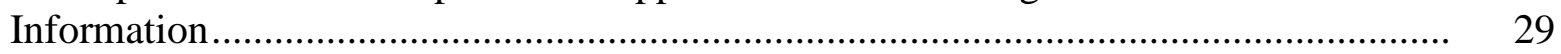

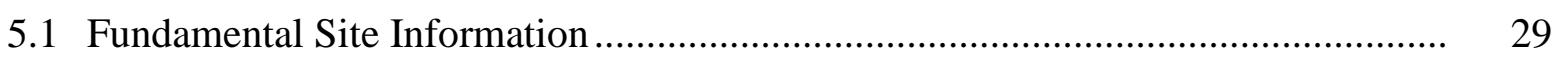

5.1.1 Site Overview and Context of the Plume and Remedy Configuration.......... 29

5.1.2 Describe the Subsurface Hydrogeology .................................................. 30

5.1.3 Describe the Hydraulic Head Distribution with and without P\&T Operating .............................................................................................. 33

5.1.4 Describe the Source, Plume, and Known Controlling Features, Events, and Processes ........................................................................................ 35

5.2 Decision Element Information.................................................................. 38

5.2.1 Contaminant Concentrations and Trends ................................................. 39

5.2.2 Contaminant Mass Discharge ............................................................... 41

5.2.3 Natural Attenuation Capacity ............................................................. 46

5.2.4 Estimates of Plume Behavior and Time to Reach RAOs ........................... 48

5.2.5 P\&T Design and Operational Information ............................................... 49 
6.0 P\&T Remedy Assessment ............................................................................... 53

6.1 Assessment With Respect to RAOs and Plume Changes........................................ 56

6.2 Assessment for Declining Plumes .................................................................... 56

6.2.1 Assessment of MNA............................................................................. 57

6.2.2 Assessment of Continued P\&T ........................................................... 61

6.3 Persistent Plume/Source Assessment ................................................................. 62

6.4 Alternative Remedy Selection ..................................................................... 65

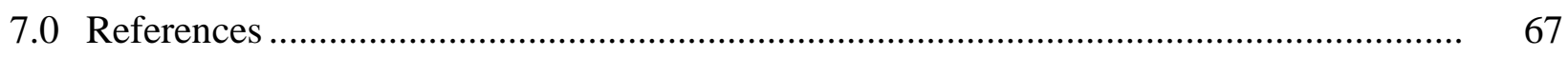

Appendix A: Case Studies ………………………................................................... A.1 


\section{Figures}

1 Diagram depicting the general pump-and-treat scenario where a source zone results in a dissolved phase plume, extraction wells are used to intercept the contaminant plume, and contaminated water is treated in an aboveground treatment system prior to final disposition

2 Conceptual application of P\&T for source control, showing the intended outcome of cutting off the source from the main dissolved phase plume

3 Change in TCE concentrations over time at plume monitoring wells located 1100 feet downgradient and 2700 feet downgradient from a Source Control P\&T system......

4 Predicted contaminant mass discharge across a flux plane located about $7500 \mathrm{ft}$ downgradient from a Source Control P\&T system, with the plane oriented perpendicular to the direction of groundwater flow and spanning the width/depth of the plume

5 Conceptual application of P\&T for plume containment, showing intended outcomes for two examples of extraction well positioning within the plume and at the leading edge of the plume

6 Lateral locations of flux planes for the estimated mass discharge analysis shown in Figure 7

7 Contaminant mass discharge across the flux planes depicted in Figure 6 for history matching and predictive portions of a numerical model simulation for a plumecontainment P\&T system

8 Conceptual application of P\&T for plume reduction, showing progress towards the intended outcome of dissolved phase plume volumetric treatment.

9 Conceptual depiction of the source flux zone being controlled by P\&T and a downgradient attenuation zone, whose extent must be determined by the site decision makers

10 Decision logic flow chart

11 Example depiction of a site plume and remedy overview from Joint Base Lewis McChord

12 Conceptual geologic cross section approximately along the centerline of the plume in the Vashon Aquifer.

13 Annotated numerical model cross section along the nominal axis of the contaminant plume in the Vashon Aquifer located above the Qpon Aquitard

14 Localized cross section of the nominal hydrogeology along the Vashon Aquifer plume centerline near the I-5 P\&T system and the window to the lower Sea Level Aquifer

15 General flow path of contamination in the Sea Level Aquifer from the window toward Puget Sound. 
16 Representative 2004 hydraulic head data for wells projected onto the cross section along the Vashon plume centerline near the I-5 P\&T system and the window to the lower Sea Level Aquifer...

17 Example initial site depiction identifying the major elements of the site that will need to be evaluated as part of contaminant fate/transport assessment and remediation design, considering contaminant fluxes and conditions that will affect contaminant fate and transport, and identifying reactive facies that participate in sorption or solubility control reactions with contaminants

18 A variety of attenuation mechanisms may be important to contaminant transport..........

19 Example of the Joint Base Lewis McChord plume system with interpretation of flow paths, TCE contaminant concentrations, and CMD for conditions prior to P\&T operations

20 Interpolation of TCE concentration data in the Vashon Aquifer at Joint Base Lewis McChord for 2007 and 2012

21 Representation of a plume captured at a pumping well

22 Concentrations at individual P\&T wells over time and grouped by individual well for each year....

23 Example of a mass flux transect

24 Given a transect of wells, the actual contaminant distribution can be assessed with passive flux measurements to provide an interpreted contaminant flux distribution .......

25 Elements of an integrated pump test in which concentration data from a transect of wells perpendicular to the plume flow direction is analyzed to determine contaminant mass flux and average concentration at the transect.

26 Conceptual examples of attenuation rate calculations for point rates, bulk rates, or biodegradation rates.

27 Example geologic cross section and contaminant data for a P\&T well system segment at Joint Base Lewis McChord.....

28 Example of modeling results for a P\&T system at defined pumping rates, showing calculated hydraulic head contours and the extent of a one-year capture zone, as determined from backwards particle tracking at different layers/elevations.

29 Decision logic, Section 6.0 cross-references, and cross-reference of outcomes and case studies

30 Conceptual depiction of the source flux zone being controlled by P\&T and a downgradient attenuation zone, whose extent must be determined by the site decision makers

\section{Tables}

1 Summary of Decision Criteria and Outcomes...... 


\subsection{Introduction}

Groundwater remediation by the pump-and-treat (P\&T) technology has been applied at numerous sites. Existing guidance (e.g., EPA 1994, 1996a, 1997, 1999a, 1999b, 2000a, 2002a, 2007a, 2008; USACE 1999, 2000) provides information on design, operation, and optimization for P\&T systems. Research has also identified factors that impact the performance of P\&T remedies (e.g., Rivett et al. 2006; Sale and Newell 2011). Consistent with the U.S. Environmental Protection Agency's Groundwater Road Map (EPA 2011a) and Groundwater Remedy Completion Strategy (EPA 2014a), performance assessment during remedy implementation may be needed and should consider optimization of a remedy, transition to alternative remedies, or remedy closure. In addition, a recent National Research Council study (NRC 2013) examined groundwater remediation at complex contaminated sites and concluded that it may be beneficial to evaluate remedy performance and the potential need for transition to alternative approaches at these sites. The intent of this document is to provide a structured approach for assessing P\&T performance to support a decision to optimize, transition, or close a P\&T remedy.

The process presented in this document for gathering information and performing evaluations to support P\&T remedy decisions includes 1) considering how the P\&T system is applied, 2) revisiting the conceptual site model, and 3) use of decision elements to distinguish between potential outcomes of a remedy decision. Case studies are used to augment descriptions of decision elements and to illustrate each type of outcome identified in the performance assessment approach.

The remainder of this introduction section presents key concepts, terms, and assumptions relevant to implementation of this guidance. Section 2.0 provides a description of the categories of P\&T applications and discusses key design and performance aspects that are important to consider when evaluating P\&T performance. The regulatory context for P\&T performance assessment and any associated remedy decisions is discussed in Section 3.0. Section 4.0 provides a description of the P\&T performance assessment approach and decision logic. Most sites will have a conceptual site model (CSM) that was used to support the original remedy design, but after P\&T operation this CSM should be revisited in the context of defining the current conditions. Data compiled during P\&T operations and any additional data needed to support optimization, transition, and closure decisions should be compiled. Section 5.0 addresses actions to update the CSM and provide technical information for the decision elements used in the P\&T performance assessment. Section 6.0 describes application of the P\&T performance assessment approach to support a remedy decision process. Full descriptions of case studies referred to in Section 6.0 are provided in Appendix A.

\subsection{Concepts Relevant to a Pump-and-Treat Scenario}

The P\&T remediation technology is conceptually simple, being comprised of three main aspects: groundwater extraction, aboveground treatment, and groundwater monitoring to assess 
performance (Figure 1). However, P\&T performance is impacted by a number of factors and the technology encompasses a broad range of variations in how it is applied. It is beyond the scope of this document to discuss all such variations, thus, P\&T closure and transition are discussed here in the context of general scenarios and major categories of P\&T implementation (Section 2.0). Each site will need to consider how their site-specific implementation is related to the general framework discussed in this document.

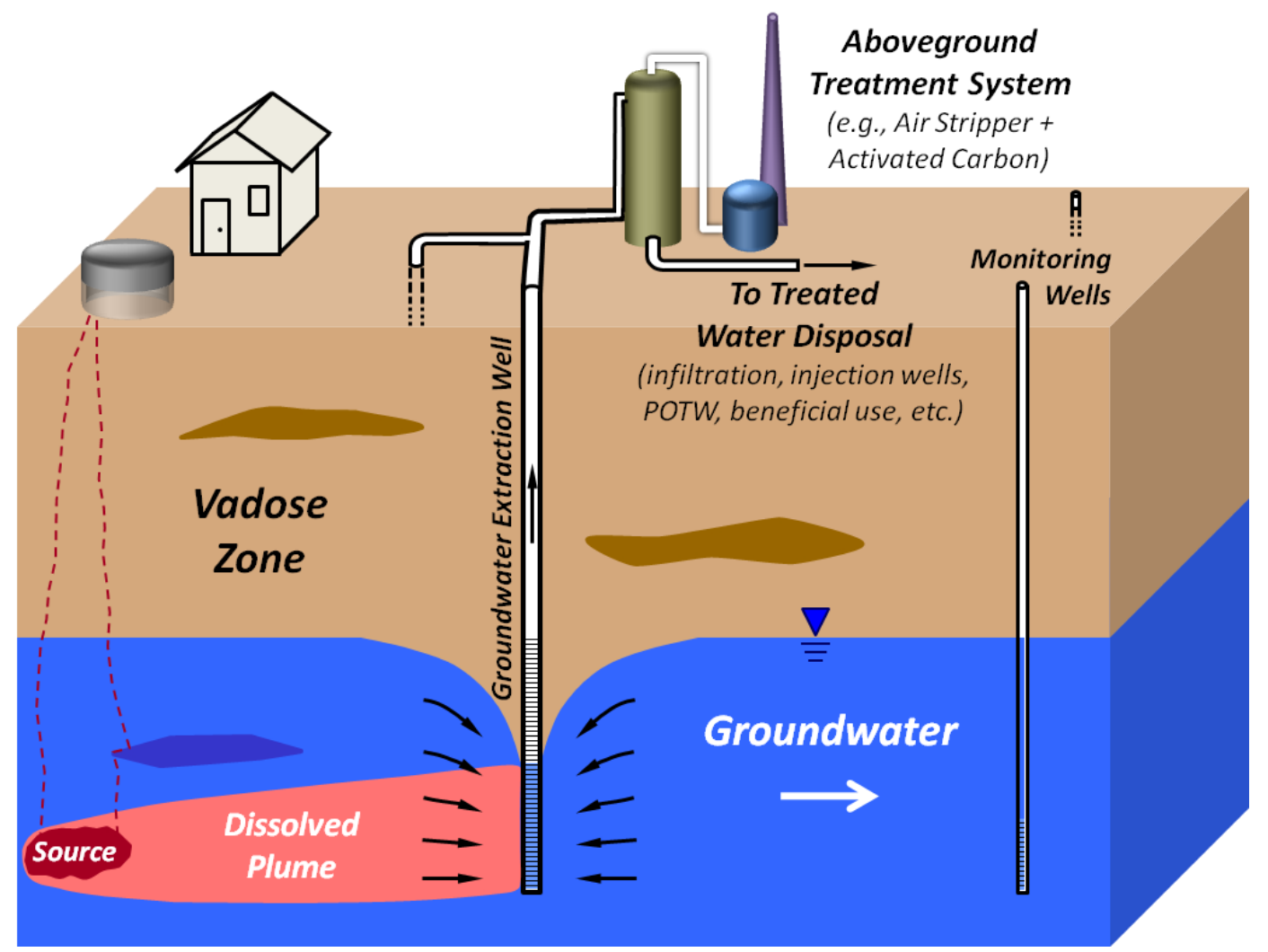

Figure 1. Diagram depicting the general pump-and-treat scenario where a source zone results in a dissolved phase plume, extraction wells are used to intercept the contaminant plume, and contaminated water is treated in an aboveground treatment system prior to final disposition. This is a simplistic depiction, which does not include all variations of $P \& T$ categories, or other important mass transfer processes like adsorption and diffusion.

A core component of $\mathrm{P} \& \mathrm{~T}$ is the process of extracting contaminated groundwater from a saturated zone (i.e., aquifer) in the subsurface via pumping wells. This is a bulk process that transfers contaminants dissolved in the groundwater from the subsurface to processing equipment/facilities located aboveground. The counterpart technology for extracting contaminants from unsaturated (vadose) zone soils is soil vapor extraction (SVE). Such bulk transfer involving fluid flow through the porous media of the subsurface also involves mass transfer processes related to the nature of the porous media, the phases present, contaminant properties, and flow regimes derived from the distribution of geological materials in the 
subsurface. One common factor in the efficiency of extracting contaminants from the subsurface is interphase mass transfer, for example between non-aqueous phase liquid (NAPL) or solid phase materials and the groundwater. A second common factor is the variation in groundwater flow characteristics resulting from geologic layering and the heterogeneity in hydrogeological property values of the subsurface materials. Zones with high permeability (e.g., sand materials) are "flushed" more readily, resulting in better removal of contaminants. In contrast, lowpermeability materials may have less advective flow, thus mass transfer of contaminant to groundwater for extraction may be limited by diffusional processes (in addition to the interphase mass transfer processes). Thus, the design and operation of the extraction well system to appropriately capture and extract contamination is of primary concern for the P\&T technology.

P\&T may also be applied for hydraulic manipulation of the aquifer for the purpose of changing the hydraulic gradient and capturing or containing contaminated groundwater. This type of manipulation can be used to help contain the impact of an ongoing source of contamination or prevent the plume from migrating further, even though overall contaminant mass reduction within the source or plume is not efficient. Hydraulic manipulation includes the effects of groundwater extraction and/or injection (or infiltration) of clean water on the hydraulic gradients in the aquifer.

Moving contamination to an aboveground location opens up many options for treating the groundwater and destroying the contaminant or reducing the volume of contaminated media. Aboveground treatment processes are very versatile and are designed with well-understood process engineering methods and treatment principles. A wide range of aboveground treatment technologies can be employed, including air stripping, granular activated carbon adsorption, ion exchange, chemical oxidation, thermal treatment, electrochemical treatment, and many others. There is often little uncertainty in the aboveground treatment system, with the considerations being more along the line of determining design specifications (e.g., the treatment system size, number of "stages," etc.) that are required to achieve the desired level of treatment in the most cost-effective manner. Because there are many variations of aboveground treatment and because it is primarily a matter of suitable engineering design to achieve the desired treatment level, the "treat" portion of P\&T will not be discussed in any detail in this document (and "P\&T" will refer mainly to the groundwater extraction portion of the technology).

Groundwater monitoring is the third aspect of applying the P\&T technology. Process and contaminant concentration data obtained from monitoring the P\&T extraction wells themselves is important, but a monitoring well network provides additional information for assessing the performance of the P\&T system. Monitoring well information may be important to augment P\&T system data for additional spatial coverage of the plume or source, in particular for assessing the portion of the plume downgradient of the P\&T system. Information on P\&T performance is useful for optimizing the P\&T groundwater extraction system and assessing P\&T closure and transition, as discussed in later sections of this document. 


\subsection{Definition of Terms}

Terminology of P\&T remediation systems is presented below to facilitate the subsequent description of P\&T performance assessment. Additional terminology/concepts related to P\&T implementation categories are discussed in Section 2.0. Concepts relevant to the P\&T performance assessment, such as contaminant mass discharge and attenuation capacity, are described in Sections 4.0 to 6.0.

\subsubsection{Contamination, Source Areas, Plumes}

The contamination addressed by P\&T consists of dissolved-phase contaminants, i.e., organic or inorganic contaminants that are solutes in the groundwater of a saturated zone in the subsurface. This document does not include applications of multi-phase extraction that are designed to extract NAPL as a source reduction method. P\&T is not applied within unsaturated (vadose) zone soils; SVE is the counterpart technology for extraction of vadose zone vapor contamination.

Contamination can be introduced to the groundwater in multiple ways. Common mechanisms by which contaminants are introduced into groundwater include infiltration of a NAPL, infiltration of dissolved aqueous solutes along with natural or artificial recharge, leaching of contaminants from soil to groundwater, or mass transfer between vadose zone soil gas and the groundwater. A less common mechanism would be direct pollution of groundwater (e.g., via leakage of waste containers or tanks placed within the saturated zone or disposal of waste via a well screened in a saturated zone). Contaminants will interact with the environment as they migrate to (and through) the groundwater and the contamination will typically result in a source area that produces a dissolved contaminant plume in the groundwater.

When organic or inorganic contaminants are introduced to the subsurface, they will interact with the environment, which can affect the mobility/availability of the contaminants for extraction processes. Interactions with the environment include mass transfer between phases (gas, aqueous, NAPL, and solid), including volatilization, dissolution, and adsorption processes. Minerals and/or organic solids may adsorb contaminant mass, depending on the contaminant concentrations, the contaminant properties, and the properties of the soil components. Other interactions include chemical reactions, either abiotic or biologically mediated. Chemical reactions can result in transformation of a contaminant to a different compound (whether that is another contaminant or an innocuous compound). Chemical reactions can also enhance adsorption or precipitation by changing the redox state of a contaminant (i.e., for inorganic contaminants). The interphase mass transfer and environmental interactions play a role in how a contaminant migrates (due to advective and/or diffusive gradients) and the potential for contaminant accumulation in a particular phase or zone. This type of accumulation could result in a long-term source of contamination. For example, adsorbed contaminant mass in a diffusionlimited zone can become a source for future aqueous phase contamination when conditions change to become suitable for desorption of the contaminant. 
The source area for a waste site is a zone of high contaminant concentration that is the origin of a groundwater contaminant plume. There may be more than one source area at a site, depending on the nature of the environmental release. For the purpose of this document, the source area is defined to be in the vicinity where waste disposal or leakage initially occurred. At this location, contaminants may be present in the vadose zone, with ongoing mass transfer to the groundwater as the groundwater plume source. The source area may also (or instead) have a continuing source within the aquifer. Aquifer locations where contaminant mass has accumulated (e.g., residual NAPL mass immobilized within the soil pore structure, such as in low permeability layers/lenses in the subsurface) can be a continuing source to the plume as mass transfers out of these zones. Depending on the history of contaminant interactions in the subsurface, continuing sources may be present downgradient of the original source area through mechanisms such as matrix diffusion. In general, these downgradient sources are more dispersed and are considered part of the plume with respect to implementing "source control."

The distribution of dissolved phase contamination in the groundwater comprises a "contaminant plume." Generally, a contaminant plume is defined as the spatial extent of dissolved phase contaminant concentrations at or above the maximum contaminant level (MCL). Contaminant plumes will have a gradation in concentrations, with high concentrations at the source area (or core of the plume) and lower concentrations further downgradient.

\subsubsection{Extraction Wells}

An extraction well uses a pump to pull water from a vertical (or occasionally from a horizontal) interval screened in the saturated zone, moving the water to the surface for further disposition (e.g., treatment, beneficial use, etc.). Pumping an extraction well "captures" water in a zone around the well, although the time it takes for water to travel to the well will differ depending on proximity to the extraction well. The spatial extent of this capture zone is related to the pumping rate, thickness of the aquifer, aquifer hydraulic properties, and the hydraulic gradient in the aquifer. These parameters also determine the "drawdown" (depression) of the groundwater hydraulic head (a measure of pressure) from static conditions. Multiple wells may be used together for an extraction system and may be located in a variety of configurations. Common multiple-extraction-well P\&T configurations include a line of wells and a V-shaped arrangement. Using multiple extraction wells can improve capture of groundwater because of the additive effects on the drawdown of hydraulic head.

Contaminated groundwater that is extracted from the saturated zone requires treatment (discussed in Section 1.1) and subsequent disposition. There are several common outlets for treated groundwater (EPA 2007b). Groundwater is often returned to the subsurface via injection wells or infiltration galleries. Injection wells or infiltration galleries can be used in conjunction with extraction wells to manipulate the local hydraulic gradient, influencing the direction and velocity of plume movement for the purpose of enhancing capture or plume control. Another common outlet for treated water, when appropriate permits are secured, would be into the collection system for a publicly owned treatment works (POTW) or into surface waters (e.g., a 
lake or river). The beneficial use of treated groundwater (for example, as the supply for a cooling water system) is a third possible category of treated water disposition.

\subsubsection{Monitoring, Receptors, and Goals}

The implementation and performance monitoring for a $\mathrm{P} \& \mathrm{~T}$ remedy are influenced by key factors, including the nature of the hydrogeological units that are contaminated, the direction of contaminant movement, how fast the contamination is migrating, what attenuation process are involved, the location of potential receptors, and the objectives of the remedial action. These factors are typically identified in a CSM as part of the remediation planning and design processes. The CSM should include quantitative information about important factors that will be used to support remedy decisions about optimization, transition, or closure of a P\&T system. After a period of remediation, it is typically necessary to update the CSM using available characterization, plume monitoring, and P\&T operational data. An important aspect of updating the CSM is inclusion of trend data that are available from the period of P\&T remediation. The trend data will help define the plume behavior and related conceptual site model elements.

Protecting potential receptors is a key focus of the remedial action and will influence the nature of the remedy. A receptor is a point where human or ecological exposure to contaminants may occur via a defined exposure route (e.g., ingestion, inhalation) as a result of contaminant migration. The location of a potential receptor and the rate of contaminant migration can lead to different requirements for the remedy. If a receptor is distant or contaminant migration is slow, then the urgency of remediation is less. In contrast, a receptor within or close to the contamination would require more urgency in remediation and would have different objectives for the remedy. In addition, future beneficial use of groundwater is typically considered as part of setting remedial action objectives (RAOs) and may also have important implications for remedy design and evaluation of $\mathrm{P} \& \mathrm{~T}$ closure or transition to alternative approaches, especially for "complex" sites (NRC 2013).

Collection of monitoring data is important to determine the effectiveness of the remedial technology. Thus, it is important to follow guidance (e.g., EPA 1994, 2002a, 2003, 2004; ITRC 2010a, 2011b) on the design and placement of monitoring wells to obtain useful data to answer the relevant questions about the remediation. The length of the screened interval and the well screen location (relative to the contamination and to hydrogeological units) are important considerations for monitoring well installation. Measured concentrations can be influenced by dilution (e.g., by water from other zones for long well screens). Similarly, layering of subsurface materials within a screened zone can affect both the interpretation of measured concentrations and, for extraction wells, the effectiveness of mass removal. In addition, it is important to consider the monitoring aspect of $\mathrm{P} \& \mathrm{~T}$ extraction wells and the $\mathrm{P} \& \mathrm{~T}$ operational information. In many cases, the $\mathrm{P} \& \mathrm{~T}$ system is particularly well suited to evaluate contaminant mass flux/discharge over time, which can be used to interpret source and plume behavior, in addition to providing input for $\mathrm{P} \& \mathrm{~T}$ operations. 


\subsection{Assumptions and Issues}

The discussion of terms and concepts pertaining to P\&T has introduced some ideas that are relevant to the limitations of the technology. The issues with $\mathrm{P} \& \mathrm{~T}$ and some overall assumptions about $\mathrm{P} \& \mathrm{~T}$ are described further in this section to provide the context for the discussion of $\mathrm{P} \& \mathrm{~T}$ performance assessment.

For the purposes of this document, several assumptions apply. As mentioned above, the focus of this document is on the groundwater extraction portion of the P\&T technology, with the assumption that the aboveground treatment has been suitably designed to achieve effective treatment. P\&T is assumed to have been operating for some period of time as part of a remedy. During this period of operation, it is assumed that some amount of data has been collected, whether that data consists of groundwater contaminant concentrations from extraction wells (individual or combined), concentrations from a spatially broader groundwater monitoring network, and/or concentration data from specific tests (e.g., an integrated pump test to determine mass flux/discharge). Along with the concentration data, it is assumed that operational data for the P\&T system is available (i.e., flow rates, timeframes for periods of operation and for periods without pumping). Relative to the groundwater contamination, it is assumed that the location of the source and the dissolved plume are generally understood. That is, this document does not cover initial site investigation or remedial investigation phases, nor are investigations to determine new sources discussed.

There are many variations in $\mathrm{P} \& \mathrm{~T}$ system configurations (well patterns, well placement relative to plume/source, operational strategy [flow rates/schedule], type of aboveground treatment, etc.). The guidance in this document is framed around typical CSM elements and categories of P\&T implementation, so the guidance may need to be adapted by the reader to account for site-specific situations.

While P\&T is a prevalent remedy, it is not uncommon to find limitations in the effectiveness of the contaminant extraction component of the P\&T technology. In particular, there may be performance limitations in terms of the technology requiring a long cleanup timeframe, including implications about associated ongoing costs. Assuming that the plume location is understood and a P\&T system was appropriately designed, P\&T may reach a point of diminishing returns. $\mathrm{P} \& \mathrm{~T}$ is a mass transfer process involving bulk extraction of groundwater and associated dissolved contaminant mass, plus processes at a smaller scale involving mass transfer between hydrogeologic units (i.e., between fine-grained and high permeability units) and between phases (either soil particles or NAPL). At some point, it is possible that the bulk extraction has successfully removed contaminant mass from high permeability materials where groundwater flows readily. Yet, contaminant may still remain and be slowly be extracted as it is released by desorption, diffusion, or dissolution. At such a point, the capture of contaminant mass encounters mass transfer limitations associated with those small-scale processes. The performance of $\mathrm{P} \& \mathrm{~T}$ over time can exhibit an initial large mass removal that declines and 
approaches a long period of tailing, possibly asymptotically approaching a concentration (which may be above the cleanup goal). Similar to SVE, it may be possible to halt the P\&T system for a period, and then observe a "rebound" to higher extracted concentrations upon restarting the system. Identifying rebound can provide useful information to support remedy decisions.

In addition to the inherent mass transfer limitations faced by $\mathrm{P} \& \mathrm{~T}$ remediation, other activities may influence the performance of the system. For example, a source treatment/removal action may have taken place concurrent with the P\&T. Such actions change the site scenario and need to be included in the CSM, after which it may be appropriate to revisit the $\mathrm{P} \& \mathrm{~T}$ remedy to assess whether the new conditions warrant $\mathrm{P} \& \mathrm{~T}$ closure or transition. 


\subsection{P\&T Categories}

The objective for deploying P\&T determines the design factors of the system, particularly with respect to the placement and operation of the extraction wells. P\&T remediation is frequently focused on extraction or control of the dissolved-phase groundwater contaminant plume located downgradient from the source. There are three basic categories of P\&T implementation, depending on the functional purpose or remedial goals of the system. These three P\&T categories are discussed in the following sub-sections.

\subsection{Source Control}

The general purpose of applying P\&T for source control (Figure 2) is to intercept and capture dissolved phase contamination from the saturated zone adjacent to or within the source area, thereby preventing or minimizing mass flux to downgradient areas. In essence, the goal for this type of application is to cut off the downgradient dissolved phase plume from the source of contamination, resulting in a "detached plume" (i.e., a dissolved-phase plume detached from the source area). The source control is typically achieved by two aspects of the P\&T. The P\&T system not only extracts contaminated groundwater to prevent downgradient migration, but it also alters the hydraulic gradient and thus decreases the driving force for downgradient advection.

Note that source control differs from source reduction, for example by multiphase extraction wells designed to remove NAPL. In source control, the objective is to manage mass flux of dissolved contamination out of the source area, while source reduction involves removal of contaminant mass to diminish the source. As noted in Section 1.2.1, source reduction is not addressed in this document. However, source reduction activities may affect the system in ways (e.g., by influencing the hydraulic gradient) that may need to be considered when defining the CSM.

Capture of the contaminants at the source area to allow the downgradient plume to diminish is a key performance goal when applying P\&T for source control. Thus, capture analysis and indication that the downgradient plume has diminished are key performance assessment elements

during operations. Decisions about potential termination of source control P\&T are related to a diminished source strength and the ability of either natural attenuation in the downgradient aquifer or an alternative technology to meet the remedial action objectives. That is, an assessment would evaluate whether there is a diminished need to contain the source. 

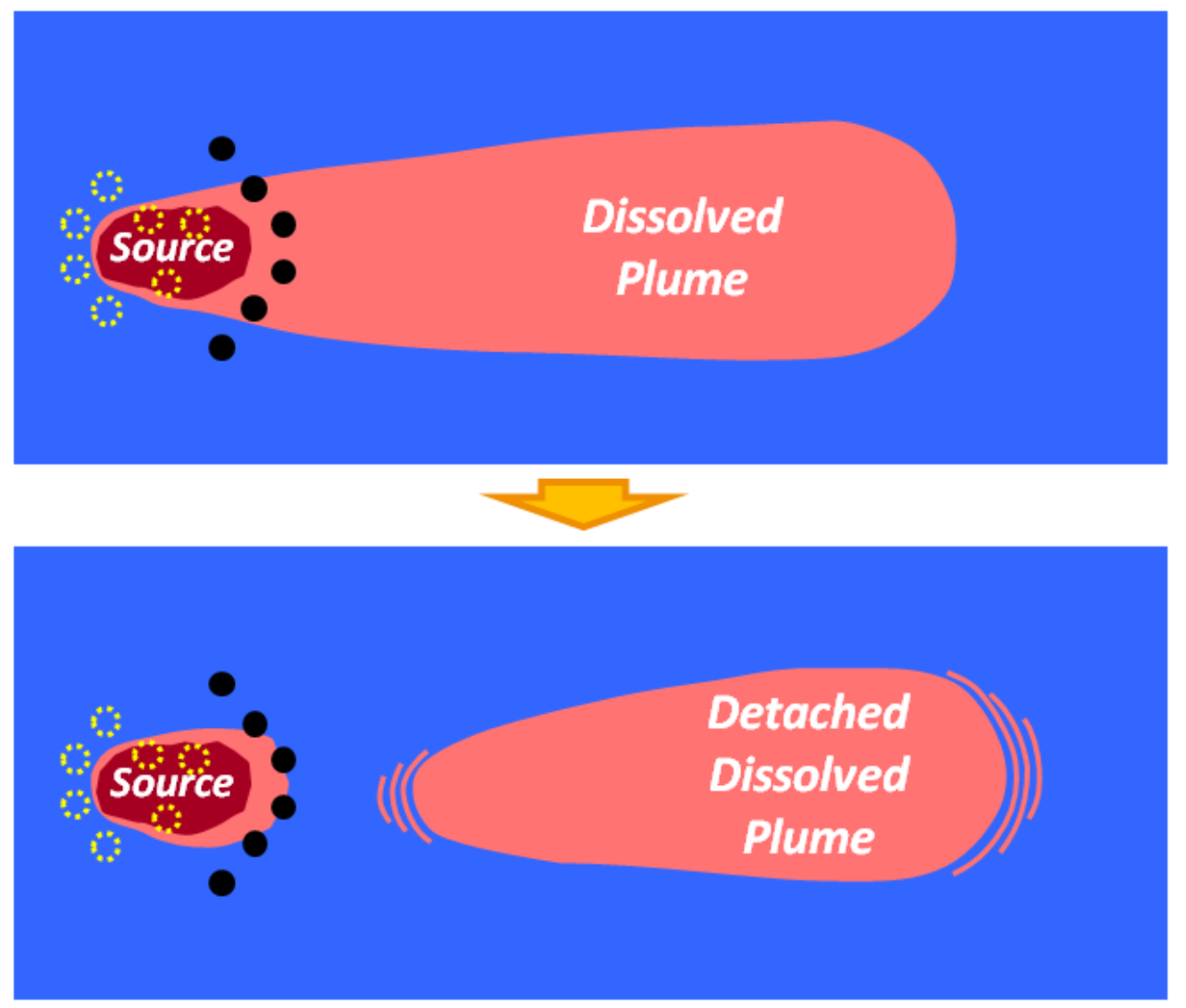

Figure 2. Conceptual application of $P \& T$ for source control, showing the intended outcome of cutting off the source from the main dissolved phase plume. The detached plume would need to be treated by natural attenuation or an active remediation technology. Solid points denote an example configuration of extraction wells just downgradient from the source area. Dashed circles indicate additional options of extraction wells within the source area (for source reduction and control), extraction wells upgradient of the source area (for hydraulic control to facilitate source control), or injection wells upgradient of the source area (for increased flushing of the source zone).

Example Site: At Joint Base Lewis McChord (Tacoma, Washington), a P\&T system is being used for source control as part of the remedy for a TCE plume. After source reduction by thermal treatment had diminished the source, a Source Control P\&T system was applied to hasten decline of the large downgradient plume (Figures 3 and 4). This action helps limit the operational duration of plume containment P\&T systems being applied further downgradient of the source area. 

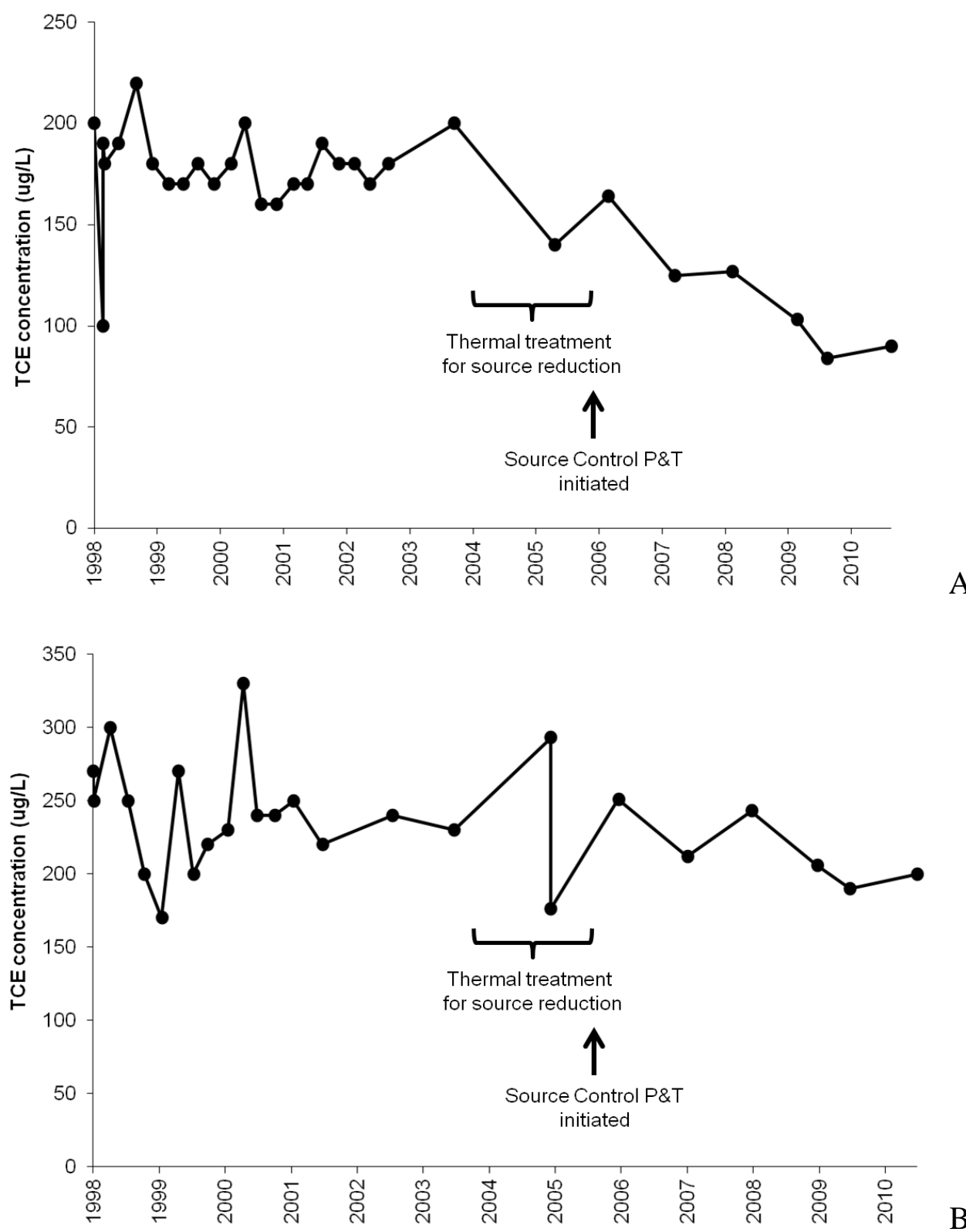

Figure 3. Change in TCE concentrations over time at plume monitoring wells located (A) 1100 feet downgradient and $(B) 2700$ feet downgradient from a Source Control P\&T system. The nearer well exhibits a noticeable decline in TCE concentrations in the period after thermal treatment was applied for source reduction and the Source Control P\&T system had been started. TCE concentrations at the farther well are slower to respond, but are expected to decline over time. 


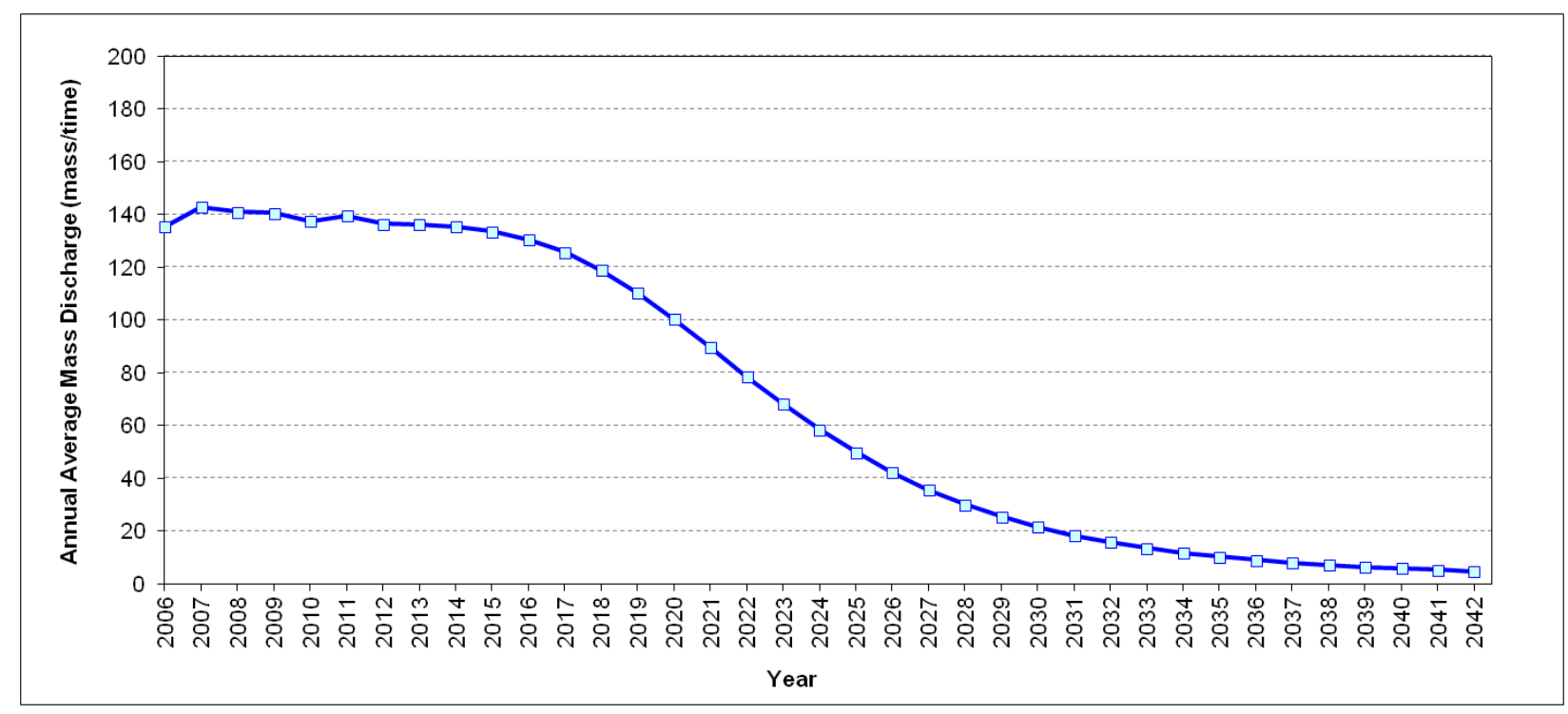

Figure 4. Predicted contaminant mass discharge across a flux plane located about $7500 \mathrm{ft}$ downgradient from a Source Control P\&T system, with the plane oriented perpendicular to the direction of groundwater flow and spanning the width/depth of the plume (adapted from Truex and Johnson [2013]). The source control P\&T was initiated in 2006 and the mass discharge response shows how the downgradient plume is predicted to diminish over time at this location (which corresponds to the location of a downgradient plume containment $P \& T$ system) as a result of "cutting off" the plume from the source. These simulations were conducted during the design phase of the Source Control P\&T.

For source control, design and operation of the P\&T system are focused on containment of dissolved phase contamination located within or at the periphery of the source area.

Distinguishing characteristics of dissolved-phase source control include the following items.

1. Extraction well(s) are positioned at the periphery of the contamination source. Some applications may include extraction wells within the source area (for source control) and/or upgradient of the source area (for hydraulic manipulation to facilitate source control) or may include injection wells (to increase flushing of the source zone).

2. Collection and extraction of contaminated groundwater outside of the source area (i.e., from the downgradient plume) is not a factor in the design, location selection, or operation of the source control P\&T wells.

3. The groundwater pumping rate is usually high enough to depress the local water table to facilitate contaminant capture and minimize contaminant migration away from source area.

4. Extraction wells are designed to remove water, not NAPL.

5. The aboveground treatment system equipment is designed to treat only dissolved phase contamination in the groundwater. 
6. Source Control P\&T extraction wells, because of their proximity to the source of contamination, may be used to capture byproducts or untreated contaminants released from a separate and independent source treatment process deployed within the source area. Examples of separate source treatment processes include thermal heating, biological treatment, or chemical oxidation of source area contaminants.

7. Source Control P\&T systems may facilitate use of other concurrently implemented actions to address downgradient plume reduction and/or containment.

\subsection{Plume Containment}

The general purpose of applying $\mathrm{P} \& \mathrm{~T}$ for plume containment is to intercept and remove dissolved-phase contamination at a specific location to prevent or minimize the continued expansion of the plume (Figure 5). Control of the extent of the dissolved-phase plume, not mass reduction, is the primary objective of $\mathrm{P} \& \mathrm{~T}$ for plume containment. Plume containment is often used to protect potential downgradient receptors or to prevent migration of the plume beyond site boundaries.

Capture of the plume to prevent further migration past the P\&T location, so that the downgradient plume can diminish and/or so that receptors are protected, is a key performance goal when applying P\&T for plume containment. Thus, capture analysis and indication that the downgradient plume is diminishing (attenuating) or is not present are key performance assessment elements during operations. Decisions about potential termination of P\&T that is applied for plume containment are related to a diminished plume upgradient of the P\&T system such that natural attenuation in the aquifer or use of an alternative technology can meet the RAOs.

Distinguishing characteristics of P\&T for plume containment include the following items.

1. The extraction well system is designed to maximize interception of plume at the selected P\&T location. Wells are placed sufficient in number and spacing to laterally intercept and capture the plume. The screened interval, pump placement, and extraction flow rate are designed to capture contamination across the vertical extent of the plume.

2. Extraction well(s) are positioned either at the downgradient edge of or within the dissolved-phase plume to intercept the contamination. When wells are located within the plume, some portion of the plume (potentially as a detached "bubble" of contamination) may continue moving downgradient, typically with the intent that natural attenuation will meet cleanup goals for this contamination.

3. Collection and extraction of contamination in the source area is not a factor in the design, location selection, or operation of the P\&T wells installed for plume containment.

4. Plume containment P\&T systems may be deployed to protect downgradient receptors or prevent migration across site boundaries while other actions are concurrently implemented to address plume reduction and/or source area treatment. 


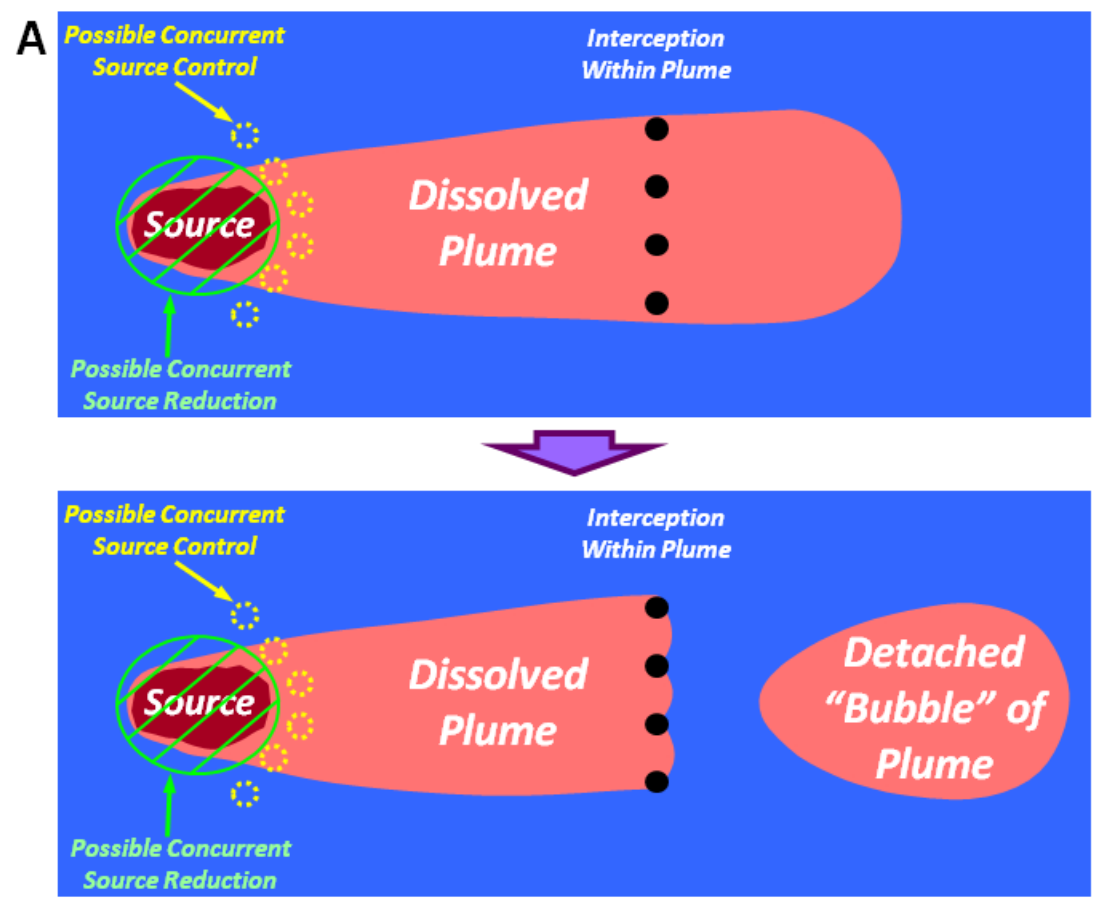

B
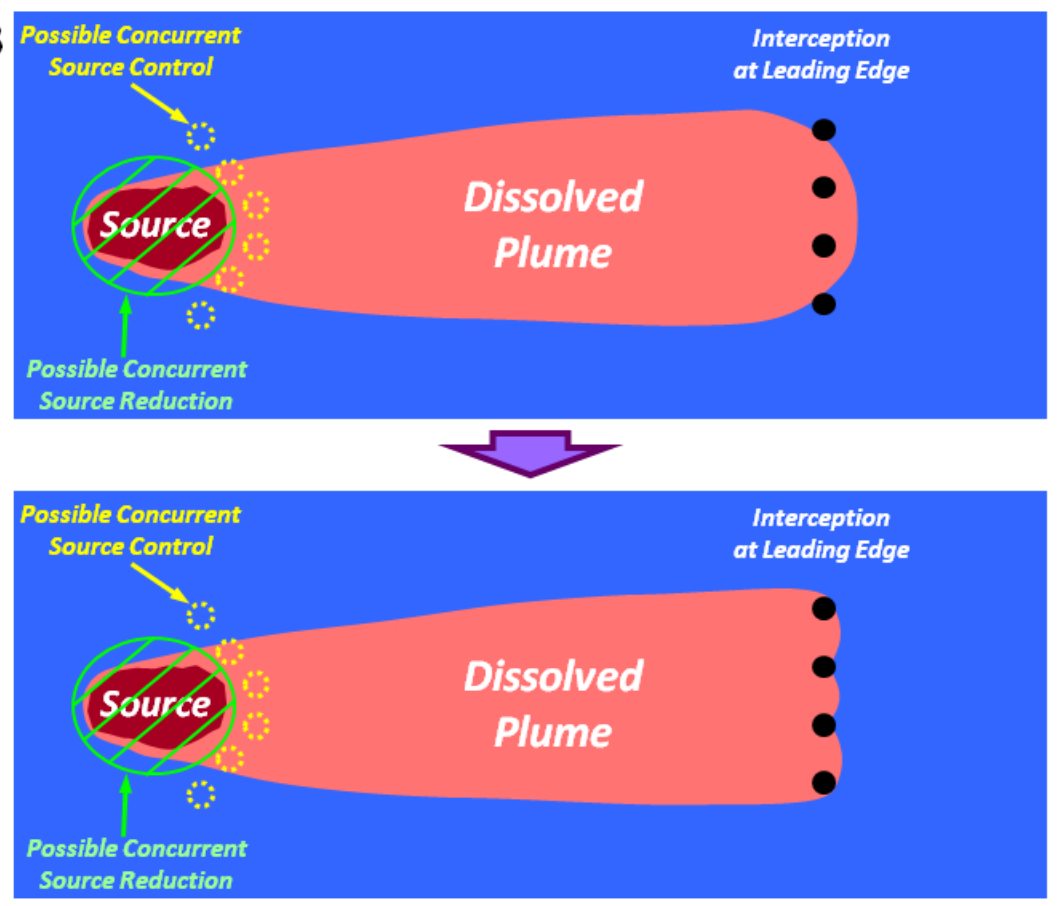

Figure 5. Conceptual application of P\&T for plume containment, showing intended outcomes for two examples of extraction well positioning $(A)$ within the plume and $(B)$ at the leading edge of the plume. With interception within the plume, contamination remains at locations downgradient from the $P \& T$ wells (potentially resulting in a "bubble" of contamination), which could be acceptable if the attenuation capacity can diminish the downgradient concentrations to meet remedial goals. Solid dots indicate extraction wells. Potential source area remediation is shown as the hatched zone covering the source area (for some source removal/reduction technology, such as thermal treatment) and dashed circles (for Source Control P\&T). 
Example Site: At Joint Base Lewis McChord, a P\&T system is being used for plume containment as part of the remedy for a TCE plume. Mass discharge across flux planes (depicted in Figure 6) was calculated from simulation results of history matching and predicted plume behavior. Figure 7 shows the simulation mass discharge decreasing when plume containment $P \& T$ is initiated, with the source control enhancing the performance over time.

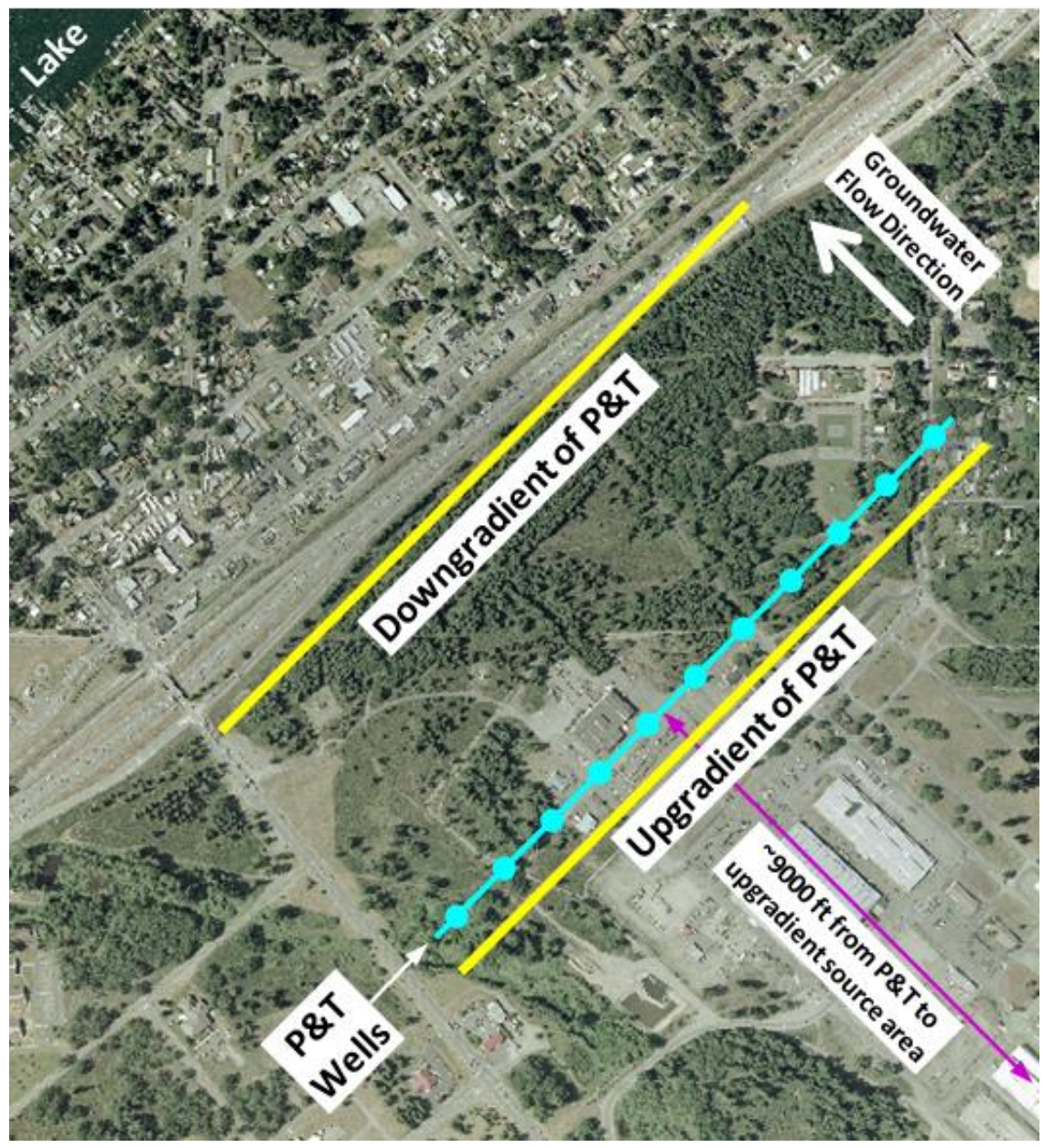

Figure 6. Lateral locations of flux planes for the estimated mass discharge analysis shown in Figure 7 (adapted from Truex and Johnson [2013]). Note that the line for wells reflects the transect location, not the details of number and position of wells. 


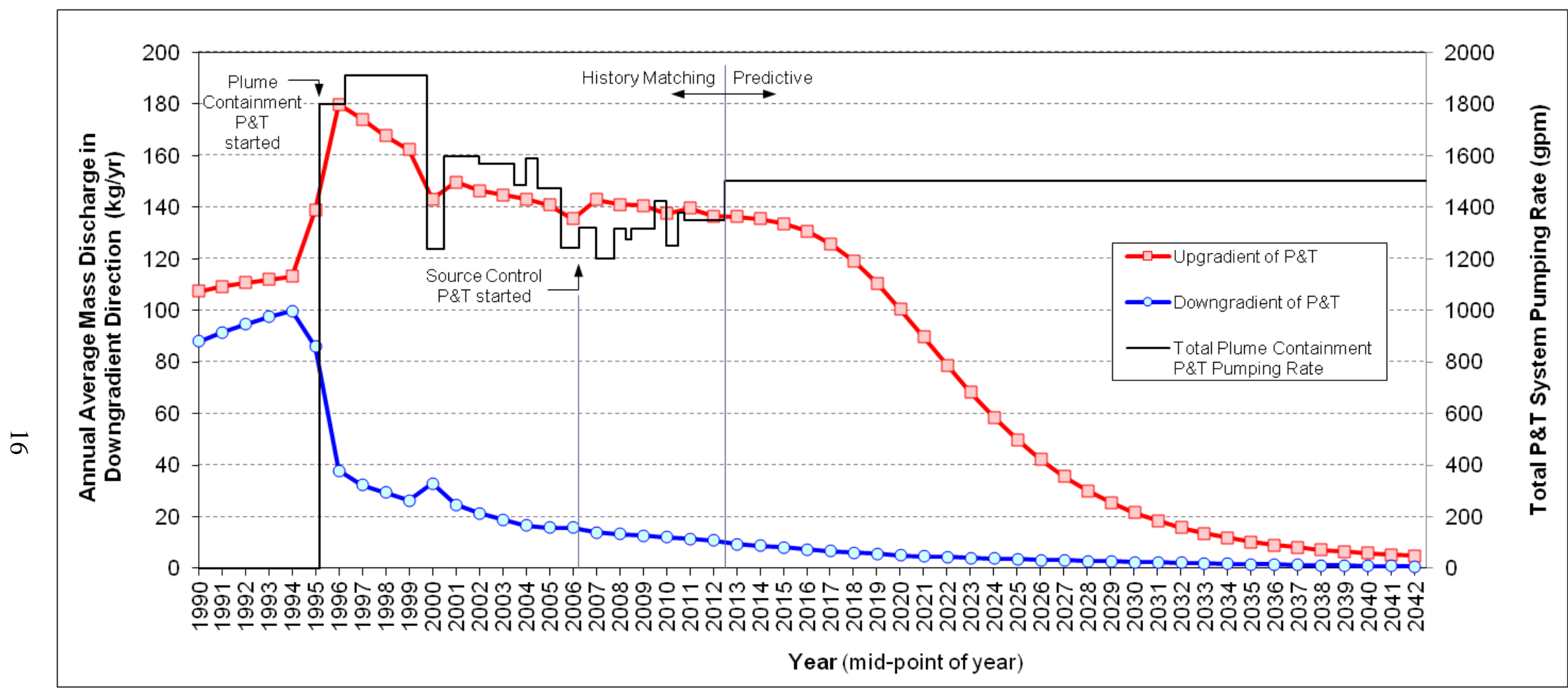

Figure 7. Contaminant mass discharge across the flux planes depicted in Figure 6 for history matching and predictive portions of a numerical model simulation for a plume-containment P\&T system (adapted from Truex and Johnson [2013]). The total pumping rate at the plume containment $P \& T$ system is plotted for reference, reflecting system startup and operational changes over time. Existing contamination downgradient of the plume containment $P \& T$ location decline over time. Startup of an upgradient Source Control P\&T system in 2006 is denoted as a key event affecting the overall plume, resulting in an eventual decrease in contaminant flux moving to the plume containment P\&T system. 


\subsection{Plume Reduction}

The general purpose of applying P\&T for plume reduction is to diminish the dissolved-phase contamination below a target value (Figure 8). Volumetric extent and concentration of the contaminant plume can be reduced by $\mathrm{P} \& \mathrm{~T}$, though typically with more aggressive manipulation of the groundwater (i.e., higher pumping rates) and generally a greater number of extraction wells than applied for source control or plume containment.
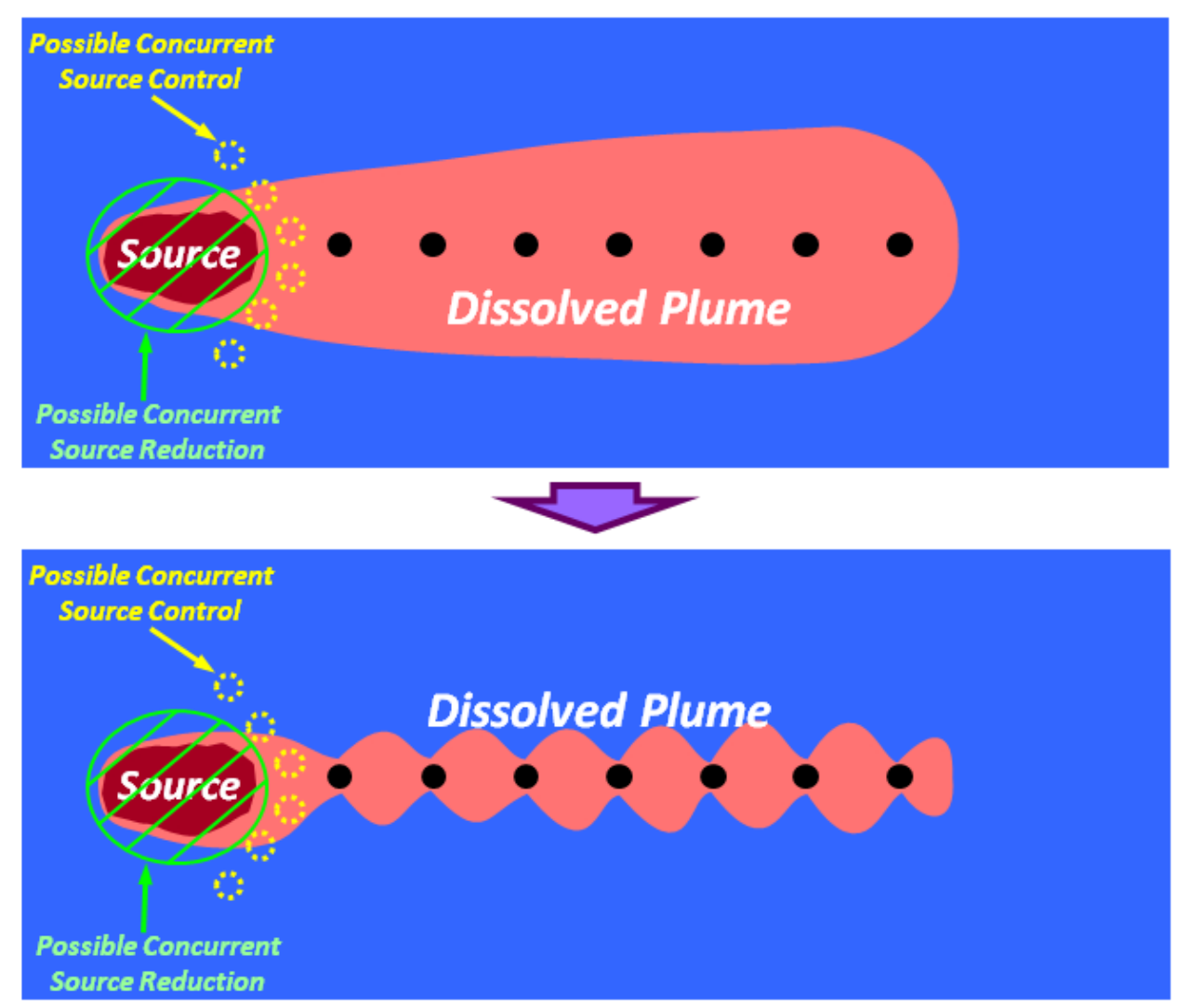

Figure 8. Conceptual application of $P \& T$ for plume reduction, showing progress towards the intended outcome of dissolved phase plume volumetric treatment. In most cases, it will be important to remove or contain the source for plume reduction to be successful. Solid dots indicate extraction wells (in one example layout). Potential source area remediation is shown as the hatched zone covering the source area (for some source removal/reduction technology, such as excavation or thermal treatment) and dashed circles (for source control).

Volumetric capture of the plume to hasten attainment of contaminant concentrations at or below the remedial goals and to prevent further migration is a key performance goal when applying P\&T for plume reduction. Thus, capture analysis and indication that the plume is diminishing are key performance assessment elements during operations. Decisions about potential termination of $\mathrm{P} \& \mathrm{~T}$ that is applied for plume reduction are related to reaching a plume condition such that natural attenuation in the aquifer or the use of an alternative technology can meet the RAOs. 
Distinguishing characteristics of P\&T for plume reduction include the following items.

1. Multiple extraction wells are positioned throughout the extent of the dissolved-phase plume to maximize capture of contamination. A distribution of extraction wells along the axis of the plume (following the plume flow path) would be a typical approach, but is just one example.

2. The P\&T system total extraction rate may be greater than would be specified for a plume containment strategy.

3. The extraction well system is designed to maximize contaminant mass removal within the plume. That is, the screened interval and pump placement are designed to capture contamination across the vertical extent of the plume and wells are placed sufficient in number and spacing to maximize capture of contamination while the pumping rate is set to minimize the overall duration of operation.

4. P\&T systems for plume reduction may be constructed with the goal of transitioning to passive technologies for attaining final cleanup goals.

Example Site: At the U.S. Department of Energy Hanford Site (Richland, Washington), a P\&T system was installed to reduce plume concentrations sufficiently that it would be feasible to transition to monitored natural attenuation (MNA) to complete remediation. With respect to P\&T implementation and subsequent MNA of the remaining plume, the Record of Decision (EPA, DOE, and WDOE 2008) includes the following statements (pp. 2-3).

A groundwater pump-and-treat system will be designed, installed, and operated in accordance with an approved remedial design/remedial action (RD/RA) work plan. The system will be designed to capture and treat contaminated groundwater to reduce the mass of carbon tetrachloride, total chromium (chromium III and chromium VI), nitrate, trichloroethylene, iodine-129, and technetium-99, throughout the 200-ZP-1 OU by a minimum of 95\% in 25 years. The pump-andtreat component will be designed and implemented in combination with monitored natural attenuation to achieve cleanup levels ... for all COCs in 125 years. Carbon tetrachloride concentrations in the groundwater above $100 \mu \mathrm{g} / \mathrm{L}$ correspond to approximately $95 \%$ of the mass of carbon tetrachloride currently residing in the aquifer.

$\cdots$

Natural attenuation processes to be relied on as part of this component include abiotic degradation, dispersion, sorption, and, for tritium, natural radioactive decay. Monitoring will be employed in accordance with the approved RD/RA documents to evaluate the effectiveness of the pump-and-treat system and natural attenuation processes. Fate and transport analyses conducted as part of the [feasibility study] indicate that the timeframe necessary to reduce the remaining COC concentrations to acceptable levels through MNA will be approximately 100 
years. Modeling also indicates that this portion of the plume area will remain on the Central Plateau geographic area during this timeframe.

The overarching requirement is to meet the groundwater cleanup levels identified in this ROD within 125 years. 


\subsection{Regulatory Setting}

It is anticipated that this document will typically be applied where a P\&T system has been installed as part of a CERCLA Record of Decision (ROD), or equivalent RCRA decision document. However, an interim ROD or other decision document may potentially be relevant for the existing P\&T system. Regardless, it is anticipated that remedial action objectives for the existing P\&T system were defined and can be used as input to the performance assessment.

In conducting the P\&T performance assessment, sites may determine that an ARAR waiver may be appropriate. For these situations, existing guidance and approaches that would be followed as part of an ARAR waiver process were recently summarized by Deeb et al. (2011), including use of a technical impracticability waiver (EPA 1993b). It is important that remedial action objectives, as initially defined, as refined by site decision makers (when appropriate), or as defined by an ARAR waiver, are part of the P\&T performance assessment approach described in this document.

The P\&T performance assessment described in this document fits within remedy assessment elements of a remedial action, for instance as included in the EPA's Groundwater Road Map (EPA 2011a). If any changes to the remediation approach are identified as being appropriate based on the P\&T performance assessment, these would need to be selected and enacted through a decision document such as a ROD, ROD amendment, ESD, or equivalent. For situations where closure of the remedy is warranted, guidance (e.g., EPA 2011c, 2013, 2014b) for remedy closure would need to be followed. 


\subsection{Performance Assessment Decision Logic}

The performance assessment approach described in this P\&T document is organized to use a set of decision elements to help decision makers distinguish between several categories of decision outcomes associated with transition, optimization, or closure of P\&T systems. This document is targeted at performance evaluation for P\&T systems that have been operated for enough time that their performance with respect to reaching RAOs can be assessed, and site decision makers have determined that the performance needs to be evaluated.

The process includes revisiting the CSM, where it is important to consider the current nature of the source and plume, as well as the aspects controlling contaminant transport and remedy performance. However, to effectively support the P\&T performance assessment and associated remedy decisions, efforts for updating the CSM are focused on describing the site and current conditions in terms of the decision elements described below. These decision elements are then applied in a decision logic framework to facilitate determining the outcome that is best supported by the performance assessment. Details of implementing this outcome can then be finalized based on the site-specific conditions. As the P\&T assessment progresses, indications of a persistent plume may generate the need to conduct additional evaluations and refine the CSM with respect to the factors causing plume persistence.

In applying the decision logic, a site may have more information about some decision elements than for others. It is expected that decision elements will be used as lines-of-evidence, similar to the balancing approach used in a CERCLA feasibility study. Thus, complete, detailed information about all decision elements may not be needed for a site to effectively interpret the performance assessment for selecting the most appropriate outcome. It is also important to recognize that the decision outcome for the $\mathrm{P} \& \mathrm{~T}$ performance assessment will be based on available data and analysis that together provide a prediction of future performance for the selected outcome in reaching the site RAOs. Like other remedy decisions, the outcome of the

P\&T performance assessment would be implemented with ongoing verification that the expected performance is being achieved (e.g., Case Study 2A).

The decision elements selected for use in the P\&T performance assessment are introduced below and described in more detail in Sections 5.0 and 6.0.

- Contaminant concentrations and trends: These data are used to evaluate whether the plume has declined during the P\&T remedy and to provide input for use in the subsequent decision element assessments.

- Contaminant mass discharge (CMD) (mass/time): The CMD at a given location in a plume (or at the source) is an indication of the amount of contaminant mass migrating past that location over time. P\&T system data can provide contaminant mass extracted over time, which is an indicator of extraction efficiency. With knowledge of the natural gradient at the site, the P\&T data can be interpreted in terms of the CMD that would occur from the capture zone if the P\&T system operations were discontinued. This CMD information is useful when assessing performance and future plume behavior using an 
approach that examines the CMD in comparison to factors that relate to the downgradient transport of the contaminants (e.g., the attenuation capacity, as described below and shown conceptually in Figure 9). It is also important to consider the variation in contaminant concentrations within the plume or source upgradient of the CMD measurement location. When there are steep concentration gradients or order of magnitude variation in concentrations across the plume, concentration-based approaches may be more appropriate than spatially averaged mass-based approaches to evaluate the downgradient transport and attenuation (e.g., a threshold concentration approach as discussed in Section 6.2.1). For example, it may be necessary to assess what happens with a high concentration core of a plume, because that is the portion of the plume that will constrain assessment/ remediation (versus lower concentrations further from the plume core).

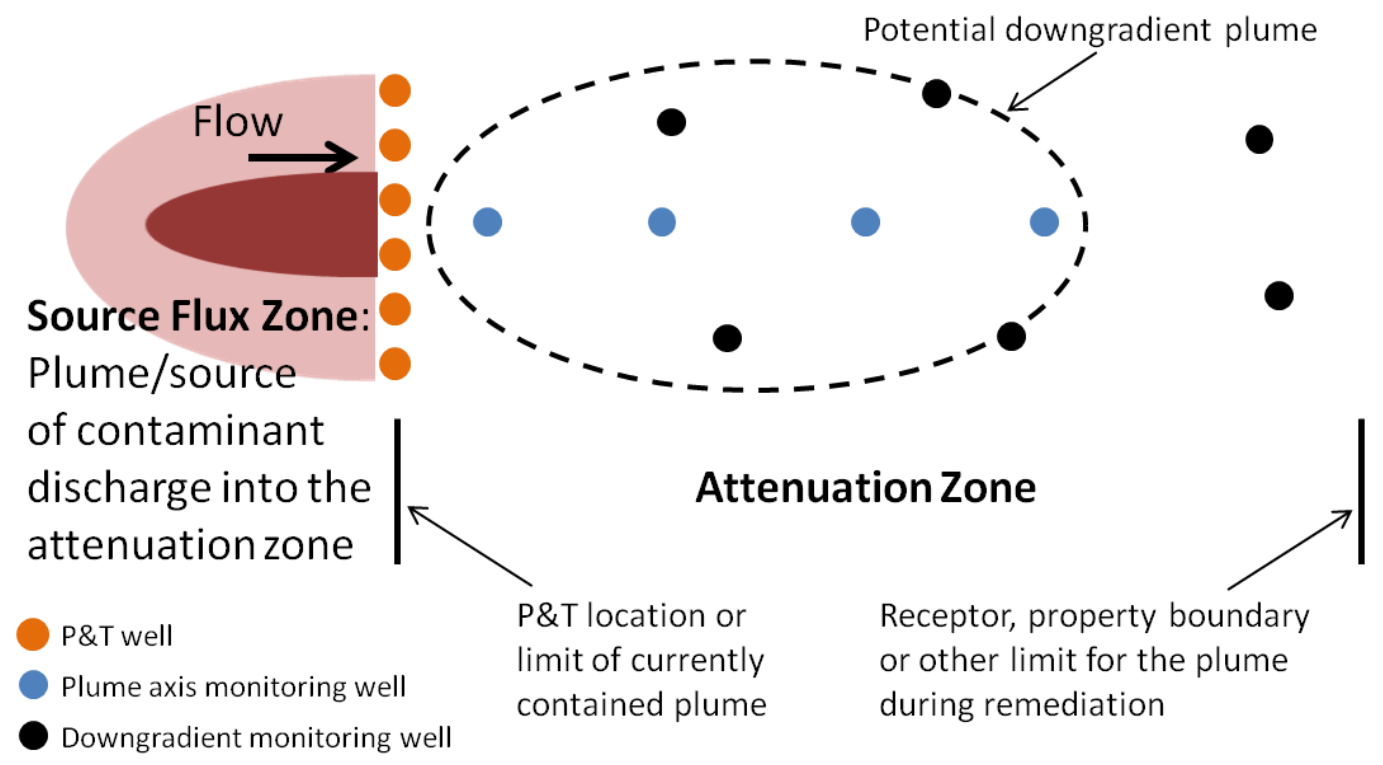

Figure 9. Conceptual depiction of the source flux zone being controlled by P\&T and a downgradient attenuation zone, whose extent must be determined by the site decision makers. Under natural-gradient conditions, the CMD from the source zone (or potentially an upgradient plume) must not be greater than the attenuation capacity in the attenuation zone for the plume to stay within the limits defined by the site decision makers (e.g., to potentially support a decision to transition to an MNA remedy). 
- Attenuation capacity (AC) of the aquifer: The $\mathrm{AC}$ is a way to quantify the ability of an aquifer (or portion of an aquifer) to decrease contaminant concentration over time without active remediation. There are multiple approaches to evaluate attenuation rates and mechanisms in the aquifer. These rates and mechanisms are important as part of assessing the role of natural attenuation during P\&T or for transitioning P\&T to MNA or another remedy that includes the contribution of natural attenuation. The attenuation capacity can be conceptually estimated as a decrease in contaminant mass over time within a given volume of the aquifer (shown in Figure 9). Performance and future plume behavior can be assessed by comparing this attenuation capacity to the CMD (described above). In some cases, especially when there is a higher concentration plume core, it may be more appropriate to represent the attenuation capacity as an attenuation rate (change in concentration per time), using the threshold concentration approach (discussed in Section 6.2.1) for evaluating the concentration emanating from the source zone plume core.

- Estimated future plume behavior and time to reach RAOs: Like any remedy decision, a prediction of plume fate and transport and the time needed to reach the RAOs is an important part of P\&T performance assessment. The plume behavior under continued P\&T, MNA, or with application of other remedy components or alternative remedies needs to be estimated. Key components of this decision element include evaluating protectiveness (e.g., controlling exposure during remediation) and estimating the time to reach the RAOs. For the plume behavior estimate, it is also important to consider the controlling features at the site (e.g., matrix diffusion) or source conditions that may contribute to extending the remediation timeframe. It is also important to consider the uncertainty associated with estimating future plume behavior and time to reach RAOs when using these estimates to support a remedy decision.

- P\&T system design, operational, and cost information: As part of the performance assessment, information about the P\&T design, operation, and cost are important to consider for assessing whether optimization would help performance or for comparison of $\mathrm{P} \& \mathrm{~T}$ to other remediation alternatives.

The following categories of decision outcomes are included in the decision logic for the P\&T performance assessment. The outcome categories are introduced below and described in more detail in Section 6.0.

- Initiate P\&T Remedy Closure: If the site conditions meet RAOs for the P\&T system, then an appropriate outcome of the analysis is to proceed with P\&T remedy closure. Criteria used to evaluate whether RAOs have been met may have been established in site remedy decision documents. In some cases, a rebound study to assess concentration trends with the P\&T system off may be needed as part of assessing whether concentration goals have been met. EPA provides guidance (e.g., EPA 2011c, 2013, 2014b) for the remedy closure process.

- Transition P\&T to MNA: This outcome is for sites where P\&T has changed plume conditions such that RAOs can now be met with MNA. 
- Continue with Existing or Optimized P\&T: If P\&T has diminished the plume, it may be appropriate to continue $\mathrm{P} \& \mathrm{~T}$ or optimize the system and continue $\mathrm{P} \& \mathrm{~T}$, if it is practical to meet RAOs. As time progresses, the P\&T system may need to be re-evaluated with respect to progress toward meeting the RAOs.

- Supplement P\&T with Other Treatment Technologies: This outcome may be appropriate at sites where P\&T has been inefficient or ineffective in progressing toward RAOs, but where a specific plume condition or feature can be addressed by a supplementary treatment (e.g., targeted treatment of a contaminant hot spot) such that RAOs can then be met with this combined approach. At some sites, there may be site complexities that need to be considered in evaluating a supplemented P\&T approach (NRC 2013; ITRC 2015). In this case, the site may need to consider adaptive remedy approaches and means to mitigate exposure while addressing contamination. It is also possible that, over time, the supplemented P\&T system may need to be re-evaluated with respect to progress toward meeting the RAOs.

- Transition to a New Remedy Approach: At sites where P\&T has been inefficient or ineffective in progressing toward RAOs, another remedy approach may be more cost effective in reaching RAOs. At some sites, there may be site complexities that need to be considered in selecting the new remedy approach (NRC 2013; ITRC 2015). In this case, the site may need to consider adaptive remedy approaches and means to mitigate exposure while addressing contamination.

The decision logic for the P\&T performance assessment, incorporating the decision elements and the decision outcomes, is presented in Figure 10. After updating the conceptual site model and assessing whether RAOs have been met, the decision logic consists of several primary assessments that distinguish between outcomes. The first assessment is based on whether the plume has declined during P\&T operations. If the plume has declined, then an assessment of whether MNA is warranted is conducted. If MNA is not appropriate, then the logic points to evaluating continued/optimized P\&T. For plumes that have not declined during P\&T or for situations where the plume has declined but RAOs cannot be practically reached with P\&T or MNA, the decision logic points to evaluation of other approaches. In this case, the decision logic specifies evaluating technologies to supplement P\&T or switching to a remedy approach based on a different technology to address factors inhibiting remediation. Site decision makers may also consider ARAR waivers or revisiting RAOs (e.g., using approaches to define objectives as described in the Integrated DNAPL Site Strategy document [ITRC 2011b]) depending on the conditions driving the need for an alternative remedy approach to P\&T.

To support the decision logic presented in Figure 10, Section 5.0 provides information on updating the CSM and gathering information on the decision elements. Section 6.0 describes the performance assessment approach to facilitate selecting an appropriate outcome based on the decision logic. Also in Section 6.0, the tools and approaches introduced in Section 5.0 are mapped to elements of the decision logic flow chart, as are case studies illustrating each category of outcome. 


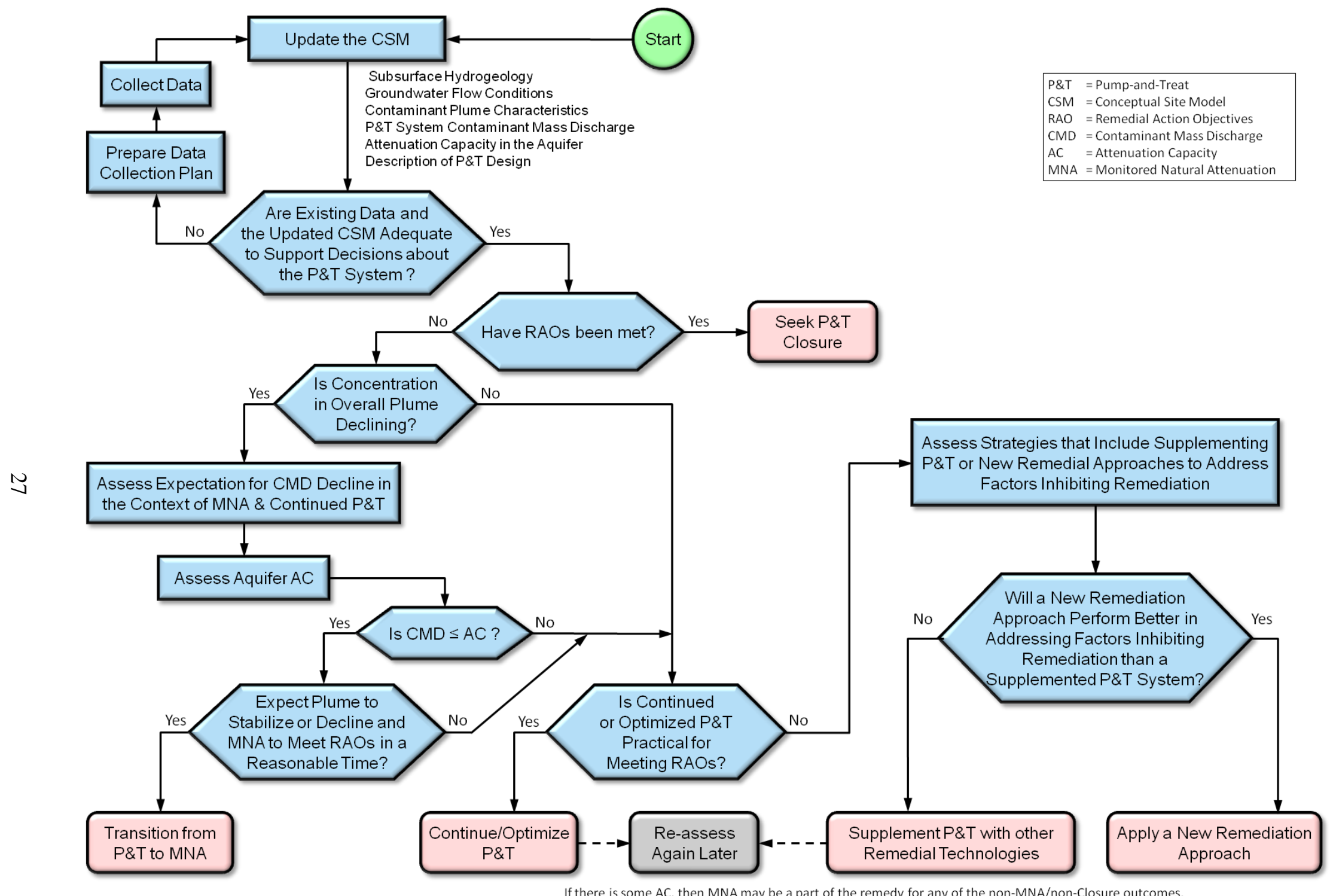

Figure 10. Decision logic flow chart. 



\subsection{Conceptual Site Model Update and Approaches for Obtaining Decision Element Information}

The fundamental site information in a conceptual site model includes descriptions of the geology, hydrology, contaminant distribution, and remedy configuration. However, to support remedy decisions such as optimization, transition, or closure of a P\&T system, the CSM should include quantitative information about the decision elements identified in Section 4.0. To support P\&T performance assessment, the CSM should be updated at the time of the assessment using available characterization, plume monitoring, and P\&T operational data. An important aspect of updating the CSM is inclusion of trend data that are available from the period of P\&T remediation. The trend data will help define the plume behavior and related conceptual site model elements. Section 5.1 reviews the type of fundamental site information that provides the foundation for the CSM. Section 5.2 then describes collection and analysis of data in support of each decision element.

Because site characteristics and remedy situations vary, some decision elements may not be important for a given site. Site decision makers will need to determine the appropriate level of detail needed for updating the CSM to support the P\&T assessment.

\subsection{Fundamental Site Information}

The following information provides the foundation for the CSM at a site.

- Overview of the site plume and remedy configuration

- Description of the subsurface hydrogeology

- Description of the groundwater flow field (with and without the P\&T system operating)

- Description of the source, plume, and known controlling features, events, and processes affecting the contamination

\subsubsection{Site Overview and Context of the Plume and Remedy Configuration}

An overview figure depicting the site plume and the remedy is useful as a starting point to provide context for displaying and discussing additional, more detailed information. Figure 11 shows an example of a site plume and remedy overview from the Joint Base Lewis McChord Logistics Center site. The overview information should also include an assessment of land use and other factors that need to be considered in the remedy, such as groundwater use in the vicinity (e.g., off-site pumping wells), surface water discharge concerns, or other adjacent soil or groundwater remediation activities. 


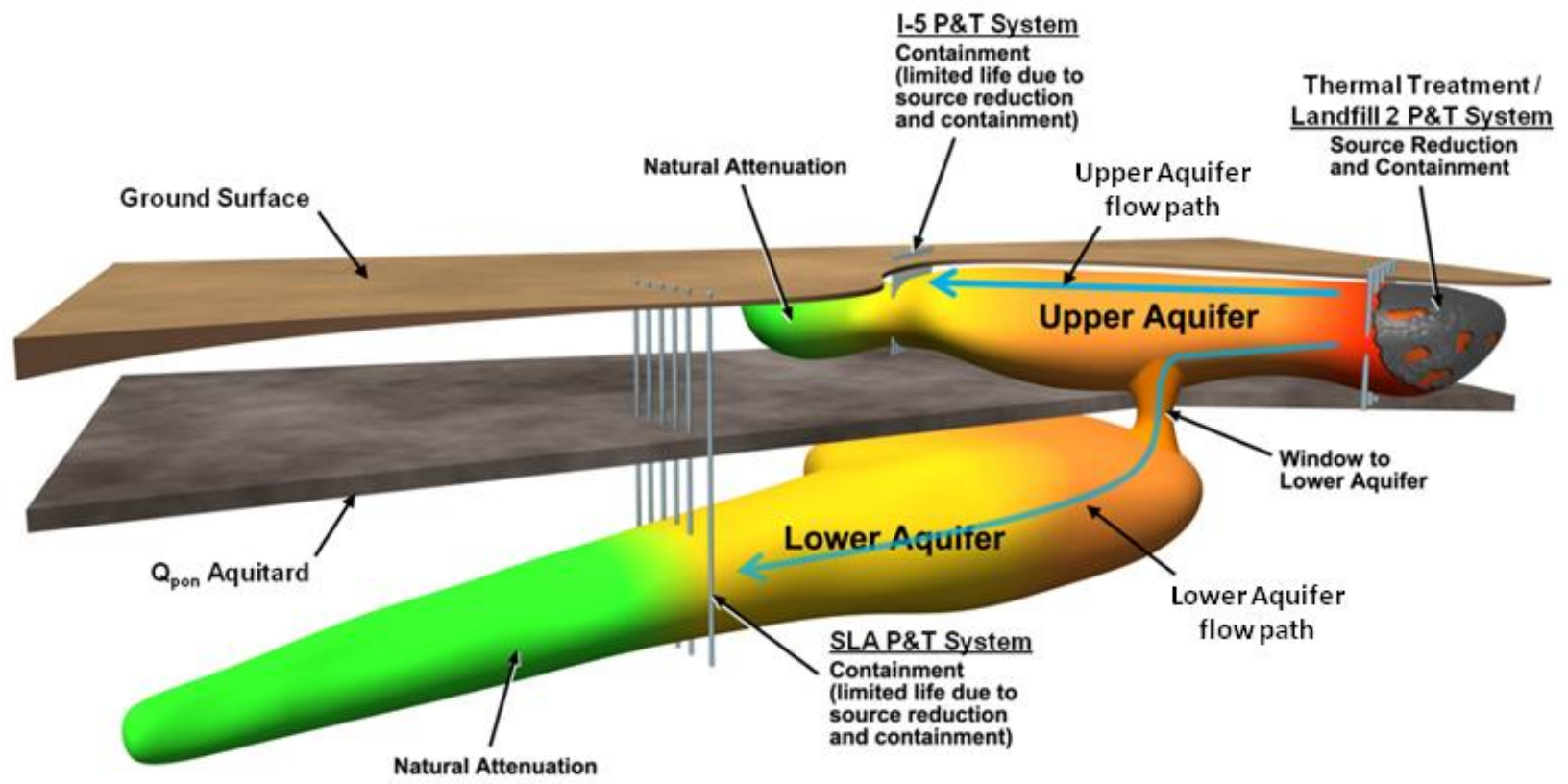

Figure 11. Example depiction of a site plume and remedy overview from Joint Base Lewis McChord.

\subsubsection{Describe the Subsurface Hydrogeology}

Cross sectional and plan views of hydrogeologic features related to plume migration and regional groundwater flow should be prepared. A key focus should be on features controlling plume migration and performance of the remedy. Thus, descriptions at a regional, plume-scale, and/or local-scale may be appropriate. For instance, some sites may benefit from high resolution characterization techniques (e.g., https://clu-in.org/) because features at a small scale are exerting significant control of plume behavior. Plume behavior at other sites may be suitably described based on larger-scale information. The purpose of this information is to provide the spatial context of the groundwater flow system in relation to plume behavior and P\&T impacts. Figures 12 through 14 show example cross sections from the Joint Base Lewis McChord Logistics Center site that progress from interpreted hydrogeology (Figure 12), to representation of the hydrogeology in a numerical model (Figure 13), to a localized hydrologic cross section overlain with observed contaminant data (Figure 14). 
B

$\mathbf{B}^{\prime}$

West

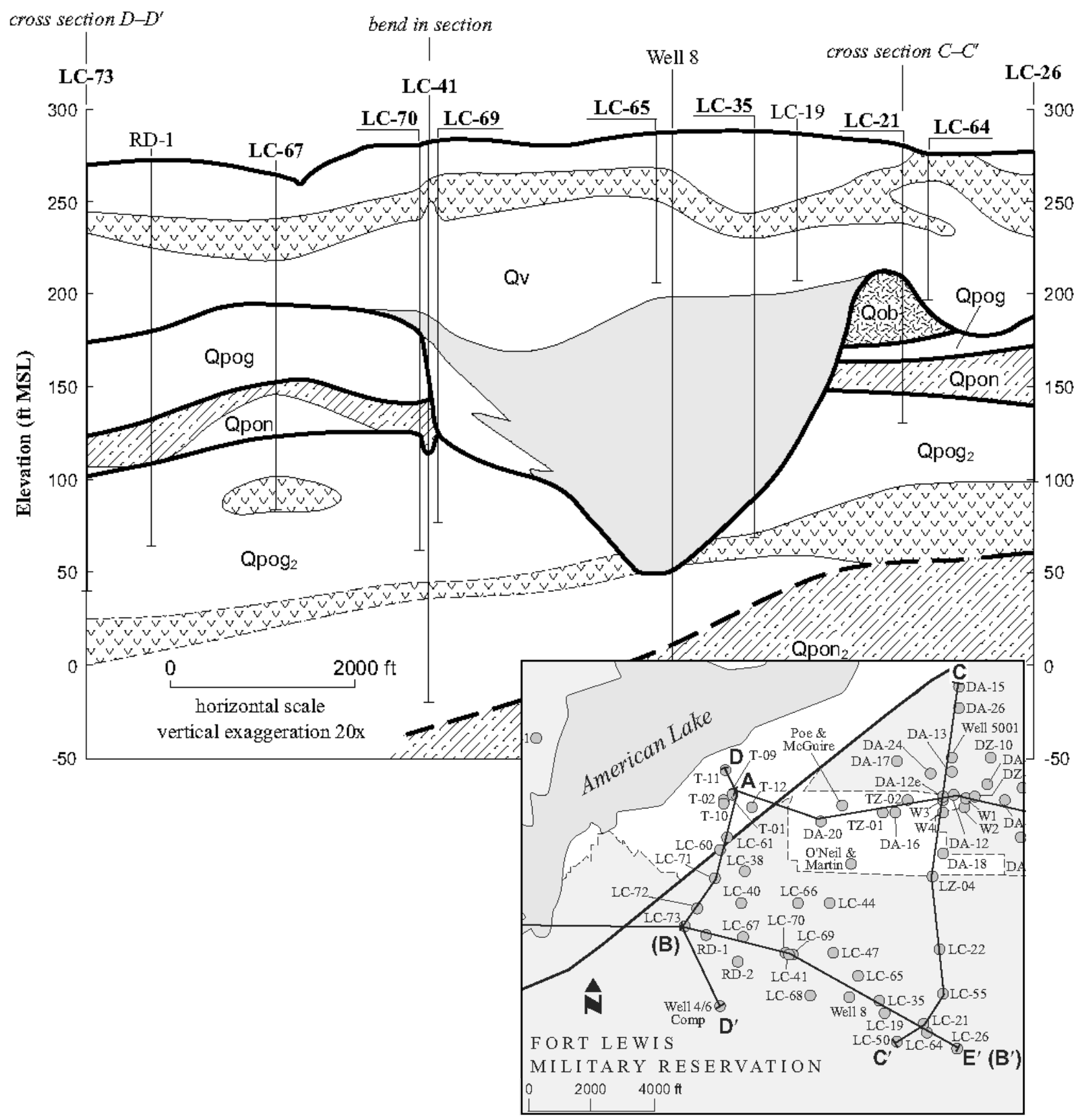

Figure 12. Conceptual geologic cross section approximately along the centerline of the plume in the Vashon Aquifer (from Truex et al. [2006]; adapted from Borden and Troost [2001]). For the cross section, white areas (Qv, Qpog, Qpog2) correspond to outwash gravels, the grey area is low-permeability glaciolacustrine sediment, the dark area (Qob) is Olympia bed material, the hashed areas (Qpon and Qpon2) are non-glacial aquitard materials, and the areas with the "v" symbol pattern correspond to low permeability till material. 


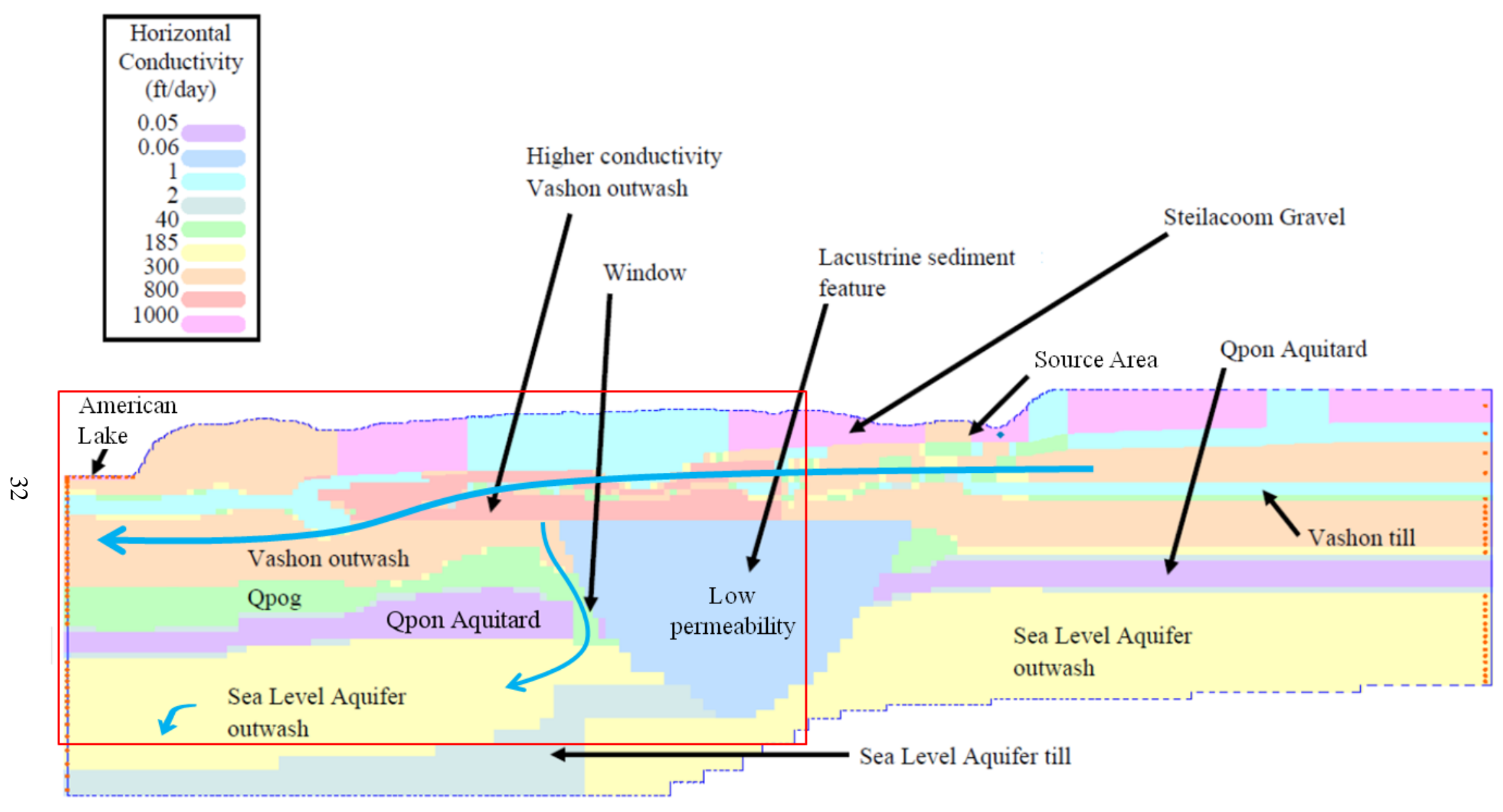

Figure 13. Annotated numerical model cross section along the nominal axis of the contaminant plume in the Vashon Aquifer located above the Qpon Aquitard (adapted from Truex et al. [2006]). Blue arrows show the groundwater flow direction (to the left towards American Lake in the Vashon Aquifer; down through the Window, then out of the page in the Sea Level Aquifer). The red box shows the nominal are of the cross section shown in Figure 14. 


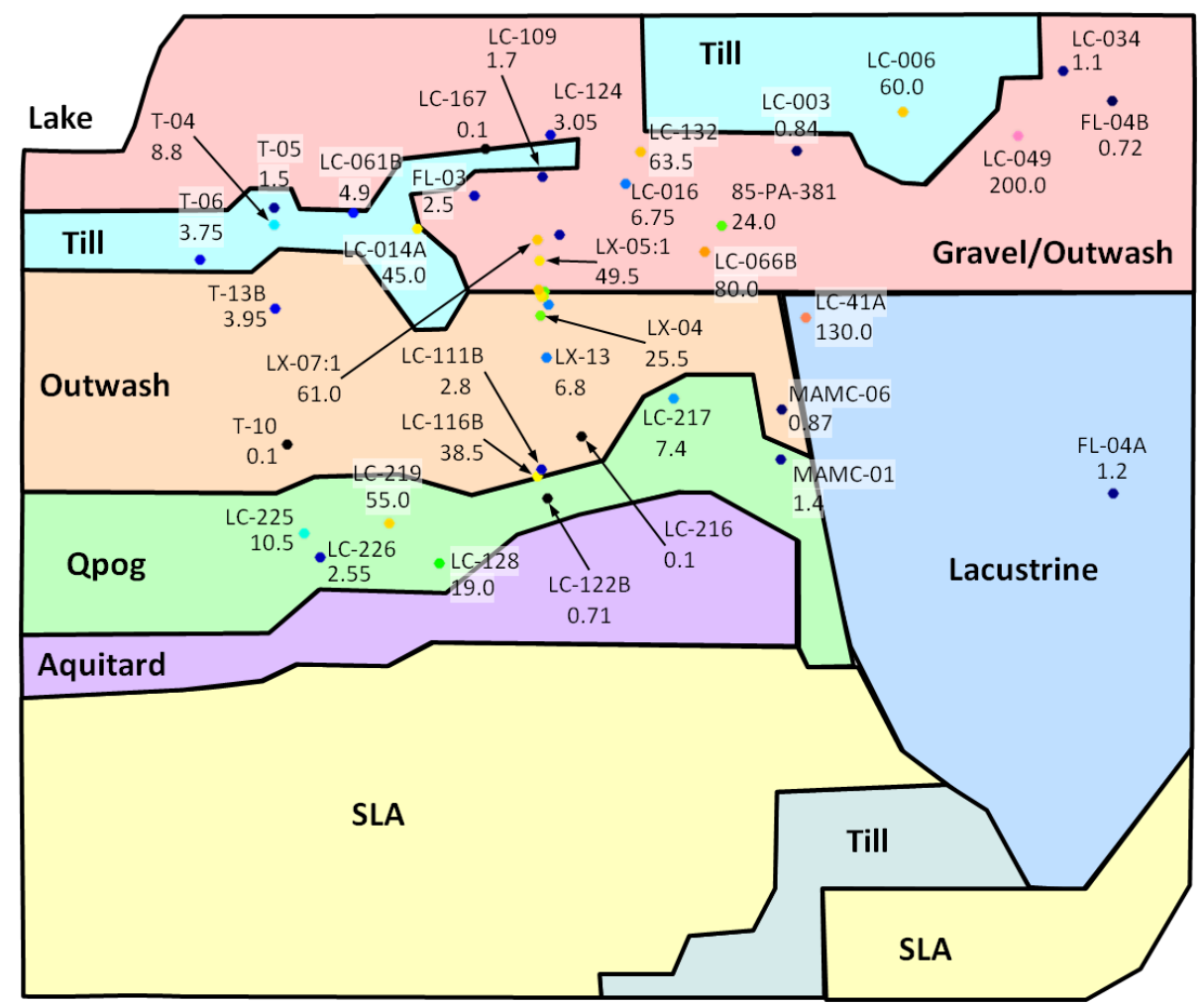

Figure 14. Localized cross section (corresponding to the red box on Figure 13) of the nominal hydrogeology along the Vashon Aquifer plume centerline near the I-5 P\&T system and the window to the lower Sea Level Aquifer (SLA) (adapted from Truex and Johnson [2013]). Labeled points indicate wells projected onto the cross section and the associated average 2012 TCE concentration in $\mu \mathrm{g} / L$ at that well.

\subsubsection{Describe the Hydraulic Head Distribution with and without P\&T Operating}

Hydraulic head data at regional, plume, and local scales, particularly in the vicinity of the P\&T system(s), should be displayed and contoured (as possible) to identify groundwater flow gradient magnitude and direction. Data with and without the P\&T system operating is important. Vertical hydraulic gradients may be important to consider for some sites. If data prior to the P\&T system operation are not available, a period of P\&T shutdown could be considered to obtain natural hydraulic gradient information. This type of shutdown would need to be coordinated with regulatory agencies because it may take weeks or longer for water levels to recover to a pseudo-equilibrium following extended pumping periods. Note, though, that at most sites, the rates of migration may be slow enough that the plume configuration would not change appreciably in a matter of several weeks while the P\&T system was shut down. At some sites, temporal or seasonal variation in hydraulic conditions (which may be a result of nearby pumping or river fluctuation, amongst other things) may also be important. The purpose of this natural hydraulic gradient information is to provide a baseline for evaluation of the groundwater flow component of contaminant mass discharge and/or contaminant attenuation capacity. Figures 15 and 16 show examples of the hydraulic head distribution from the Joint Base Lewis McChord Logistics Center site. 


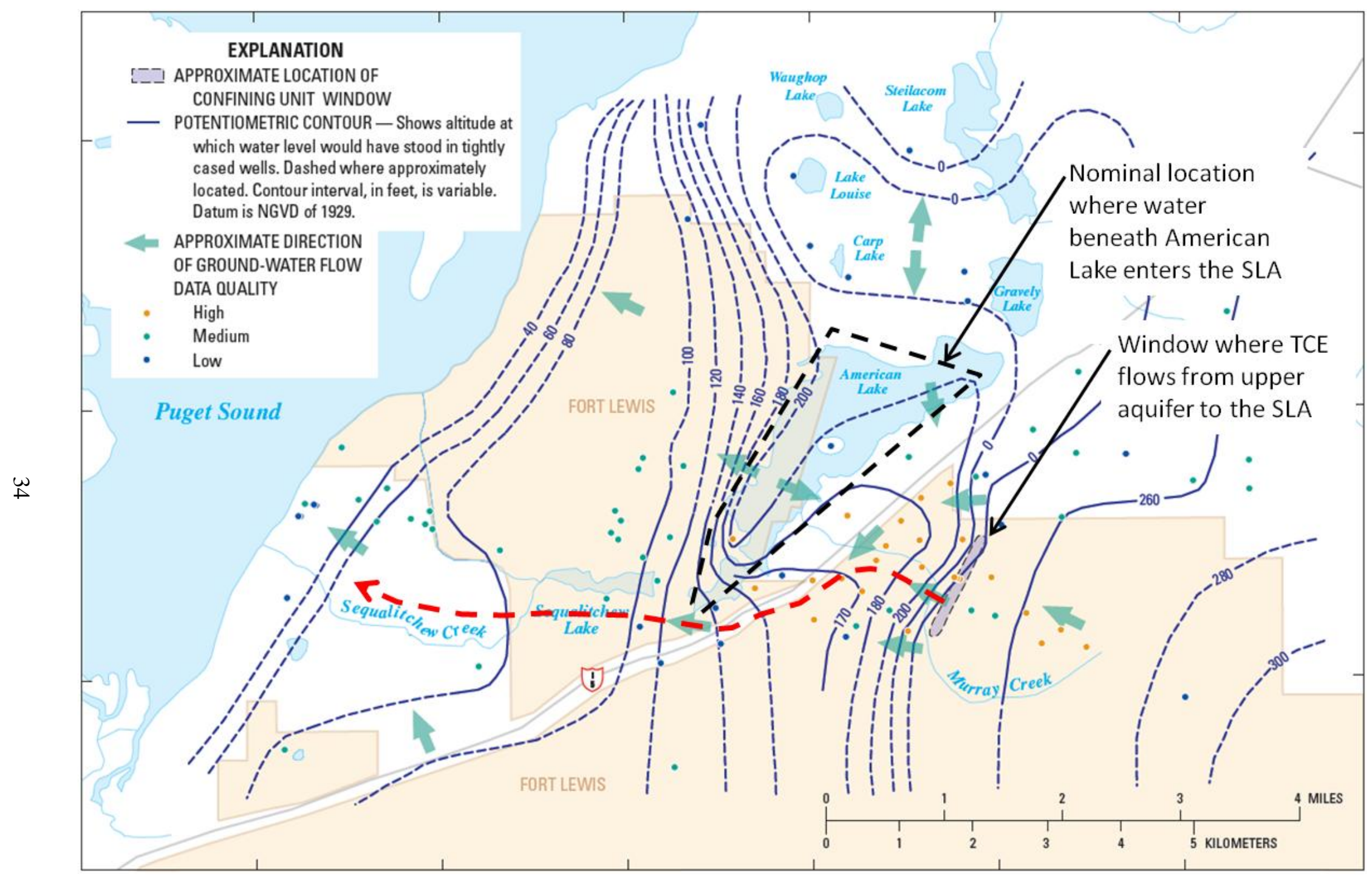

Figure 15. General flow path (red dashed arrow) of contamination in the Sea Level Aquifer (SLA) from the window toward Puget Sound. Contour lines are hydraulic head under natural gradient conditions (adapted from Truex et al. [2006] and Dinicola [2005]). 


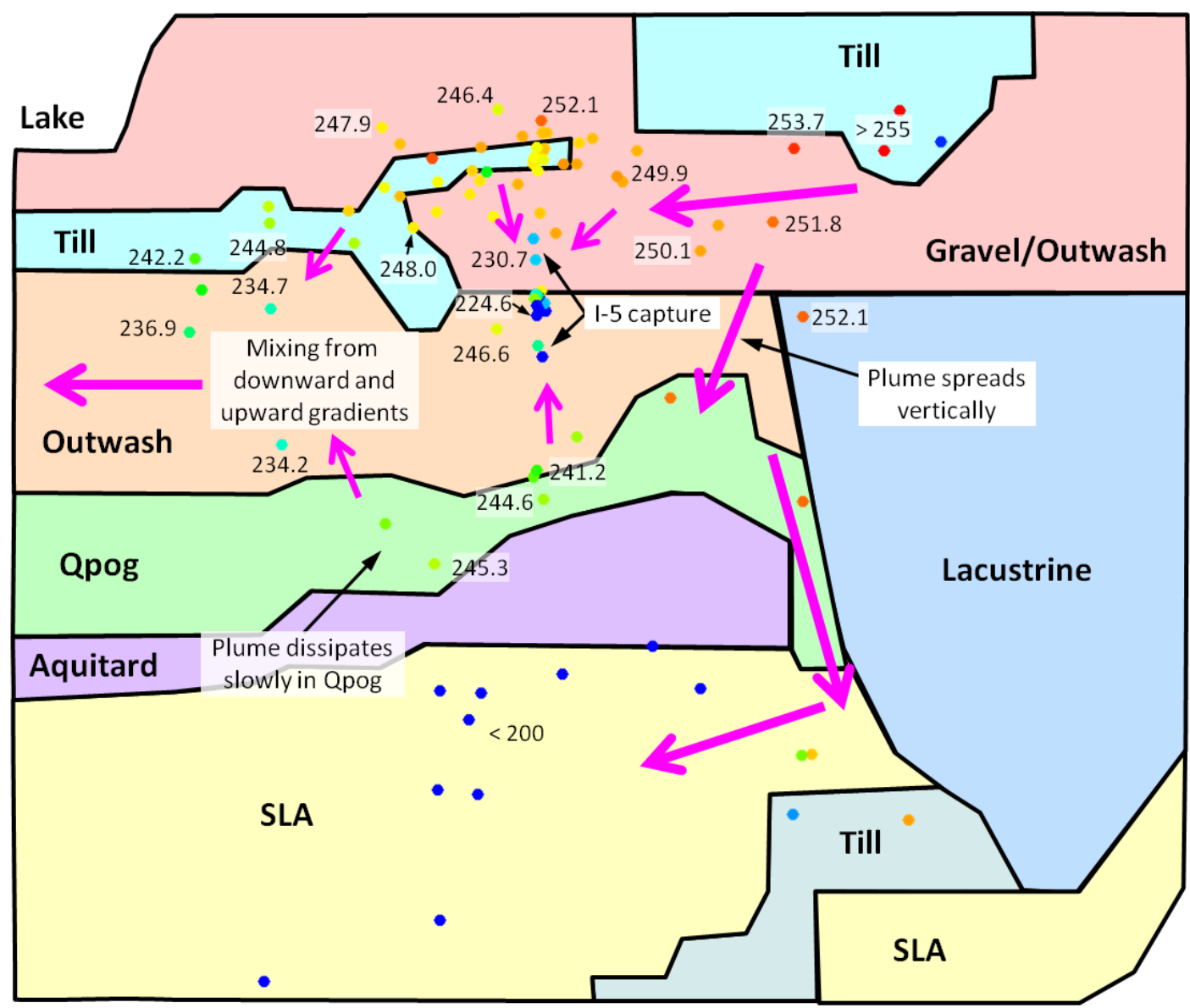

Figure 16. Representative 2004 hydraulic head data (feet relative to mean sea level) for wells projected onto the cross section along the Vashon plume centerline near the I-5 P\&T system and the window to the lower Sea Level Aquifer (SLA) (adapted from Truex and Johnson [2013]). Annotations and magenta arrows describe the interpretation of groundwater flow paths and contaminant plume behavior.

\subsubsection{Describe the Source, Plume, and Known Controlling Features, Events, and Processes}

As a refinement of the overview of the site plume and remedy configuration (Section 5.1.1), the fundamental site information should culminate in a CSM depiction of the source, plume, and known controlling features, events, and processes. At every site, multiple factors collectively control the groundwater flow and associated contaminant plume behavior. A high-level description of the important system components is a key communication tool that helps describe a systematic understanding of the site and factors affecting contaminant fate and transport. In addition, this type of conceptual site model is a starting point from which more detailed aspects of the conceptual site model can be identified and put into context. Figures 17 and 18 from The Scenarios Approach to Attenuation Based Remedies for Inorganic and Radionuclide Contaminants (Truex et al. 2011) provide some examples of system-level conceptual site model depictions. 


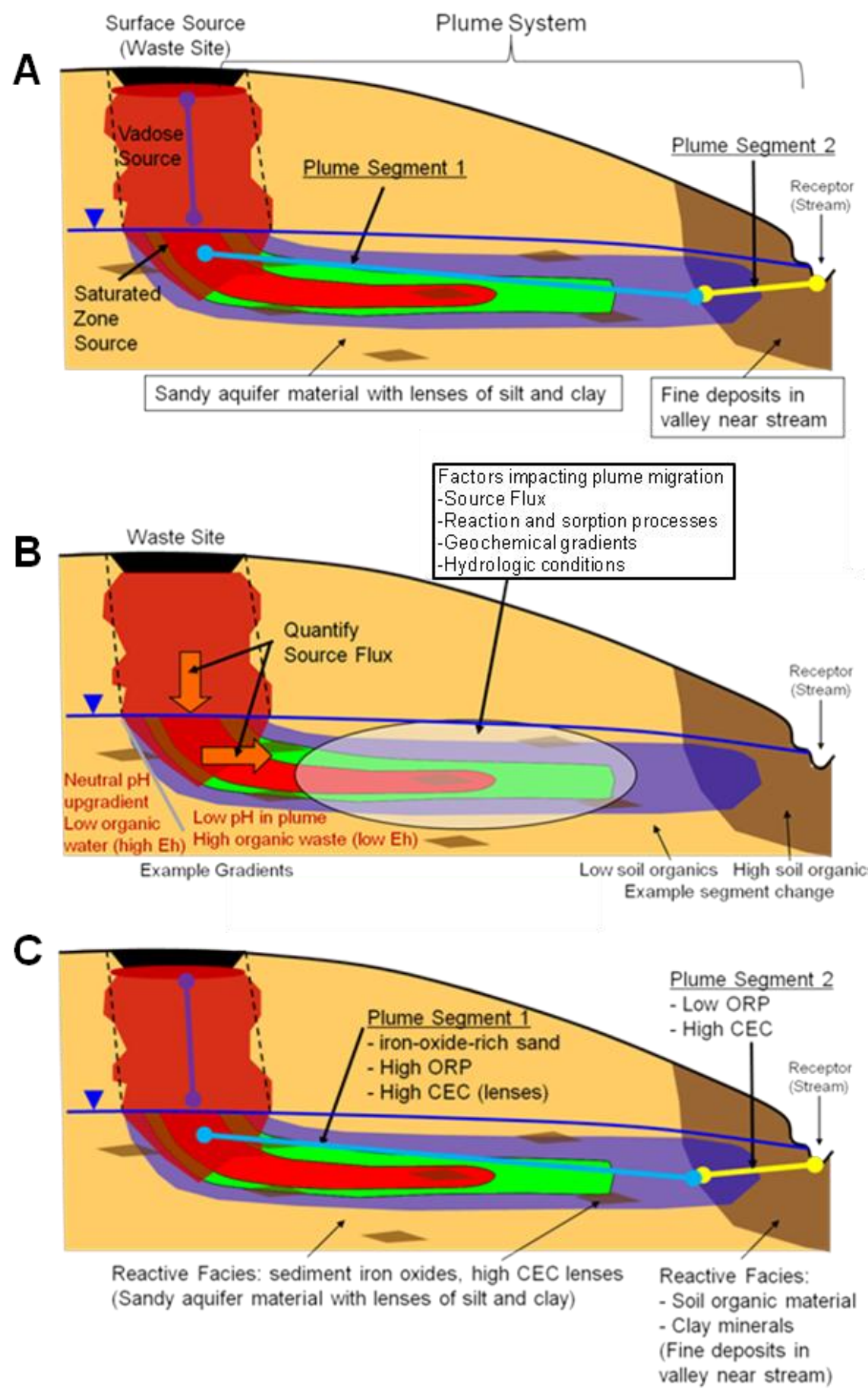

Figure 17. Example initial site depiction (a) identifying the major elements of the site (defined as source components and plume segments) that will need to be evaluated as part of contaminant fate/transport assessment and remediation design, (b) considering contaminant fluxes and conditions that will affect contaminant fate and transport, and (c) identifying reaction, sorption, or solubility control processes with contaminants (which can be helpful in describing the conceptual site model and controlling features and processes relevant to contaminant transport at the site) (adapted from Truex et al. [2011]). In some cases, changes in conditions are expected at the site. When a change occurs, there is a "gradient" between the existing conditions and the future conditions that may be important to evaluate and monitor (e.g., as shown in (b)). 


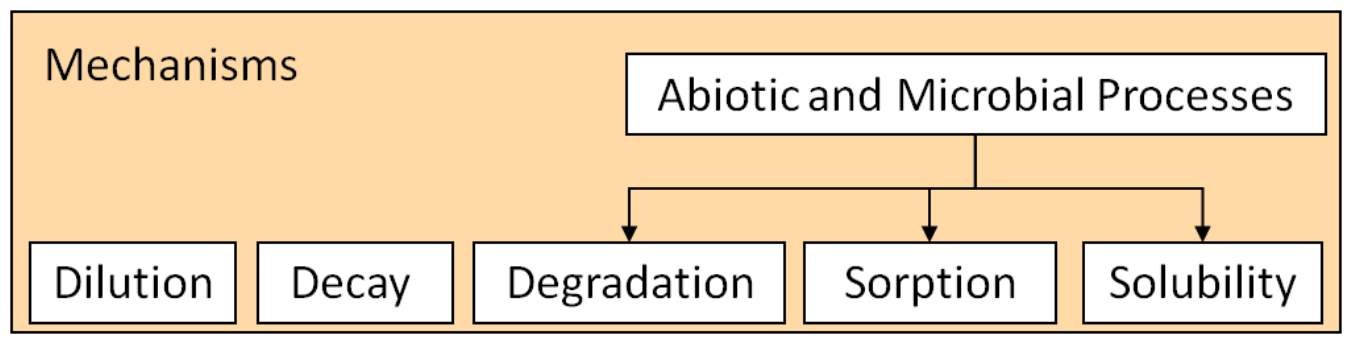

Figure 18. A variety of attenuation mechanisms may be important to contaminant transport. Identification and description of these processes, along with data supporting how they can be evaluated and modeled, can be helpful in describing the conceptual site model and the controlling features and processes at the site (adapted from Truex et al. [2011]).

In some cases, it may be useful to describe the site and factors that affect contaminant fate and transport by listing features, events, and processes (FEPs) that are important to consider as part of a systematic understanding of the site and for design of mitigation measures. Features refer to the general subsurface structure and localized variations that are important to consider for groundwater flow (and contaminant transport). Features may also include buildings or other facility elements that affect groundwater flow. Events occur at a distinct time or as part of some periodic occurrences and their impact on the groundwater system needs to be evaluated.

Processes are basic elements of the groundwater system such as tidal effects, surface-water interactions, or contaminant transport behavior. Other important elements of FEPs include utilities such as sanitary sewers or storm water systems that may leak and the presence of other pumping wells in the area that may affect groundwater flow. In particular, it may be important to consider how pumping rates have (or will be) changed over time. Descriptions of FEPs may be useful for planning and communication as part of a conceptual site model. In some cases, FEPs are readily described by the other forms of a conceptual site model and do not need to be explicitly listed.

In addition to the above types of CSM depictions, the plume configuration can be described based on plume contours and, where possible, with indication of contaminant mass discharge between key segments of the plume or subsurface (e.g., between the source and the plume or between different hydraulic zones). This type of depiction for conditions before P\&T and for the conditions at the time of the P\&T assessment can be useful in demonstrating the impact of the P\&T remedy and in organizing the collection of additional information to predict post-P\&T behavior for options being considered. A plume map may also be overlain on top of key hydrogeologic and/or hydraulic head information to help highlight features affecting plume behavior. Plume maps can be generated for multiple time points to show historical plume dynamics and remediation progress. Care should be taken with respect to use of consistent well data sets when comparing plume maps. Figure 19 shows an example figure depicting the plume configuration for the Joint Base Lewis McChord Logistics Center site. Some sites may need to develop more detailed three-dimensional plume descriptions and contaminant trend analyses than are depicted in this example. 


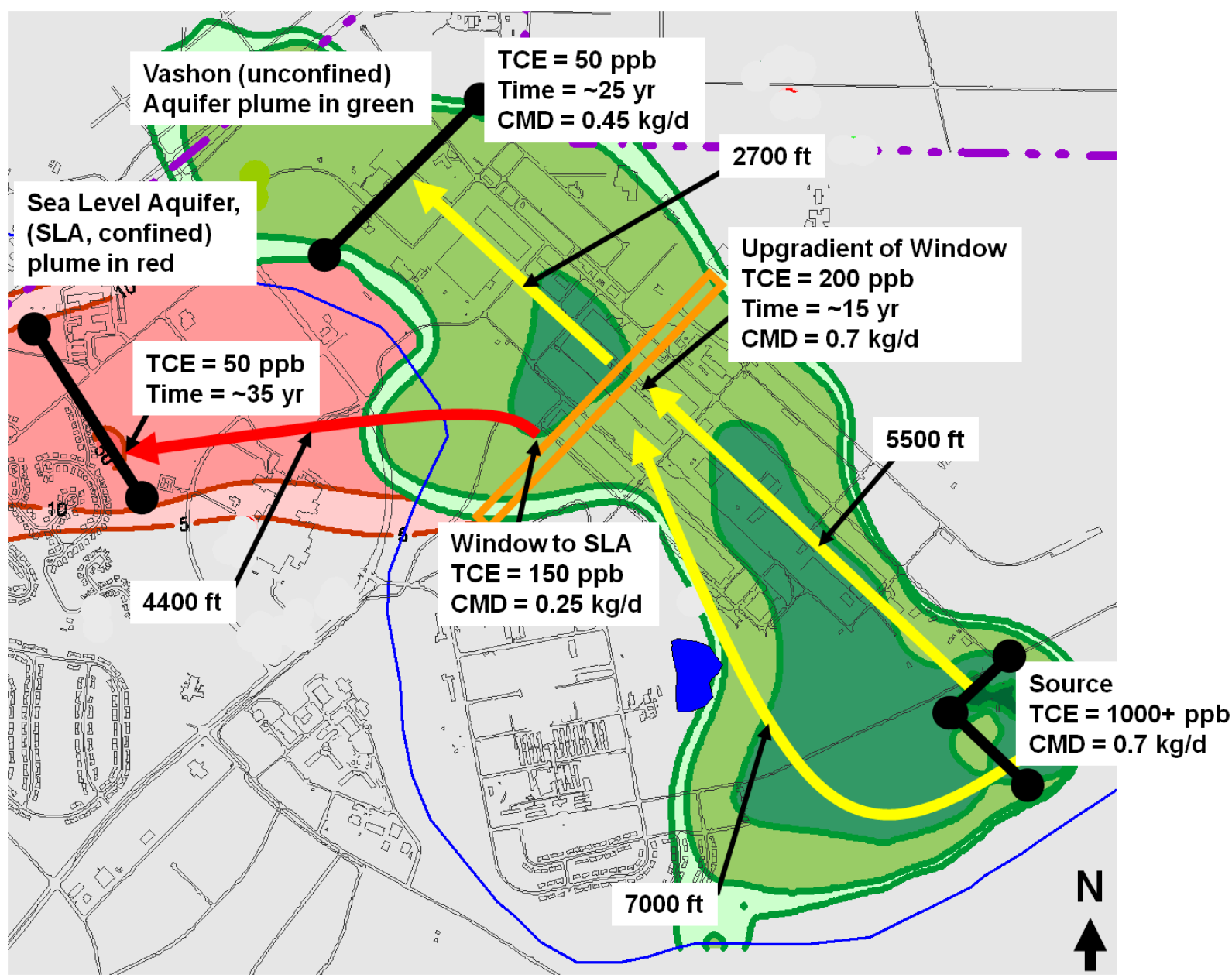

Figure 19. Example of the Joint Base Lewis McChord plume system with interpretation of flow paths, TCE contaminant concentrations, and CMD for conditions prior to $P \& T$ operations. Black bars represent the location of $P \& T$ systems. General plume configuration and key features such as the "window" between the Vashon and Sea Level Aquifers are also shown on Figures 11, 13, and 15.

\subsection{Decision Element Information}

The following decision element information for the CSM is discussed in this section.

- Quantitative description of the plume contaminant concentration distribution and trends

- Contaminant mass discharge estimates for key locations in the plume system (including the P\&T system location[s])

- Estimates for contaminant attenuation and the aquifer attenuation capacity

- Estimated future plume behavior and time to reach RAOs

- P\&T system design, performance, and cost information 


\subsubsection{Contaminant Concentrations and Trends}

Contaminant concentration distribution and trend data are used to evaluate whether the plume has declined during the P\&T remedy and to provide input for use in the subsequent decision element assessments. Overall plume descriptions as discussed in Section 5.1 (and more specifically in Section 5.1.4) provide a context for evaluating the plume contaminant concentration distribution and trends using plume maps. These plume maps provide a visual depiction of plume behavior and, with comparison of plume maps over time, can provide information on overall trends (e.g., Figure 20). Plume-scale contamination changes can be quantified using a mass-based assessment, as described in EPA (2002b). In addition, trends at individual wells or along transects of plume movement are also useful to quantify plume changes over time. The information gathered for contaminant concentrations and trends needs to provide a basis for assessing whether or not the overall plume has declined during the P\&T remedy. However, it may also be useful to examine segments of the plume to determine if there are segments that are recalcitrant to the P\&T remedy (i.e., resulting in a persistent plume or plume segment). Some sites may need to develop more detailed three-dimensional plume descriptions and contaminant trend analyses using high-resolution characterization and monitoring. 

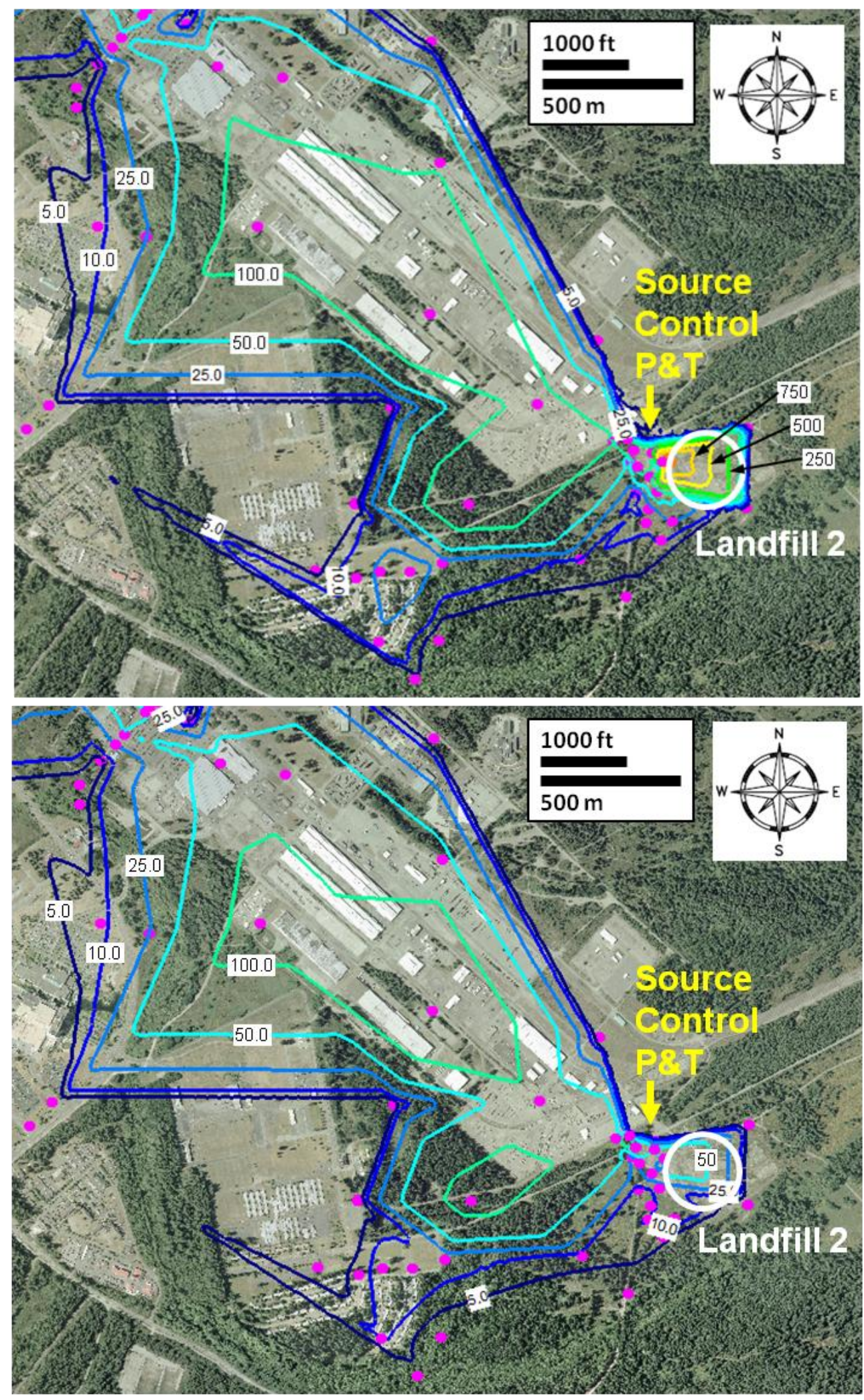

Figure 20. Interpolation of TCE concentration data $(\mu \mathrm{g} / \mathrm{L})$ in the Vashon Aquifer at Joint Base Lewis McChord for 2007 (top) and 2012 (bottom) (adapted from Truex and Johnson [2013]). Source Control P\&T at Landfill 2 was initiated in 2006. 


\subsubsection{Contaminant Mass Discharge}

The CMD at a given location in a plume (or at the source) is an indication of the amount of contaminant mass migrating past that location over time. ITRC (2010a) provides a thorough discussion of CMD and can serve as a resource for this portion of the P\&T performance assessment. The P\&T system data can provide contaminant mass extracted over time, which is an indicator of extraction efficiency and can be interpreted in terms of the CMD that would occur from the capture zone if the P\&T system were terminated. The CMD information is useful when assessing performance and future plume behavior using a mass balance approach (e.g., ITRC 2008) that examines the CMD in comparison to factors relating to the downgradient transport of the contaminants (e.g., the attenuation capacity, described below).

For any pumping well (or group of pumped wells), CMD at the well is readily calculated from measured extraction flow rate and concentration data. This CMD is a measure of the CMD in the aquifer within the capture zone of the well (or well system), as depicted in Figure 21. Thus, standard data collected for a P\&T system can be translated into a measure of CMD in the captured portion of the aquifer. Using data collected over time, the changes in CMD over time can be determined. Figure 22 shows example data for CMD of a source control P\&T system depicting the impact of a source reduction treatment technology applied in the source zone. The P\&T system CMD is a reasonable estimate of CMD in the aquifer within the capture zone. However, if the CMD is to be used for estimates of post-P\&T plume behavior, then this CMD from the P\&T system must be scaled based on the ratio of the groundwater flow through the capture zone during P\&T operations to the flow under natural-gradient conditions. Interpretation of CMD computed for plume reduction P\&T systems may be more complex than for source control or plume containment P\&T systems because of the (typical) significant change in flow direction between pumping conditions versus natural flow conditions.

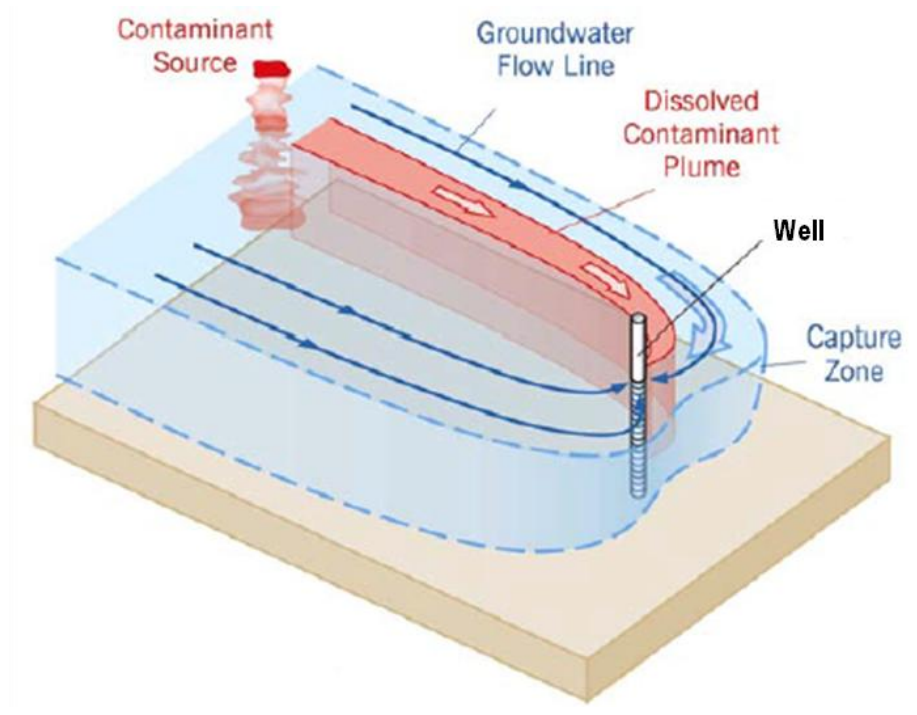

Figure 21. Representation of a plume captured at a pumping well. Here, contaminant concentration multiplied by the extraction flow rate at the well would provide a measure of the contaminant mass discharge for the capture zone (adapted from ITRC [2010a]). 

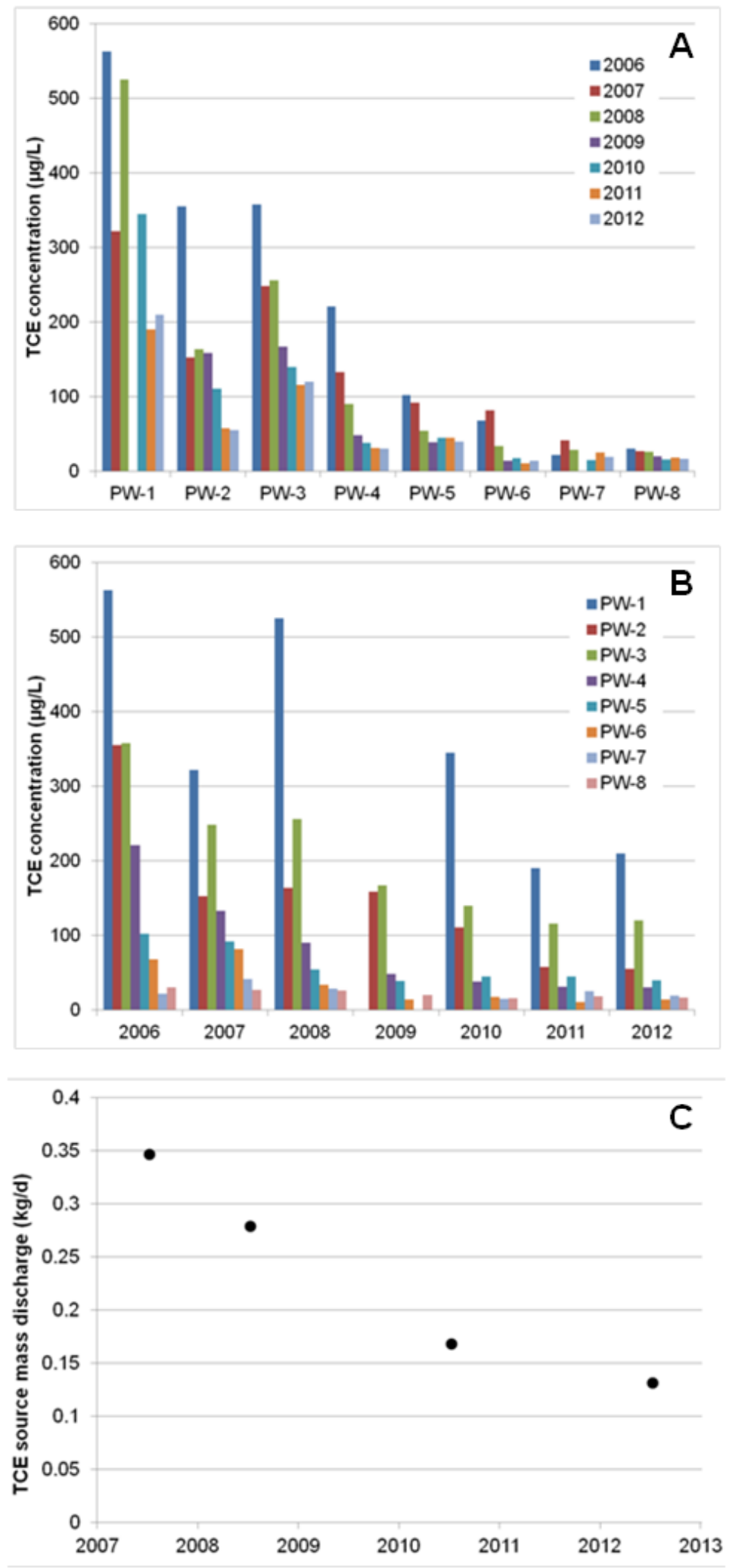

Figure 22. Concentrations at (A) individual P\&T wells (PW-\#) over time and (B) grouped by individual well for each year. Also shown is a plot $(C)$ of total system CMD for times when coincident flow and concentration data were available. 
The distribution of CMD between wells, in conjunction with knowledge of the upgradient capture for individual wells within the P\&T system, may be useful in identifying zones of more significant source or the location of plume cores. For instance, in Figure 22, the most significant remaining source is within the capture zone of wells PW-1, PW-2 and PW-3. This information may be combined with upgradient monitoring well data to further refine conditions upgradient of the P\&T system. The CMD is a volume-averaged measurement of the plume or source upgradient of the measurement location. It is also important to consider the concentration profile across the plume or within the source upgradient of the CMD measurement location. When concentrations are highly variable, concentration-based approaches to evaluate the downgradient transport and attenuation may be more appropriate than spatially averaged mass-based approaches (e.g., a threshold concentration approach as discussed in Section 6.2.1). Thus, when collecting CMD information, concentration profile information should also be collected.

CMD (i.e., mass flux) data from transects of monitoring wells perpendicular to the direction of flow (Figure 23) can be computed from concentration data and groundwater flow data (e.g., as interpreted from hydraulic head data). In addition, passive flux meters (ITRC 2010a) can be employed in a transect of monitoring wells perpendicular to the direction of plume movement to estimate the vertical and lateral distribution and magnitude of contaminant mass flux across the plane represented by the transect of wells. Figure 24 depicts the concept of how passive flux meter data is interpreted as an estimate of the actual mass flux across the transect. A transect of monitoring wells perpendicular to the direction of plume movement can also be used to conduct an integrated pumping test (Figure 25). The integrated pump test analyzes the observed concentration data over the duration of the test to determine contaminant mass flux and average concentration in the plume at that transect. Note that the P\&T system wells can be used for the above CMD determination if pumping is suspended for a period of time or applied as described for the integrated pump test. Note that all of these techniques may be more difficult to apply for highly heterogeneous sites, such as those with fractured flow. 


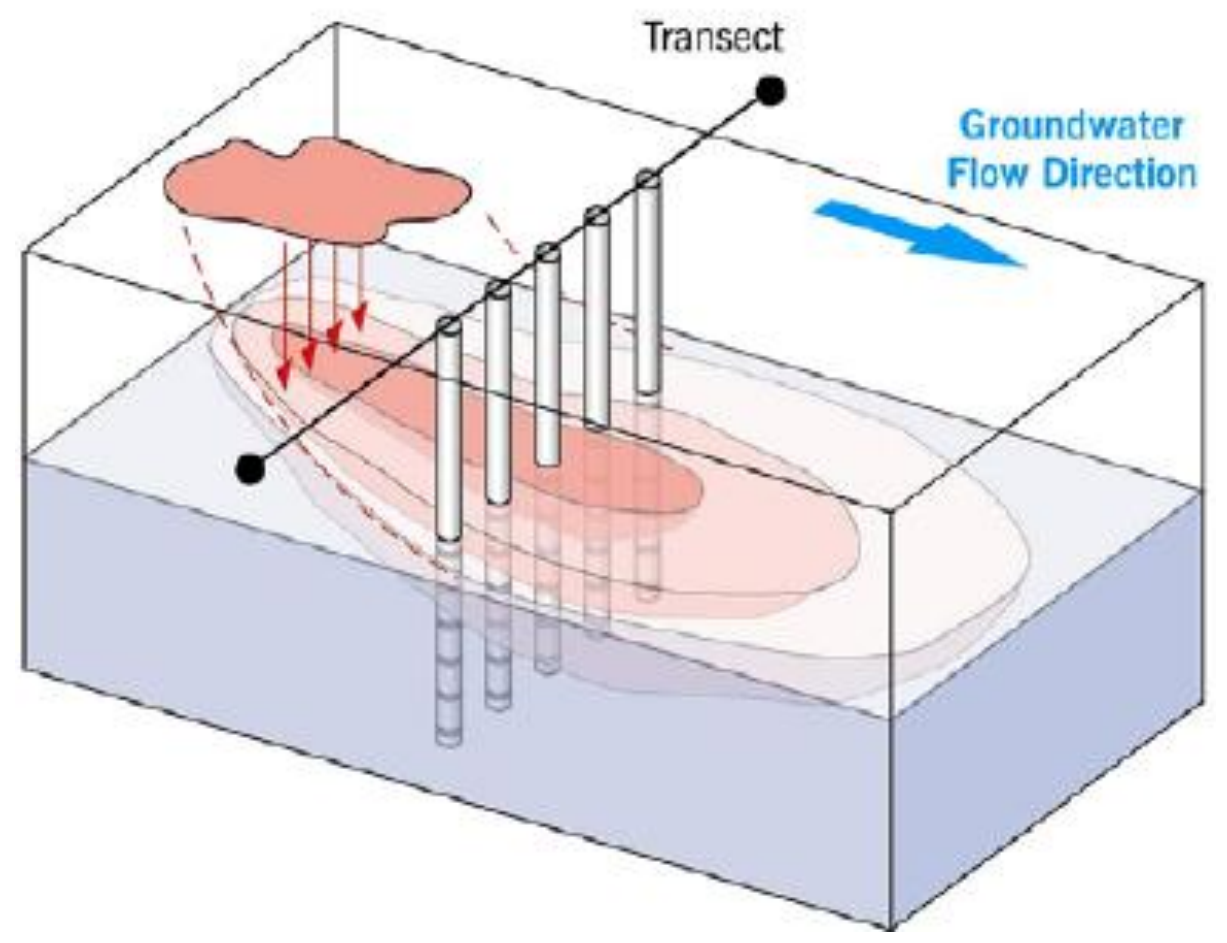

Figure 23. Example of a mass flux transect (ITRC 2010a).
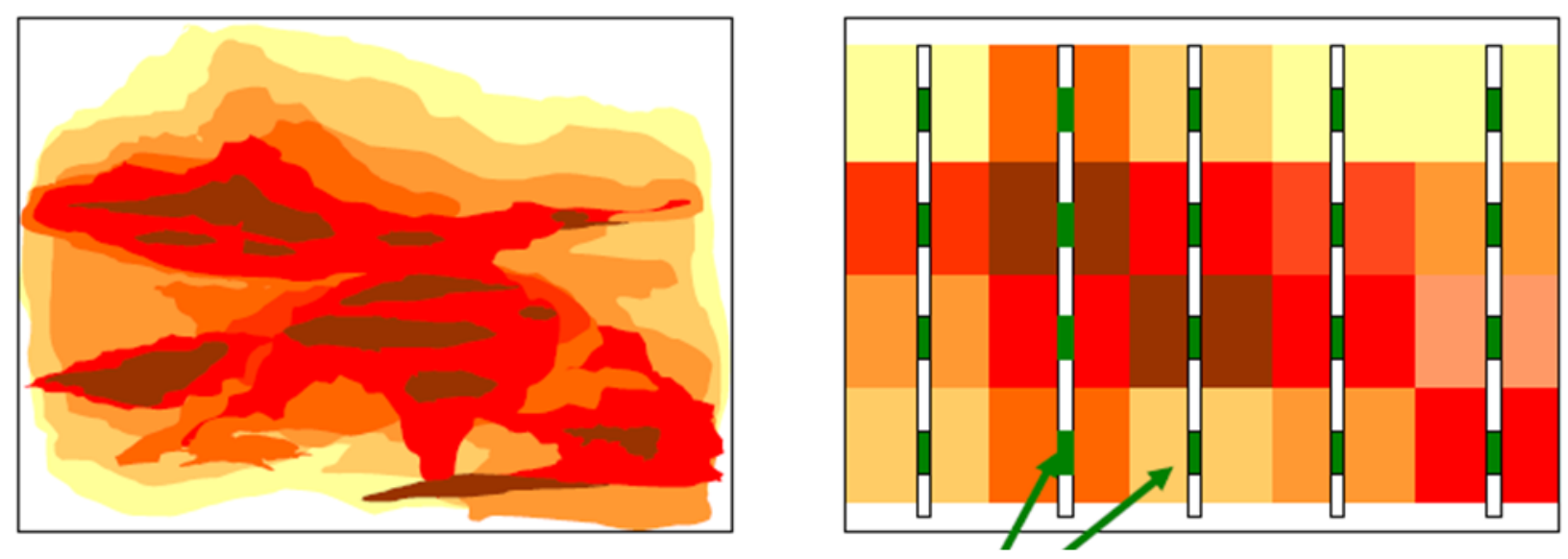

Individual passive flux meters with higher (left) and lower (right) measured mass flux for the corresponding cross section segments

Figure 24. Given a transect of wells, the actual contaminant distribution (e.g., the conceptual distribution in the picture at the left where darker colors represent higher concentrations) can be assessed with passive flux measurements to provide an interpreted contaminant flux distribution (picture at right with the same scale and color code) (adapted from ITRC [2010a]). 


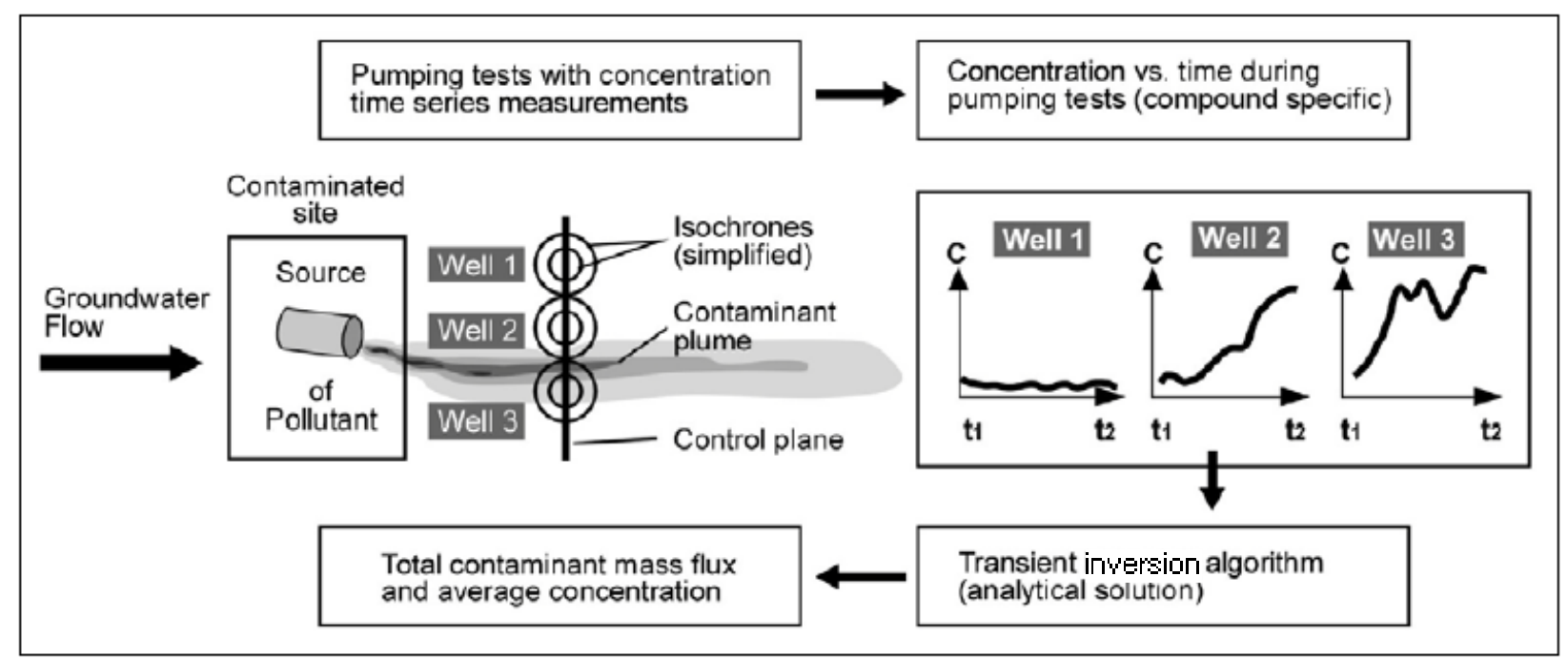

Figure 25. Elements of an integrated pump test in which concentration data from a transect of wells perpendicular to the plume flow direction is analyzed to determine contaminant mass flux and average concentration at the transect (ITRC 2010a).

If the P\&T system can be turned off temporarily, the P\&T wells and monitoring wells in the vicinity may be suitable for field measurements to estimate a post-P\&T CMD. The cessation of P\&T operations need only be a temporary action of sufficient duration to collect the data of interest. The data under natural conditions would be important for assessing termination of P\&T and the potential transition to a different treatment technology. During the non-operational period, concentration data from monitoring wells can be observed over time to determine the magnitude of any concentration rebound. The water discharge component may be known from initial site characterization and modeling or could be evaluated by measuring the hydraulic gradient in the vicinity of the P\&T system with the P\&T system off. The hydraulic gradient can be used with estimates of hydraulic conductivity to estimate the water discharge through the P\&T location. With the P\&T system off, contaminant concentrations at the P\&T wells and appropriate monitoring wells in the vicinity can be collected to evaluate the concentration component of the CMD. Note that the water level rebound that occurs with the P\&T system off may allow contact between ground water and "stranded" contaminant in the previously dewatered soil, which may affect observed concentrations.

The above field measurements of CMD can also be augmented with numerical contaminant transport modeling, if available for the site. The CMD at locations of interest can be readily extracted from numerical model results and used as an estimate for the CMD decision element. Numerical modeling would enable estimates of CMD under both pumping and non-pumping conditions. The numerical model could also be used to supply an estimate for just the groundwater flow component of the CMD evaluation. This estimate could then be combined with measured concentration data to estimate the CMD at the selected location. 


\subsubsection{Natural Attenuation Capacity}

There are multiple approaches to evaluate attenuation rates and mechanisms in the aquifer. These are important as part of assessing the role of natural attenuation during P\&T or for transitioning P\&T to MNA or another remedy that includes the contribution of natural attenuation. For assessing performance and future plume behavior using a mass balance approach (e.g., ITRC 2008), attenuation capacity can be estimated as a decrease in contaminant mass over time within a given volume of the aquifer for comparison to the CMD (Section 5.2.2). The attenuation capacity is a volumetric assessment and is conceptually useful in evaluating when natural attenuation may be sufficient to meet RAOs. In some cases, especially when there is a higher concentration plume core, use of an attenuation rate (change in concentration per time) with comparison to the concentration emanating from the source zone plume core should also be considered in evaluating the ability to meet concentration-based RAOs (e.g., a threshold concentration approach as discussed in Section 6.2.1).

Attenuation capacity is the degree to which natural attenuation process can reduce contaminant plume concentrations to the remedial goals within spatial and time constraints. The natural attenuation processes providing the attenuation capacity comprise all of the processes that diminish plume concentrations along a flow path, including dispersion, sorption, and biogeochemical reactions. These reactions can include biologically mediated transformation of contaminants, or abiotic processes such as contact with reactive minerals (e.g., magnetite for chlorinated compounds [EPA 2009a]) or hydrolysis.

Existing guidance documents (e.g., EPA 1998, 1999c, 2002b, 2003, 2004, 2007c, 2007d, 2010, 2011b; ITRC 1999a, 1999b, 2008, 2010b; USGS 2003; Wiedemeier et al. 1999) provide information on the approaches for assessing natural attenuation at a site. A variety of metrics can be employed to assess attenuation and provide lines of evidence for the attenuation capacity of the aquifer. These metrics include rate assessments, measurement of specific attenuation processes, and assessment of contaminant fate and transport. Components contributing to the attenuation capacity can be evaluated using measurements that target specific processes. Examples of these measurements are laboratory evaluations with site sediments and groundwater, environmental molecular diagnostics (EMD), and push-pull tests. Information about options for evaluating the attenuation capacity associated with specific processes is available in multiple published documents (e.g., EPA 2004, 2011b; ITRC 2011a, 2013; Gilmore et al. 2006).

Attenuation rates can be computed in different ways and each provides slightly different information about contaminant attenuation (EPA 2002b; Figure 26). A point attenuation rate is based on contaminant concentrations at a single monitoring location over time and primarily imparts information about the duration of the plume (i.e., time required to meet remedial goals). However, point attenuation rates for multiple wells across the plume can be useful to assess the overall plume attenuation. A bulk attenuation rate can be calculated from concentration versus distance data (typically for a transect of wells extending from the source to a downgradient 
location along the axis of the plume) and provides information to assess whether the plume is being attenuated or not. A biodegradation rate (from laboratory studies, modeling studies, or in some situations field experiments) describes the impact of microbial activity on transformation of contaminants. Biodegradation rates provide information about the potential for attenuation, relative contribution to the attenuation processes, and (in conjunction with a numerical model) the plume attenuation. Data on plume mass over time can be used to assess plume attenuation and may have advantages for non-standard plumes (e.g., plumes where the centerline changes with seasonal flow variations or for a detached plume).
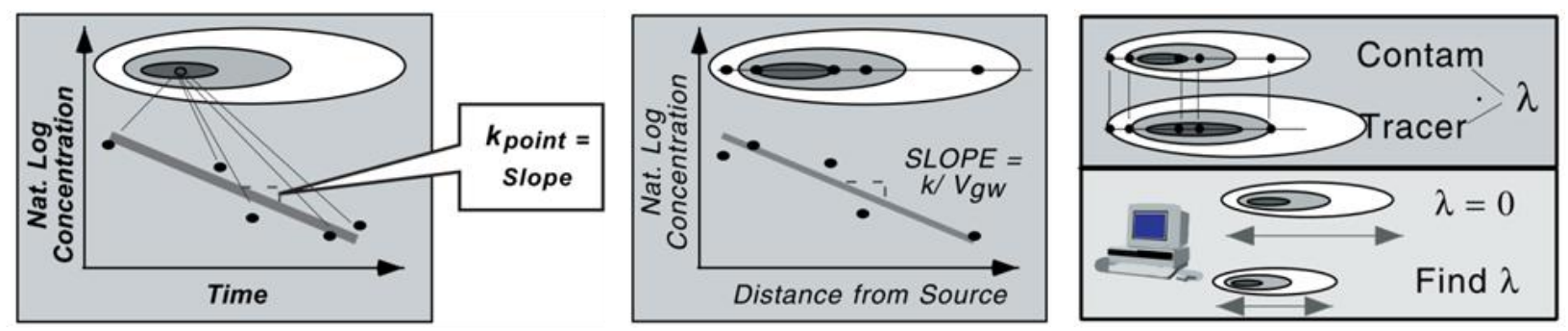

Figure 26. Conceptual examples of attenuation rate calculations for point rates (left), bulk rates (middle), or biodegradation rates (right) (adapted from EPA [2002b]). These rates are typically applied for evaluating concentration changes over time as part of estimating attenuation processes and timeframe. This type of information can also be interpreted in conjunction with plume or plume segment volumes to assess attenuation in comparison to a threshold upgradient concentration (discussed in Section 6.2.1).

Mass flux (i.e., CMD) data from transects of monitoring wells perpendicular to the direction of flow (Figure 23) and located at several distances from the source area can provide information on the stability of a plume (shrinking/expanding/stable), plume attenuation, and the biodegradation rate in the aquifer. Care is needed in applying these estimates for plumes that are in transition (e.g., that are not at a steady-state condition) for some reason. These estimates will provide a volumetric estimate of plume attenuation. In some cases, especially when there is a higher concentration plume core, use of an attenuation rate (change in concentration per time) with comparison to the concentration emanating from the source zone plume core should also be considered in evaluating the ability to meet concentration-based RAOs (e.g., a threshold concentration approach as discussed in Section 6.2.1).

A fate and transport assessment can be conducted, with comparison to historical data, to determine what level of attenuation capacity reasonably matches the observed data. Analytical or numerical models can be used, with parameters corresponding to attenuation processes (e.g., reaction rates) being adjusted to achieve a match to observed data. The above-mentioned specific attenuation process measurements can form a basis for selecting parameter values in the fate and transport assessment. An additional use of numerical modeling is to compare observed plume dissipation downgradient of P\&T (or at plume fringes for a P\&T plume reduction application) to predicted responses with different levels of attenuation capacity included in the model. 
If the P\&T system can be turned off temporarily, the P\&T wells and monitoring wells in the vicinity may be suitable for field measurements to estimate contaminant rebound and subsequent plume behavior as input to assessment of natural attenuation. The cessation of P\&T operations would need to be of sufficient duration to collect the data of interest. Thus, this type of shutdown would need to be coordinated with regulatory agencies.

Example calculations of attenuation capacity for use in comparison to CMD as part of the performance assessment approach are provided in Section 6. In Section 6, these examples are presented in the context of applying the performance assessment decision logic.

\subsubsection{Estimates of Plume Behavior and Time to Reach RAOs}

Like any remedy decision, a prediction of plume behavior and the time needed to reach the RAOs is an important part of a P\&T remedy assessment. The estimated plume behavior under continued P\&T, MNA, or with application of other remedy components or alternative remedies needs to be estimated. Key components are evaluating protectiveness (e.g., controlling exposure during remediation) and estimating the time to reach the RAOs. In estimating the remediation timeframe, consideration of whether this timeframe is reasonable is important in evaluating remedy performance and in assessing whether the site has complexities that cause difficulties with remediation that need to be considered in developing the remediation strategies (NRC 2013; ITRC 2015; Hawley et al. 2014). For the plume behavior estimate, it is also important to consider the controlling features at the site (e.g., matrix diffusion) or the source conditions that may contribute to extending the remediation timeframe. The decision makers at each site will need to determine how to define a reasonable time for remediation based on the site-specific circumstances.

Key input to the plume behavior estimate will be the data on plume behavior collected during P\&T operations. The rate of plume decline within the capture zone can be used to assess expectations for continued decline with $\mathrm{P} \& \mathrm{~T}$ and/or to identify areas of recalcitrance in plume concentrations. Here, plume maps over time and concentration trends at diagnostic wells can be used for the assessment. In addition, the change in CMD over time at P\&T system wells or at flux measurement points may also be useful. The rate of plume decline downgradient of a P\&T capture zone is also instructive in similar ways by using an assessment of whether the plume is diminishing as expected or whether there are areas that remain recalcitrant. Because of the impact of P\&T on groundwater flow patterns, interpretation of plume behavior and concentration distributions may be facilitated by conducting a contaminant rebound test. In this approach, the P\&T system is shut down for a period of time so that concentrations in the plume under natural gradient conditions can be better assessed (e.g., Case Studies 1, 2A, and 2B).

For some portions of the performance assessment, it will be important to estimate future plume behavior with a reconfigured P\&T system or with application of other treatment/remedy options. To support this assessment, an approach to estimating plume behavior and remedy 
performance, such as that used in a screening-level or remedy-alternative-analysis-level performance assessment for a feasibility study process, is recommended (EPA 1988, 1993a).

A fate and transport assessment, with comparison to historical data, may be a key tool to evaluate protectiveness and estimate the time to reach the RAOs to support remedial decisions. Analytical or numerical models, such as REMChlor (Falta 2008), BIOCHLOR (EPA 2000b; Aziz et al. 2002), BIOSCREEN (EPA 1996b), NAS (Widdowson et al. 2005), MT3D/RT3D (Harbaugh 2005; Clement et al. 1998; Johnson et al. 2006), STOMP/eSTOMP (White et al. 2015a, 2015b), and ASCEM (DOE 2015), can be used with estimates of transport and attenuation parameters to assess remedy performance. Because models can have limitations in how system features can be represented and there are often uncertainties in the nature of the subsurface, it may be important to use a sensitivity analysis based on reasonable variations in input parameters to assess the range of potential future plume behavior and timeframes to reach the RAOs. Uncertainty may come from limited knowledge about preferential groundwater flow, residual NAPL dissolution, matrix diffusion, etc. The fate and transport assessment using available tools provides a basis for decision making, though site decision makers should update the estimates of plume behavior and timeframes as conditions change and/or more data is collected.

\subsubsection{P\&T Design and Operational Information}

As part of the performance assessment, information about the P\&T design, operation, and cost are important to consider. Such information is useful for assessing whether optimization would help performance or for comparison of $\mathrm{P} \& \mathrm{~T}$ to other remediation alternatives. Thus, the $\mathrm{P} \& \mathrm{~T}$ design and operational approach are important aspects of the CSM. It is also important to define both the benefits being provided by the $\mathrm{P} \& \mathrm{~T}$ system and any potential detrimental impacts of the P\&T system (e.g., issues with secondary wastes or the induced hydraulic gradients with respect to plume behavior). This information is important in terms of evaluating the costs, benefits, and impacts of the current remedy design to support the P\&T system performance assessment.

The locations of well screen intervals should be identified relative to the geological stratigraphy and hydrology information. Figure 27 shows an example for the Joint Base Lewis McChord Logistics Center site where P\&T well screen locations are identified on a cross section, along with stratigraphy and contaminant data. The impact of the P\&T system on the hydraulic head distribution and an understanding of the capture zone are also important elements of the CSM. A capture zone analysis (EPA 2008) provides information about both how the groundwater extraction (and any associated groundwater infiltration/injection) affects the groundwater flow in the aquifer and the extent of the capture zone. This information can be overlaid with contaminant data to assess the effectiveness of the treatment system and can be used to update fate and transport models, as appropriate. As an example, Figure 28 depicts the capture zone extent and resulting hydraulic head contours for a P\&T system at the Joint Base Lewis McChord Logistics Center site. 


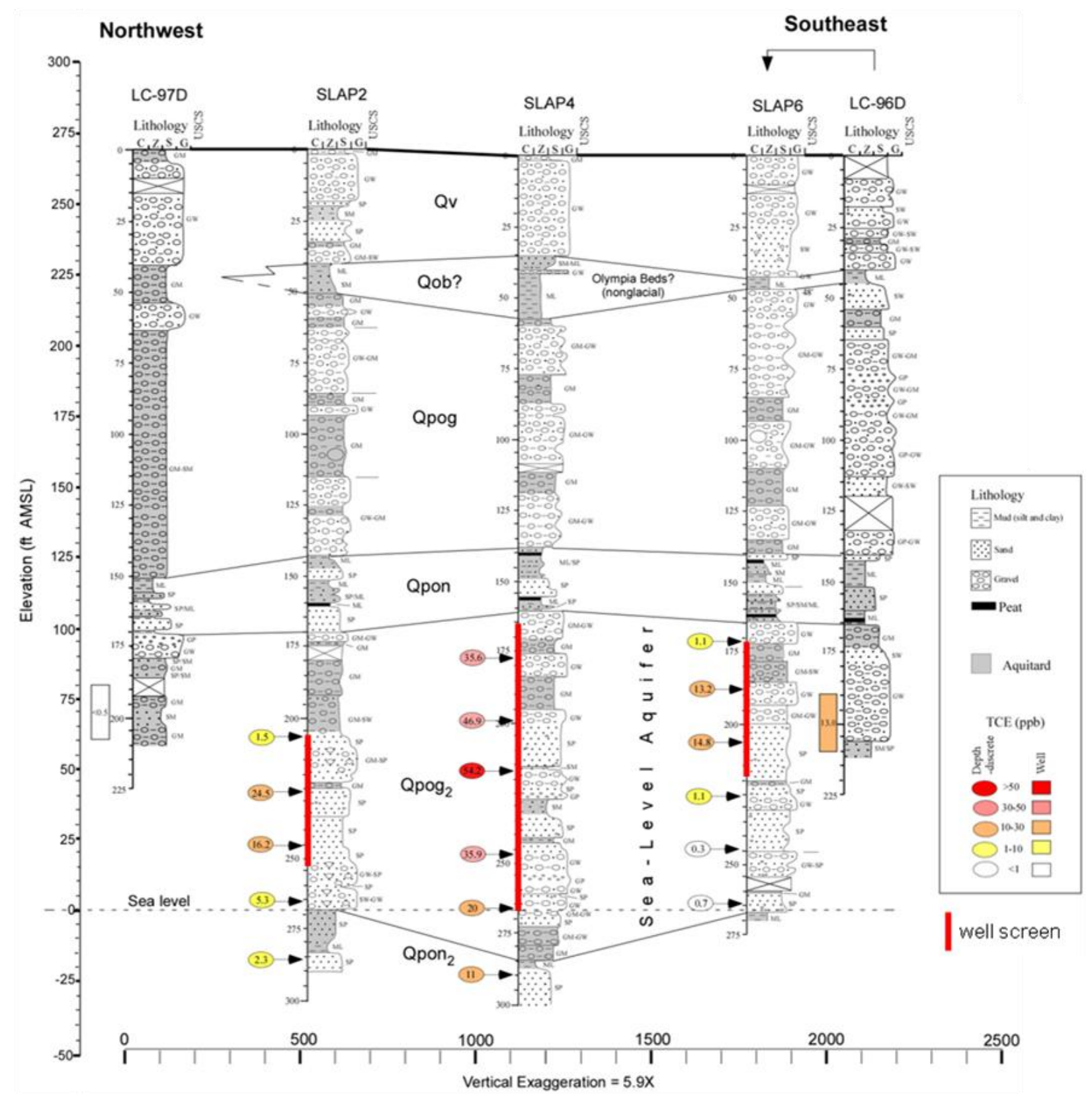

Figure 27. Example geologic cross section and contaminant data for a P\&T well system segment at Joint Base Lewis McChord (Truex et al. 2008). 

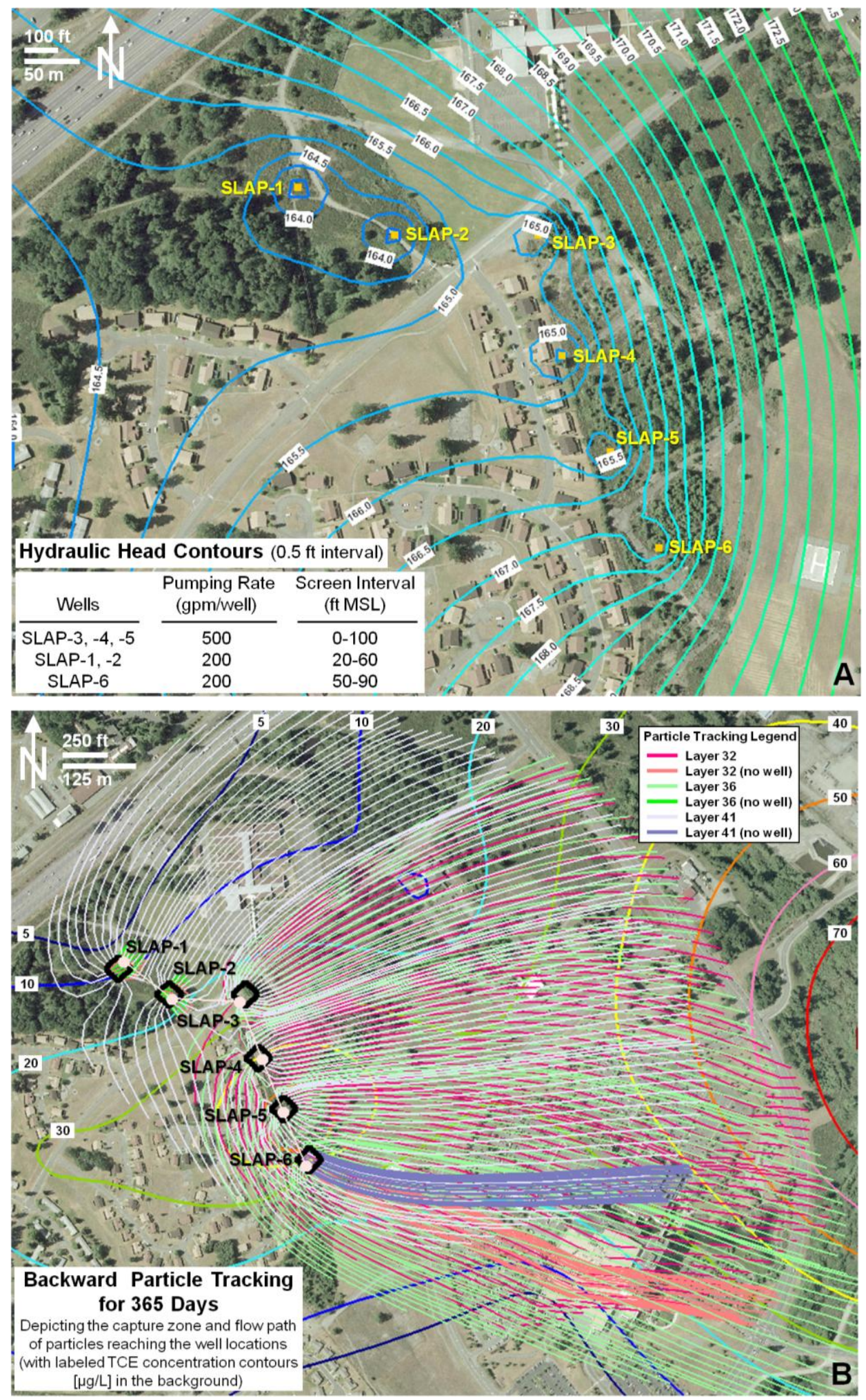

Figure 28. Example of modeling results for a P\&T system at defined pumping rates, showing (A) calculated hydraulic head contours and $(B)$ the extent of a one-year capture zone, as determined from backwards particle tracking at different layers/elevations (adapted from Truex et al. [2008]). The "no-well" pathlines show flow paths without pumping. 
Where a remedy already includes a combination of P\&T and other in situ treatment technologies, the nature of the treatment and how the overall system is designed to meet remediation goals needs to be included as part of the CSM.

Operational and cost information is best compiled using the approaches for conducting feasibility studies (EPA 1988, 1993a). This type of format provides a useful structure for the information and facilitates comparison with similar data for other remediation alternatives that may be assessed as part of the P\&T performance assessment process (Section 4.0 and 6.0).

To support assessment of P\&T systems, especially in comparison to other options, a listing of benefits and detrimental effects should be developed. Benefits may include items such as effective plume or source containment, plume reduction, beneficial use of extracted water, robust aboveground operational performance, or complementary performance with other technology elements of a remedy. Detrimental effects may include items such as difficult secondary waste handling and disposal, high energy and operational costs, poor sustainability performance, poor aboveground operational performance, hydraulic gradients that induce accelerated downgradient contaminant migration (e.g., stretching out a plume toward a downgradient P\&T system), or injection well/gallery fouling. 


\subsection{P\&T Remedy Assessment}

As discussed in Section 4.0, the P\&T performance assessment is organized to use a set of decision elements to help decision makers distinguish between several categories of decision outcomes associated with transition, optimization, or closure of P\&T systems. Using the CSM update and information about the decision elements, as described in Section 5.0, the structured approach for the P\&T performance assessment using the decision logic described in Section 4.0 (Figure 10) is elaborated upon in this section. In essence, this approach is based on collecting a weight of evidence to identify the most appropriate outcome for a site. Table 1 provides an overview of how decision element evidence maps to each outcome. The remainder of this section provides a description of the recommended steps of the P\&T performance assessment, starting after the site has revisited the CSM and gathered initial supporting information for this assessment.

The P\&T performance assessment presented in this section follows the decision logic using sub-sections as depicted on Figure 29. The steps of the assessment include the following elements.

- Perform an initial evaluation of plume conditions with respect to RAOs (Section 6.1).

- If the plume has not met RAOs, but has declined during P\&T, the assessment focuses on whether MNA or continued P\&T will meet RAOs (Section 6.2).

- For persistent plumes, that is, plumes that have not declined during P\&T or plumes that have declined but will not meet RAOs with P\&T or MNA within a reasonable time, the ability of alternative approaches to meet RAOs needs to be assessed (Section 6.3).

- Based on potential alternative approaches from Section 6.3, a process such as a feasibility study is needed to support a remedy decision associated with the performance assessment. Selection of the preferred alternative is described in Section 6.4.

Case study examples illustrating components of the performance assessment and each outcome are included in the sub-sections. Full descriptions of the case studies are provided in Appendix A. 
Table 1. Summary of Decision Criteria and Outcomes

\begin{tabular}{|c|c|c|c|c|c|}
\hline \multirow[b]{2}{*}{ Decision Element } & \multicolumn{5}{|c|}{ Outcomes and Associated Criteria } \\
\hline & $\begin{array}{c}\text { P\&T } \\
\text { Closure }\end{array}$ & MNA & Continue/Optimize P\&T & Supplement P\&T & New Remedy Approach \\
\hline $\begin{array}{c}\text { Contaminant } \\
\text { Concentrations }(\mathrm{C})\end{array}$ & $\mathrm{C}<$ goal & $\begin{array}{c}\mathrm{C}>\text { goal and } \\
\text { concentration has } \\
\text { declined }\end{array}$ & $\begin{array}{c}\mathrm{C}>\text { goal but is } \\
\text { expected to decline } \mathrm{w} / \\
\text { continued/optimized P\&T }\end{array}$ & C > goal & $C>$ goal \\
\hline $\begin{array}{l}\text { Contaminant Mass } \\
\text { Discharge (CMD) } \\
\text { and Source/Plume } \\
\text { Characteristics }\end{array}$ & NA & $\begin{array}{l}\text { CMD has declined } \\
\text { CMD }<A C\end{array}$ & $\begin{array}{c}\mathrm{CMD}>\mathrm{AC} \\
\text { CMD expected to decline } \mathrm{w} / \\
\text { continued/optimized P\&T }\end{array}$ & $\begin{array}{l}\text { CMD > AC } \\
\text { CMD expected to decline } \\
\text { with supplemented P\&T }\end{array}$ & $\begin{array}{l}\text { CMD > AC } \\
\text { CMD expected to decline } \\
\text { with new remedy approach }\end{array}$ \\
\hline $\begin{array}{l}\text { Attenuation Capacity } \\
\text { (AC) }\end{array}$ & NA & $\begin{array}{l}\text { Documentation of } \\
\text { significant } \\
\text { attenuation } \\
\text { mechanisms }\end{array}$ & $\begin{array}{c}\text { Attenuation mechanisms } \\
\text { may not be significant. If } \\
\text { they are, MNA may be a } \\
\text { component of the remedy } \\
\text { with P\&T. }\end{array}$ & $\begin{array}{c}\text { Attenuation mechanisms } \\
\text { may not be significant. If } \\
\text { they are, MNA may be a } \\
\text { component of remedy with } \\
\text { supplemented P\&T. }\end{array}$ & $\begin{array}{l}\text { Attenuation mechanisms } \\
\text { may not be significant. If } \\
\text { they are, MNA may be a } \\
\text { component of a new remedy. }\end{array}$ \\
\hline $\begin{array}{l}\text { Plume Behavior and } \\
\text { Time to RAOs }\end{array}$ & NA & $\begin{array}{l}\text { Plume is expected to } \\
\text { stay within an area } \\
\text { with control of } \\
\text { exposure pathways } \\
\text { and stabilize/decline } \\
\text { within a reasonable } \\
\text { time to reach RAOs }\end{array}$ & $\begin{array}{c}\text { Plume is expected } \\
\text { to decline } \mathrm{w} / \\
\text { continued/optimized P\&T }\end{array}$ & $\begin{array}{l}\text { Supplementing P\&T will } \\
\text { enable RAOs to be } \\
\text { reached }\end{array}$ & $\begin{array}{l}\text { A new remedy approach is } \\
\text { needed to meet RAOs }\end{array}$ \\
\hline $\begin{array}{l}\text { P\&T System Design, } \\
\text { Performance, and } \\
\text { Cost }\end{array}$ & NA & NA & $\begin{array}{l}\text { Continued/optimized P\&T } \\
\text { can meet RAOs, balance } \\
\text { time with cost for comparing } \\
\text { to other approaches }\end{array}$ & $\begin{array}{l}\text { P\&T alone has difficulty in } \\
\text { meeting RAOs, balance } \\
\text { time with cost for } \\
\text { comparing to other } \\
\text { approaches }\end{array}$ & $\begin{array}{l}\text { P\&T has difficulty in meeting } \\
\text { RAOs and costs are better } \\
\text { for a new remedy approach }\end{array}$ \\
\hline
\end{tabular}

NA = Not applicable 


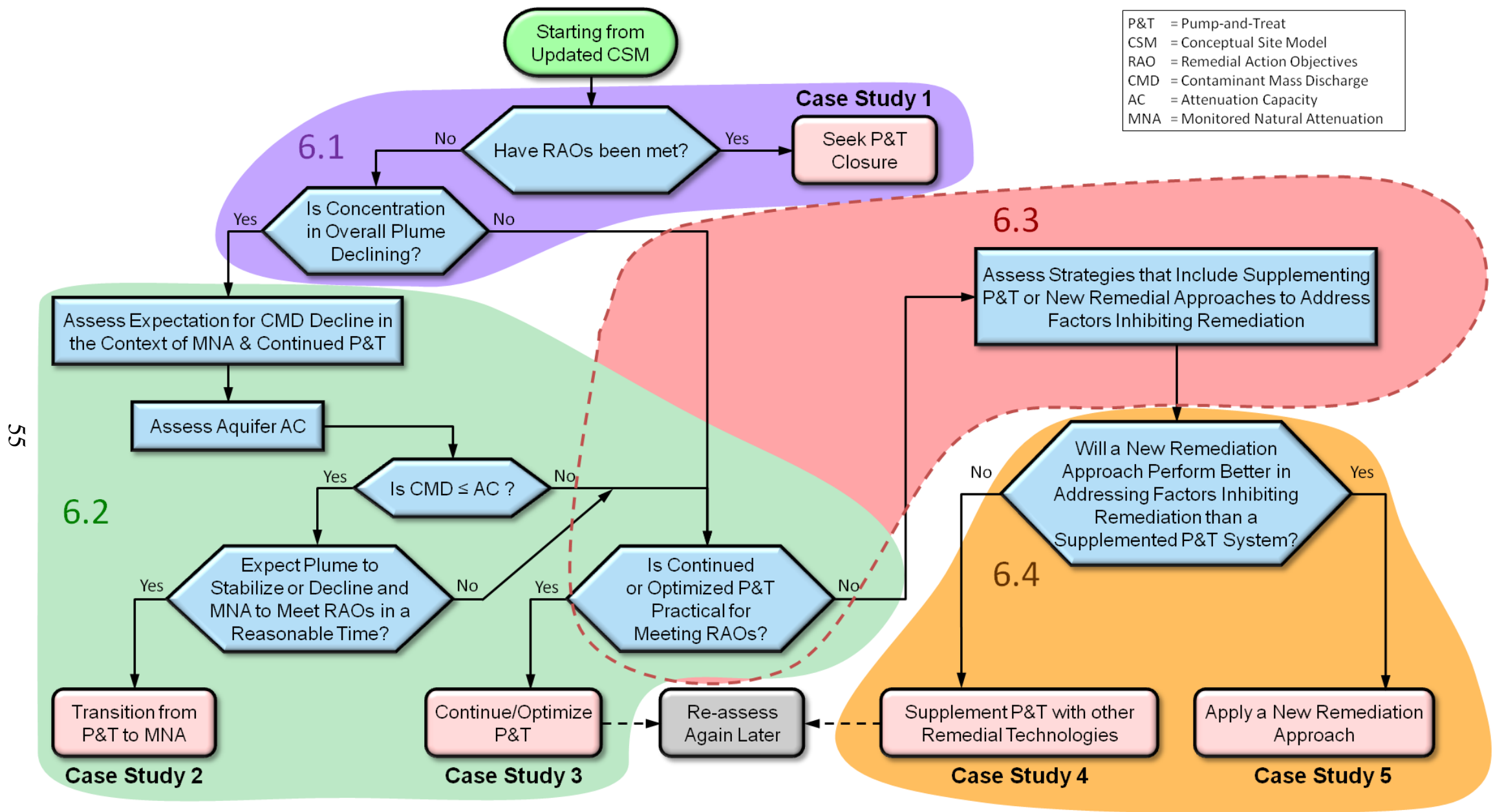

Figure 29. Decision logic, Section 6.0 cross-references, and cross-reference of outcomes and case studies. 


\subsection{Assessment With Respect to RAOs and Plume Changes}

Criteria used to evaluate whether RAOs have been met may have been established in site remedy decision documents. RAOs may include multiple elements, but most include some threshold related to contaminant concentrations. In some cases, it may be appropriate to evaluate concentrations in comparison to RAOs for the condition with the P\&T system temporarily shut down (e.g., a rebound test) as discussed in Case Study 1. Sites where decision makers determine that the $\mathrm{P} \& \mathrm{~T}$ remedy (potentially in conjunction with other remedy components) has met the RAOs can proceed with a closure process, as described by CERCLA and related EPA documentation (e.g., EPA 2009b, 2011a, 2011c, 2013, 2014a, 2014b). For source control P\&T systems, the assessment will need to take into account that the RAOs in the source area may be different than are applied within the plume.

For those plumes not meeting RAOs, an important next step is to assess how the plume has changed during the P\&T remedy. Evaluation of plume maps (Section 5.2.1), well concentration trends (Section 5.2.1), or the temporal changes in P\&T system CMD (Section 5.2.2) can be applied to evaluate how the plume has changed during the $\mathrm{P} \& \mathrm{~T}$ remedy. At this point in the process, it is important to evaluate whether the overall plume is declining, and therefore, there may be a chance that the plume has been diminished sufficiently that MNA or continued P\&T can meet RAOs in a reasonable time. If plume maps show reduced plume volume, concentration trends at individual wells (all wells or at diagnostic locations) or collectively (such as with a mass-based assessment) that are decreasing, and/or the P\&T CMD has declined over time sufficiently that the decisions makers agree that the plume has declined during the P\&T remedy, then the P\&T performance assessment should continue with Section 6.2, assessment for declining plumes. If the plume has not declined during the P\&T remedy, then the P\&T assessment should continue with Section 6.3, assessment for persistent plumes. In some cases, segments of the plume may decline while others portions do not. Decision makers may elect to evaluate different plume segments separately, if that approach makes sense in the context of overall plume remediation management.

\subsection{Assessment for Declining Plumes}

A primary assessment for declining plumes is to evaluate whether the plume or source and associated driving force for migration (i.e., the CMD) have declined sufficiently that natural attenuation would meet the RAOs within a reasonable time if $\mathrm{P} \& \mathrm{~T}$ were discontinued. Considering a conceptual mass balance context for this assessment (e.g., ITRC 2008; Figure 30), if the estimated CMD (Section 5.2.2) of the source flux zone is less than AC (Section 5.2.3) in the attenuation zone under natural-gradient conditions, then transition to MNA may be viable and the P\&T assessment should continue with Section 6.2.1, assessment of MNA. If the CMD is clearly greater than $\mathrm{AC}$ in the attenuation zone under natural-gradient conditions, then MNA is less likely to be appropriate and the P\&T assessment should continue with Section 6.2.2, assessment of continued P\&T. 


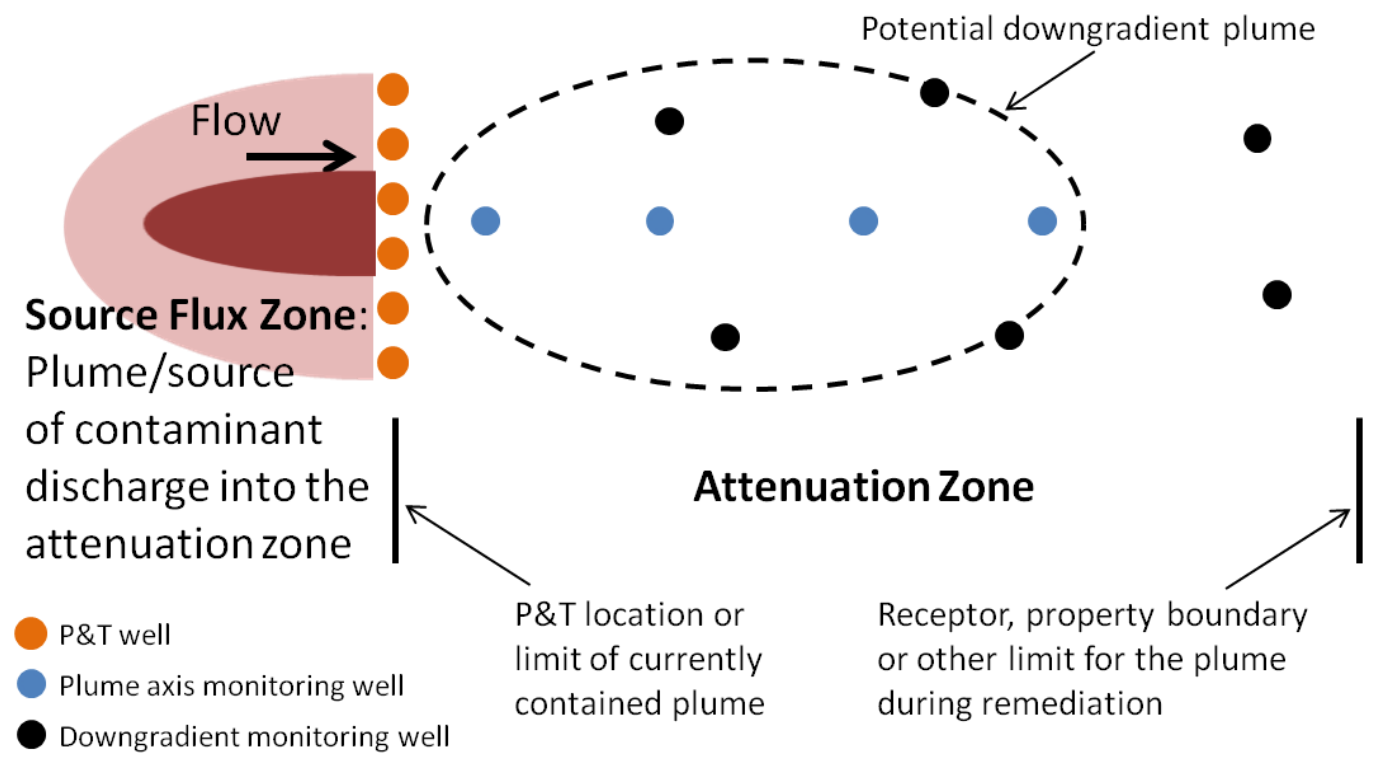

Figure 30. Conceptual depiction of the source flux zone being controlled by $P \& T$ and a downgradient attenuation zone, whose extent must be determined by the site decision makers. Under natural-gradient conditions, the CMD from the source zone must not be greater than the attenuation capacity in the attenuation zone for the plume to stay within the limits defined by the site decision makers (e.g., to potentially support a decision to transition to an MNA remedy). This figure is the same as Figure 9, but is repeated here for convenience.

In evaluating MNA or continued P\&T for a declining plume, site decision makers will need to incorporate consideration of uncertainty in these analyses. The following sections provide approaches to collect suitable information to support this evaluation. A "rebound test" measuring the concentrations during a period of P\&T system shutdown, with comparison to estimated plume attenuation rates and downgradient migration distances, is one way to evaluate the balance of CMD and AC under natural-gradient conditions. This scenario is highlighted in Case Studies 2A and 2B and in Section 6.2.1 below. This method offers a way to collect data in an observational approach to help verify aquifer response if a transition is made. It is also important that the site determine the appropriate MNA performance monitoring to verify expected remedy performance if a transition is made.

\subsubsection{Assessment of MNA}

MNA may be a viable post-P\&T remedy if the site decision makers agree that there is a specified zone of the aquifer where, in conjunction with site-specific institutional controls, MNA can be allowed to occur over time to reduce plume concentrations and will meet the RAOs in a reasonable time. If MNA is not viable (based on the evaluation in this section), then assessment of continued or optimized P\&T as described in Section 6.2.2 would be conducted. The MNA evaluation will need to be conducted in the context of the MNA OSWER directive (EPA 1999c) and existing guidance and protocols for MNA remedy evaluation (e.g., EPA 1998, 2002b, 2003, 
2004, 2007c, 2007d, 2010, 2011b; ITRC 1999a, 1999b, 2008, 2010b; USGS 2003; Wiedemeier et al. 1999). However, in the situation where $P \& T$ has been applied at a site, evaluation of transition to MNA after P\&T is terminated, or reduced, must consider different lines of evidence than can be applied for a site where active remedies have not been applied. For instance, evaluation of whether a plume is stable, shrinking, or expanding is not relevant because the plume conditions have been affected by $P \& T$ and will change again when $P \& T$ is terminated. The items below discuss elements that may need to be incorporated into this evaluation because P\&T has been applied at a site. Analyses should include consideration of the conceptual site model as a basis to evaluate plume behavior and features or processes that control plume behavior.

In assessing the attenuation capacity for conditions where the P\&T system is terminated, estimates of attenuation rate can be used to evaluate threshold concentrations for which attenuation can reduce concentrations along a downgradient flow path and meet RAOs. For example, concentrations within the portion of the plume previously controlled by the P\&T system need to be low enough that they can decline to the RAO concentration limit before the plume migrates beyond a defined footprint or specified downgradient location. This approach may be particularly appropriate when there is a higher concentration plume core where calculation of an attenuation rate (change in concentration per time) and comparison to the concentration emanating from the source zone plume core facilitates evaluating the ability to meet concentration-based RAOs. Case Study 2B, the Test Area North (TAN) site, used this approach, determining an attenuation rate based on tracer-corrected contaminant concentration attenuation within the plume. This rate was then applied to define the concentration reduction goal for the P\&T system. If the P\&T system reduced concentrations to this level, the plume was predicted to remain within an acceptable zone of administrative control. As P\&T (and source reduction) progressed, rebound tests were used to determine if the concentration goal was met and the P\&T could be turned off. This type of assessment is most feasible when the plume size characteristics are appropriate to use concentration change determinations for estimating the attenuation rate (EPA 2002b). 


\section{Example Calculation:}

With a threshold concentration approach, a concentration-based attenuation rate in the downgradient plume needs to be computed. EPA (2002b) (see also Section 5.2.3) provide information on calculating rates (e.g., $\mathrm{mg} \mathrm{L}^{-1} \mathrm{~d}^{-1}$ ) along the plume migration axis (Attenuation rate $\left.\right|_{\text {plume axis }}$. In most cases, the rate estimated along a plume migration axis is expected to be representative of the attenuation rate within the plume. The method for estimating an attenuation rate highlighted in Case Study 2B may also be applicable to some sites. Using the estimated attenuation rate and the computed contaminant transport velocity $\left(v_{\text {contaminant }}\right)$, a threshold concentration at the upgradient "source" zone or location of the P\&T system can be calculated such that the RAO concentration goal ( $\left.\mathrm{C}_{\mathrm{RAO}}\right)$ is reached by a selected maximum downgradient plume migration distance. This threshold concentration can then be compared to concentrations within the upgradient plume or to a concentration measured during a rebound test.

Threshold concentration $=\mathrm{C}_{\mathrm{RAO}}+\left(\right.$ Attenuation rate $\left.\right|_{\text {plume axis }} \times$ distance $\left./ \mathrm{v}_{\text {contaminant }}\right)$

$$
\text { where } v_{\text {contaminant }}=\left(q_{\text {natural }} / n\right) / R_{\text {contaminant }}
$$

Notes:

Estimation of the Attenuation rate $\left.\right|_{\text {plume axis }}$ needs to consider plume migration conditions that may affect the calculation (see EPA 2002b).

distance $=$ the maximum downgradient plume migration distance acceptable as a zone of MNA (i.e., with no impact to receptors or other downgradient constraints like property boundaries)

qnatural = the Darcy flux (hydraulic conductivity $\times$ hydraulic gradient) under natural (non-pumped) conditions

$\mathrm{n} \quad=$ effective porosity

$\mathrm{R}_{\text {contaminant }}=$ the retardation factor for the contaminant

The above threshold-concentration approach fits within a mass balance concept for MNA (e.g., ITRC 2008). For a mass balance, the CMD from the source area (source flux) (Section 5.2.2), or CMD past a specified transect of the plume (Section 5.2.2), is compared to the attenuation capacity in the aquifer (Section 5.2.3) downgradient of that location. Mass balance calculations can be used, as discussed in the example calculations below, to provide input on whether MNA will maintain the plume within an acceptable volume of the aquifer after ceasing P\&T. Site decision makers will need to determine the extent of the acceptable aquifer volume for MNA. Any continuing sources, such as from matrix diffusion, would need to be considered in these analyses if these conditions are present at a site. The following example provides information about using volumetric evaluation of CMD versus AC to support the P\&T performance assessment. 


\section{Example Calculation:}

This example provides a general framework related to the scenario depicted in Figure 30. One element is to assess the CMD from the source area (source flux) or CMD past a specified transect of the plume. It also provides an example for estimating the AC in a case where a plume of sufficient size is present downgradient of the P\&T system such that concentration change within this plume can be used to estimate an attenuation rate.

When P\&T is applied for source control or plume containment, with some adjustments, the CMD at the P\&T system (during pumping operations) is a measure of the CMD that the downgradient aquifer will need to attenuate if the P\&T is terminated or reduced (Section 5.2.2). Assessment of the post-P\&T CMD should consider the groundwater flow system under natural gradient conditions because flow conditions during P\&T operations differ from those without pumping. This type of analysis transforms the P\&T CMD into a CMD that can be used in an MNA evaluation. In this analysis, the CMD assessment would need to consider any continuing sources such as from matrix diffusion that persist after P\&T were terminated. Post-P\&T CMD could be estimated using several methods. The individual site should consider the available data and associated uncertainties in selecting an estimation method.

1. Post $-P \& T C M D=C_{P \& T} \times q_{\text {natural }} \times A_{\text {capture cross section }}$

2. Post-P\&T CMD $=\left(q_{\text {natural }} \times A_{\text {source zone }} / Q_{P \& T}\right) \times C M D_{P \& T}$

3. Post-P\&T CMD $=C_{\text {source }} \times q_{\text {natural }} \times A_{\text {source zone }}$

Notes:

$\mathrm{C}_{\mathrm{P} \& \mathrm{~T}}=$ the contaminant concentration from the P\&T extraction system for the wells used in the analysis

Qnatural $=$ the Darcy flux (hydraulic conductivity $\times$ hydraulic gradient) under natural (non-pumped) conditions

$A_{\text {capture cross section }}=$ the cross sectional area that is captured by the P\&T wells used in the analysis

A source zone $\quad=$ the cross sectional area of the source zone through which groundwater under a natural gradient would flow and become contaminated

Q $\quad=$ the P\&T extraction flow rate for the wells used in the analysis

$\mathrm{CMD}_{\mathrm{P \& T}} \quad=$ the $\mathrm{P} \& \mathrm{~T}$ system CMD calculated as $\mathrm{C}_{\mathrm{PQT}} / \mathrm{Q}_{\mathrm{P} \& \mathrm{~T}}$ for the wells used in the analysis

$\mathrm{C}_{\text {source }} \quad=$ the contaminant concentration selected to represent the source zone (or plume upgradient of the P\&T system) - this concentration could be a maximum observed concentration or an average concentration of some designated area

An attenuation rate assessment can be conducted using historical downgradient plume data before and/or during P\&T operations. Approaches as described by EPA (2002b) are useful, but the dynamics in plume behavior induced by the P\&T system operation must be considered. One potentially useful approach, given dynamics induced by a P\&T system for source control or plume containment, would be to use the mass-based rate assessment (EPA 2002b) for the monitoring network downgradient of the P\&T system to estimate how the total mass of the plume is changing within a constant footprint of the aquifer. This rate of change for the given capture efficiency of the P\&T system could be interpreted as a rate of plume attenuation and generate an estimate of the attenuation capacity within the selected downgradient volume of aquifer (that must include the entire downgradient plume).

Attenuation Capacity $=\mathrm{C}_{\text {ave-wellstlime1 }}-\mathrm{C}_{\text {ave-wellstlime2 }} \times \mathrm{V}_{\text {analysis }}$ (continued on next page) 


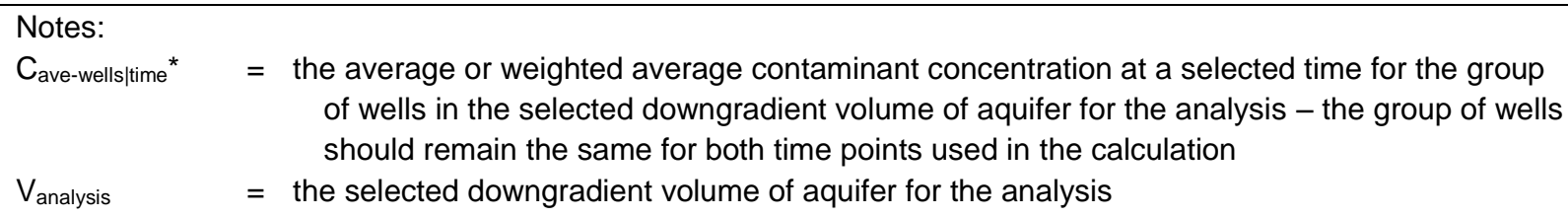

A similar calculation to the one shown above could be conducted based on estimating the plume mass at different times using plume contouring techniques.

Note: When using volume-averaged approaches like CMD and AC, the site should consider the concentration variations within the plume. If there is a plume core with a much higher concentration than other portions of the plume, then the threshold concentration analysis, as described in the preceding example, should be applied to assess the ability to meet concentration targets for the plume core.

In some cases, P\&T will have been deployed such that there is not a significant downgradient plume for which concentration changes can be monitored to estimate the attenuation rate and associated attenuation capacity within the zone of aquifer that site decision makers agree is suitable for MNA. In these cases, other estimates of attenuation processes and rates need to be applied. Section 5.2.3 discusses options to obtain this information. These methods would provide an estimate of an attenuation process that can be represented in a modeling analysis to evaluate the potential for MNA to meet goals, as described below.

Whether there is an existing downgradient plume or not, available tools (such as REMChlor [Falta 2008], BIOCHLOR [EPA 2000b; Aziz et al. 2002], BIOSCREEN [EPA 1996b], NAS [Widdowson et al. 2005], MT3D/RT3D [Harbaugh 2005; Clement et al. 1998; Johnson et al. 2006; Johnson and Truex 2006]) and guidance (e.g., EPA 1998, 2002b, 2011b; ITRC 1999a, 1999b, 2010b; Looney et al. 2006) that are based on conducting a fate and transport assessment can be effectively applied to support a determination for transitioning from P\&T to MNA. Numerical or analytical simulations using these tools predict responses as a function of contaminant conditions and estimated future fate and transport conditions. Inputs to the model need to consider the flow conditions without P\&T, the expected concentration and/or CMD conditions, and attenuation rate and capacity estimates as part of predicting contaminant fate and transport. In addition, it may be important to use a sensitivity analysis based on reasonable variations in input parameters to assess the range of responses due to uncertainty about aspects such as preferential groundwater flow, residual NAPL dissolution, or matrix diffusion. It may also be useful to supplement this type of analysis with information about the initial CMD from the contaminant source and resultant plume that developed. This information can then be compared to the post-P\&T remedy CMD to provide a context supporting why the post-P\&T plume will be smaller and potentially amenable to having MNA meet the RAOs.

\subsubsection{Assessment of Continued P\&T}

If the P\&T remedy has caused contaminant concentrations to decline, but not sufficiently for MNA to meet the RAOs in a reasonable time (Section 6.2.1), then it is appropriate to consider 
whether continuation of the existing, or an optimized, P\&T system can meet RAOs in a reasonable time. Plotting the P\&T system CMD as a function of time or plume maps over time during the P\&T remedy may be instructive to determine whether the plume decline has been steady or the rate of decline has slowed (i.e., asymptotic conditions are being approached). If the decline has not stalled, a projection of future performance and time to reach the RAOs can be made based on a simple projection or using a fate and transport model. Decision makers can then use this projected time to evaluate whether the time is reasonable for supporting continuation $\mathrm{P} \& \mathrm{~T}$ as the remedy. In assessing this projected remediation time for cases where the rate of plume declined has slowed or stalled, it is important to evaluate whether there are specific areas of persistence of the plume that may need to be addressed. It is also important to conduct a capture analysis for the P\&T system (EPA 2008) and consider optimization opportunities that could enable continued plume decline (EPA 1999a, 1999b; Minsker et al. 2004; Becker et al. 2006).

For instance, the DOE Fernald site P\&T system for a uranium plume showed indications of decreased operational effectiveness resulting in a longer projected remediation timeframe to reach the RAOs. The site applied the groundwater model that was used for initial P\&T design to evaluate optimization alternatives for the P\&T system. This optimization study was able to identify a revised $P \& T$ system configuration that is predicted to accelerate cleanup in key portions of the aquifer and meet site RAOs in a reasonable time, with reduced costs compared to the original P\&T design (see Case Study 3).

If the assessment of continued P\&T indicates that the current system or an optimized system is likely to meet the RAOs within a reasonable additional time of operation, the decision makers can decide to continue P\&T or evaluate alternatives on a cost/benefit basis using a feasibility study type approach. In essence, this assessment of continued P\&T can be similar to a feasibility study assessment except that site-specific performance data are available. If the analysis indicates that the existing or optimized P\&T system is unlikely to reach RAOs in a reasonable time (for instance, due to a persistent source zone that was unknown when P\&T was initially selected), then the P\&T assessment should continue to Section 6.3, persistent plume assessment.

\subsection{Persistent Plume/Source Assessment}

If assessment of continued P\&T or MNA for a declining plume shows that the plume cannot be remediated by these methods in a reasonable time, or if the plume/source is not declining, the plume/source is categorized as persistent and other approaches need to be considered. In this case, an assessment of the factors causing the persistence is needed with respect to 1) evaluating the potential for P\&T optimization to meet RAOs (an extension of Section 6.2.2) and 2) supporting evaluation of the expected performance of other technologies in meeting the RAOs, potentially including assessment of a continued role for P\&T in this strategy. In conducting the assessment of a persistent plume/source, the site should consider whether the lack of plume decline is due to an insufficient P\&T system design or operational issues. If P\&T optimization has a potential to improve remedy performance and address plume/source persistence, then it 
should be evaluated as described in Section 6.2.2 and potentially carried forward as an option for comparison to other alternative technologies or the use of a supplemental technology.

Situations where the contaminant concentrations are persistent indicate that contaminants are being released into the transmissive portion of the aquifer at a rate high enough to maintain contaminant concentrations above the RAOs. Categories of factors that may cause this persistence include contaminant discharge from the vadose zone, matrix diffusion processes, remaining source material such as NAPL, desorption (e.g., a tailing plume), dissolution of solidphase contaminants (e.g., due to redox conditions or other geochemical gradients), or (potentially) large plumes within heterogeneous aquifers where it is difficult to effectively extract contaminants in a reasonable time. The evaluation of persistent plume/source factors is an element of refining the CSM and can be addressed through approaches discussed in Section 5.0.

Based on the identified factors causing a persistent plume/source, supplemental or alternative technologies (along with P\&T system optimization) need to be evaluated in terms of addressing the contamination and enabling the site to reach RAOs. Plotting the P\&T system CMD as a function of time or plume maps over time during the P\&T remedy, as discussed in Section 6.2.2, may be instructive for evaluating the persistence of the plume/source. Where possible, individual P\&T extraction well data may be useful in identifying locations of persistence based on the capture area of an individual well. This situation is depicted in Figure 22, Section 5.2.2. Additional high-resolution characterization may also be helpful. Analysis of plume persistence should be coupled with an associated consideration of P\&T optimization (Section 6.2.2) and may require consideration of a supplemental or alternative technology as discussed in here. The assessment of supplemented P\&T and alternate remedies should follow an approach like that used to evaluate technology options and assemble remedial alternatives for a feasibility study (EPA 1988, 1993a). There are a variety of technology resources that provide information about technologies and their performance (e.g., https://clu-in.org/). These, along with an engineering and fate/transport assessment, can be used to determine if options are likely to meet RAOs. If there are promising options, then the site can continue with an evaluation to select the preferred alternative using a feasibility study approach, as discussed in Section 6.4.

For instance, in Case Study 4, a large plume at the former Cornhusker Army Ammunition Plant was contained, but not significantly declining. Bioremediation was applied as a means to hasten plume decline by supplementing the P\&T system. In Case Study 5A, at a Superfund Site in Nebraska, P\&T was not effectively diminishing the plume. A ROD amendment process was used to change to a remedy with in-situ thermal remediation for the source area and chemical oxidation or enhanced bioremediation for the dissolved plume. In Case Study 5B, an arsenic plume was being contained by P\&T, but not declining. The transition to an immobilization remedy, driven by air sparging, was evaluated and is predicted to allow the cessation of P\&T with a large cost reduction. At a minimum, it would allow a substantial reduction in pumping, with a lesser, but still significant, savings for plant operations. Currently, pilot testing of air 
sparging is being conducted as a means to sequester arsenic as part of the transition evaluation, with promising results.

Sites with complexities that lead to persistent plumes/sources have been recognized in NRC (NRC 2013) and ITRC (ITRC 2011c, 2012, 2015) studies. For sites that are, by nature, going to be difficult to remediate (as supported by difficulties in reaching goals with the P\&T system), remediation strategies that incorporate appropriate exposure control, contaminant reduction approaches, and adaptive management should be considered. In some cases, site decision makers may restructure RAOs (e.g., using approaches to define objectives as described in the Integrated DNAPL Site Strategy document [ITRC 2011b]) to improve management of a site (Case Study 5C). Sites that will have difficulty in reaching RAOs may also need to consider ARAR waivers such as technical impracticability (Case Study 5D). As summarized by Deeb et al. (2011), the potential ARAR waivers are the following six options (40 CFR 300.430(f)(1)(ii)(C); see also ITRC 2012):

1. Interim Measure. If the remedy is an interim action, ARARs need not be met. However, the final remedy still needs to achieve ARARs.

2. Greater Risk. If compliance with the ARAR would result in greater risk to human health and environment compared with an alternative that does not comply with ARARs.

3. Technical Impracticability. If compliance with ARARs is technically impracticable from an engineering standpoint, within a reasonable timeframe (specific guidance is found in EPA [1993b]).

4. Equivalent Standard of Performance. If the selected remedy will attain a standard of performance that is equivalent to the ARAR. This waiver is typically used for actionspecific or location-specific ARARs.

5. Inconsistent Application of State Standards. If the ARAR is a state standard that has not been consistently applied to other remedial actions within the state.

6. Fund Balancing. If compliance with the ARAR would threaten the ability of the Fund (applicable to sites that have Superfund support) to respond to and achieve protectiveness at other sites (EPA 1991).

Other alternatives and associated resources for more information are listed below (see also ITRC 2012).

- Alternative Concentration Limits (CERCLA: Section 121(d)(2)(B)(ii)); RCRA: 40 CFR 264.94, EPA 2005)

- Groundwater management/containment zones (Deeb et al. 2011)

- Groundwater reclassification/classification exemptions (Deeb et al. 2011)

- Remediation to the extent practicable (Deeb et al. 2011). 
While site complexities may cause difficulty with remediation, a remediation strategy can be developed to make progress toward RAOs, potentially recognizing that a long remediation time will be needed. Core elements of this type of strategy would be expected to include:

- control of contaminant exposure pathways during the remediation process;

- mitigation of plume or source expansion, especially to maintain contamination within an area where institutional or engineering controls to limit exposure can be applied during remediation;

- inclusion of an appropriate approach to contaminant reduction, realizing that contaminant reduction will be difficult and may require a long duration;

- engineering controls and remedy components appropriate to complement any ARAR waivers or RAO changes that are selected; and

- adaptive approaches using effective intermediate goals to guide implementation. The fundamental concepts of adaptive management approaches are described by NRC (2003). The ITRC has several relevant resources that incorporate adaptive management and other strategies for sites that are difficult to remediate (ITRC 2011b, 2011c, 2012, 2015).

The steps outlined for a P\&T assessment in this document are consistent with providing a foundation for developing this type of remediation strategy. Refining the CSM and identifying factors that cause plume/source persistence provides the technical foundation for evaluating an appropriate strategy. Evaluating P\&T remedy performance and assessing other alternatives to address causes of persistence is important in considering options for remediation and establishing reasonable expectations for the remediation timeframe. It is also likely effective to incorporate optimization approaches and adaptive management, recognizing conditions will change over time and that information gathered during remediation can be used to refine the knowledge of the site and adapt the remedy approach. Thus, monitoring approaches such as those described in Bunn et al. (2012) may be useful to consider.

In some cases, P\&T may be applied as part of the strategy and serve to meet some site goals even though, alone, it will not effectively diminishing the plume. Examples may include situations where P\&T is providing hydraulic containment of the plume or source control or the extracted water is being used for a beneficial purpose. As part of strategy development, periodic optimization and transition assessments of the P\&T system should be conducted and the role and cost/benefit of continued P\&T should be evaluated.

\subsection{Alternative Remedy Selection}

If supplemental or alternative remedies have been identified that are likely to be able to meet RAOs (Section 6.3), then the site should proceed with selecting the preferred alternative for transitioning from the P\&T remedy to a new remediation approach. The process for this selection should follow an EE/CA or FS methodology (or related RCRA methods) commensurate with the guiding regulatory documents at the site and the expected regulatory documentation for the change in remedy (e.g., an ESD or a ROD amendment). This assessment 
would include a comparative evaluation of the performance and cost aspects of each option using the threshold and balancing criteria for selection of a preferred remedy. The P\&T system benefits and detrimental effects identified in Section 5.2.5 should be considered as part of the balancing criteria comparison. These methods are appropriate if the selection process is expected to result in a remedy that will meet the RAOs. For some sites, consideration of ARAR waivers and revisiting RAOs (e.g., using approaches to define objectives as described in the Integrated DNAPL Site Strategy document [ITRC 2011b]) may be appropriate in conjunction with the above selection process. 


\subsection{References}

Aziz, C.E., C.J. Newell, and J.R. Gonzales. 2002. BIOCHLOR Natural Attenuation Decision Support System Version 2.2 User's Manual Addendum. Air Force Center for Environmental Excellence, Technology Transfer Division, Brooks AFB, San Antonio, Texas.

Becker, D., B. Minsker, R. Greenwald, Y. Zhang, K. Harre, K. Yager, C. Zheng, and R. Peralta. 2006. "Reducing Long-Term Remedial Costs by Transport Modeling Optimization." Ground Water, 44(6):864-875.

Bunn, A.L., D.M. Wellman, R.A. Deeb, E.L. Hawley, M.J. Truex, M. Peterson, M.D. Freshley, E.M. Pierce, J. McCord, M.H. Young, T.J. Gilmore, R. Miller, A.L. Miracle, D. Kaback, C. Eddy-Dilek, J. Rossabi, M.H. Lee, R.P. Bush, P. Beam, G.M. Chamberlain, J. Marble, L. Whitehurst, K.D. Gerdes, and Y. Collazo. 2012. Scientific Opportunities Monitoring at Environmental Remediation Sites (SOMERS): Integrated Systems-Based Approaches to Monitoring. PNNL-21379, Pacific Northwest National Laboratory, Richland, Washington.

Clement, T.P., Y. Sun, B.S. Hooker, and J.N. Petersen. 1998. "Modeling Multi-species Reactive Transport in Groundwater Aquifers." Groundwater Monit. Remed. J., 18(2):79-92.

Deeb, R., E. Hawley, L. Kell, and R. O’Laskey. 2011. Final Report-Assessing Alternative Endpoints for Groundwater Remediation at Contaminated Sites. ESTCP Project ER200832, Environmental Security Technology Certification Program, U.S. Department of Defense, Washington, D.C. Available at https://www.serdp-estcp.org/content/ download/10619/130969/file/ER-200832-FR.pdf.

Dinicola, R.S. 2005. Hydrogeology and Trichloroethene Contamination in the Sea-Level Aquifer Beneath the Logistics Center, Fort Lewis, Washington. Scientific Investigations Report 2005-5035, U.S. Geological Survey, Reston, Virginia.

DOE. 2015. Advanced Simulation Capability for Environmental Management (ASCEM) (website). U.S. Department of Energy, Washington, D.C. Available at: http://esd.lbl.gov/research/projects/ascem/.

EPA. 1988. Guidance for Conducting Remedial Investigations and Feasibility Studies under CERCLA, Interim Final. EPA/540/G-89/004, U.S. Environmental Protection Agency, Washington, D.C.

EPA. 1991. ARARs $Q$ 's and A's: The Fund-Balancing Waiver. 9234.2-13/FS, U.S. Environmental Protection Agency, Washington, D.C. Available at: http://epa.gov/superfund/policy/remedy/pdfs/92-34213fs-s.pdf. 
EPA. 1993a. Guidance on Conducting Non-Time-Critical Removal Actions under CERCLA. EPA/540/R-93/057, U.S. Environmental Protection Agency, Washington, D.C.

EPA. 1993b. Guidance for Evaluating the Technical Impracticability of Groundwater Restoration. EPA/540/R-93/080, OSWER Directive 9234.2-25, U.S. Environmental Protection Agency, Washington, D.C.

EPA. 1994. Methods for Monitoring Pump-and-Treat Performance. EPA/600/R-94/123, U.S. Environmental Protection Agency, Office of Research and Development, Washington, D.C.

EPA. 1996a. Pump-and-Treat Ground-Water Remediation: A Guide for Decision Makers and Practitioners. EPA/625/R-95/005, U.S. Environmental Protection Agency, Office of Research and Development, Washington, D.C.

EPA. 1996b. BIOSCREEN Natural Attenuation Decision Support System User's Manual Version 1.3. EPA/600/R-96/087, U.S. Environmental Protection Agency, Washington, D.C.

EPA. 1997. Ground Water Issue: Design Guidelines for Conventional Pump-and-Treat Systems. EPA/540/S-97/504, U.S. Environmental Protection Agency, Office of Research and Development, Washington, D.C.

EPA. 1998. Technical Protocol for Evaluation Natural Attenuation of Chlorinated Solvents in Groundwater. EPA/600/R-98/128, U.S. Environmental Protection Agency, Washington, D.C.

EPA. 1999a. Hydraulic Optimization Demonstration for Groundwater Pump-and-Treat Systems, Volume I: Pre-Optimization Screening (Method and Demonstration). EPA/542/R-99/011A, U.S. Environmental Protection Agency, Washington, D.C.

EPA. 1999b. Hydraulic Optimization Demonstration for Groundwater Pump-and-Treat Systems, Volume II: Application of Hydraulic Optimization. EPA/542/R-99/011B, U.S. Environmental Protection Agency, Washington, D.C.

EPA. 1999c. "Use of Monitored Natural Attenuation at Superfund, RCRA Corrective Action, and Underground Storage Tank Sites." OSWER Directive 92000.4-17P, U.S. Environmental Protection Agency, Office of Solid Waste and Emergency Response, Washington, D.C.

EPA. 2000a. "Superfund Reform Strategy, Implementation Memorandum: Optimization of Fund-lead Ground Water Pump Treat (P\&T) Systems." OSWER Directive 9283.1-13, U.S. Environmental Protection Agency, Office of Solid Waste and Emergency Response, Washington, D.C. 
EPA. 2000b. BIOCHLOR Natural Attenuation Decision Support System User's Manual Version 1.0. EPA/600/R-00/008, U.S. Environmental Protection Agency, Washington, D.C.

EPA. 2002a. "Elements for Effective Management of Operating Pump and Treat Systems." EPA/542/R-02/009, U.S. Environmental Protection Agency, Office of Solid Waste and Emergency Response, Washington, D.C.

EPA. 2002b. Calculation and Use of First-Order Rate Constants for Monitored Natural Attenuation Studies. EPA/540/S-02/500, U.S. Environmental Protection Agency, National Risk Management Research Laboratory, Cincinnati, Ohio.

EPA. 2003. Performance Monitoring for Natural Attenuation Remedies in Ground Water. EPA/540/R-03/004, U.S. Environmental Protection Agency, Washington D.C.

EPA. 2004. Performance Monitoring of MNA Remedies for VOCs in Ground Water. EPA/600/R-04/027, U.S. Environmental Protection Agency, National Risk Management Research Laboratory, Cincinnati, Ohio.

EPA. 2007a. Optimization Strategies for Long-Term Ground Water Remedies (with Particular Emphasis on Pump and Treat Systems). EPA/542/R-07/007, U.S. Environmental Protection Agency, Washington D.C.

EPA. 2007b. "Options for Discharging Treated Water from Pump and Treat Systems." EPA/542/R-07/006, U.S. Environmental Protection Agency, Washington, D.C.

EPA. 2007c. Monitored Natural Attenuation of Inorganic Contaminants in Ground Water Volume 1, Technical Basis for Assessment. EPA/600/R-07/139, U.S. Environmental Protection Agency, Washington, D.C.

EPA. 2007d. Monitored Natural Attenuation of Inorganic Contaminants in Ground Water Volume 2, Assessment for Non-Radionuclides Including Arsenic, Cadmium, Chromium, Copper, Lead, Nickel, Nitrate, Perchlorate, and Selenium. EPA/600/R07/140, U.S. Environmental Protection Agency, Washington, D.C.

EPA. 2008. A Systematic Approach for Evaluation of Capture Zones at Pump and Treat Systems. EPA/600/R-08/003, U.S. Environmental Protection Agency, National Risk Management Research Laboratory, Cincinnati, Ohio.

EPA. 2009a. Identification and Characterization Methods for Reactive Minerals Responsible for Natural Attenuation of Chlorinated Organic Compounds in Ground Water. EPA/600/R-09/115, U.S. Environmental Protection Agency, Washington, D.C.

EPA. 2009b. "Summary of Key Existing EPA CERCLA Policies for Groundwater Restoration." OSWER Directive 9283.1-33, U.S. Environmental Protection Agency, Office of Solid Waste and Emergency Response, Washington, D.C. 
EPA. 2010. Monitored Natural Attenuation of Inorganic Contaminants in Ground Water -

Volume 3. EPA/600/R-10/093, U.S. Environmental Protection Agency, Washington, D.C.

EPA. 2011a. "Groundwater Road Map: Recommended Process for Restoring Contaminated Groundwater at Superfund Sites." OSWER 9283.1-34, U.S. Environmental Protection Agency, Washington, D.C.

EPA. 2011b. An Approach for Evaluating the Progress of Natural Attenuation in Groundwater. EPA/600/R-11/204, U.S. Environmental Protection Agency, National Risk Management Research Laboratory, Ada, Oklahoma.

EPA. 2011c. Close Out Procedures for the National Priorities List Sites. OSWER 9320.2-22, U.S. Environmental Protection Agency, Washington, D.C.

EPA. 2013. Guidance for Evaluating Completion of Groundwater Restoration Remedial Actions. OSWER 9355.0-129, U.S. Environmental Protection Agency, Office of Solid Waste and Emergency Response, Washington, D.C.

EPA. 2014a. Groundwater Remedy Completion Strategy. OSWER 9200.2-144, U.S. Environmental Protection Agency, Office of Solid Waste and Emergency Response, Washington, D.C.

EPA. 2014b. Recommended Approach for Evaluating Completion of Groundwater Restoration Remedial Actions at a Groundwater Monitoring Well. OSWER 9283.1-44, U.S. Environmental Protection Agency, Office of Solid Waste and Emergency Response, Washington, D.C.

EPA, DOE, and WDOE. 2008. Record of Decision Hanford 200 Area 200-ZP-1 Operable Unit Superfund Site, WA. U.S. Environmental Protection Agency, U.S. Department of Energy, and Washington State Department of Ecology, Seattle, Washington. EPA/541/R-08/115. Available at: http://pdw.hanford.gov/arpir/index.cfm/viewDoc ?accession $=00098825$.

Falta, R.W. 2008. "Methodology for Comparing Source and Plume Remediation Alternatives." Ground Water, 46(2):272-285.

Gilmore, T., B.B. Looney, N. Cutshall, D. Major, T. Wiedemeier, F.H. Chapelle, M. Truex, T. Early, M. Heitkamp, J. Waugh, D. Peterson, G. Wein, C. Bagwell, M. Ankeny, K.M. Vangleas, K.M. Adams, and C.H. Sink. 2006. Characterization and Monitoring of Natural Attenuation of Chlorinated Solvents in Ground Water: A Systems Approach. WSRC-STI-2006-00084, Washington Savannah River Company, Aiken, SC. 
Harbaugh, A.W. 2005. MODFLOW-2005, The U.S. Geological Survey Modular Ground-Water Model - the Ground-Water Flow Process. Techniques and Methods 6-A16, U.S. Geological Survey, Reston, Virginia.

Hawley, E.L., R.A. Deeb, and H. Levine. 2014. "Groundwater Remediation and the Use of Alternative Endpoints at Highly Complex Sites." In: Chlorinated Solvent Source Zone Remediation, B.H. Kueper, H.F. Stroo, C.M. Vogel, and C.H. Ward, (eds.). Springer, New York. pp. 627-652.

ITRC. 1999a. Natural Attenuation of Chlorinated Solvents in Groundwater: Principles and Practices. ISB-3, Interstate Technology and Regulatory Council, Washington, D.C. Available at: http://www.itrcweb.org/GuidanceDocuments/ISB-3.pdf.

ITRC. 1999b. ITRC/RTDF Training Course: Natural Attenuation of Chlorinated Solvents in Groundwater. ISB-7, Interstate Technology and Regulatory Council, Washington, D.C. Available at: http://www.itrcweb.org/GuidanceDocuments/ISB-7.pdf.

ITRC. 2008. Enhanced Attenuation: Chlorinated Organics. EACO-1, Interstate Technology and Regulatory Council, Washington, D.C. Available at: http://www.itrcweb.org/ GuidanceDocuments/EACO-1.pdf.

ITRC. 2010a. Use and Measurement of Mass Flux and Mass Discharge. MASSFLUX-1, Interstate Technology and Regulatory Council, Washington, D.C. Available at: http://www.itrcweb.org/GuidanceDocuments/MASSFLUX1.pdf.

ITRC. 2010b. A Decision Framework for Applying Monitored Natural Attenuation Processes to Metals and Radionuclides in Groundwater. APMR-1, Interstate Technology and Regulatory Council, Washington, D.C. Available at: http://www.itrcweb.org/ GuidanceDocuments/APMR1.pdf.

ITRC. 2011a. Environmental Molecular Diagnostics Fact Sheets. EMD-1, Interstate Technology and Regulatory Council, Washington, D.C. Available at: http://www.itrcweb.org/GuidanceDocuments/EMD1.pdf.

ITRC. 2011b. Integrated DNAPL Site Strategy. IDSS-1, Interstate Technology and Regulatory Council, Washington, D.C. Available at: http://www.itrcweb.org/ GuidanceDocuments/IntegratedDNAPLStrategy_IDSSDoc/IDSS-1.pdf.

ITRC. 2011c. Project Risk Management for Site Remediation. RRM-1, Interstate Technology and Regulatory Council, Washington, D.C. Available at: http://www.itrcweb.org/ GuidanceDocuments/RRM-1.pdf. 
ITRC. 2012. Using Remediation Risk Management to Address Groundwater Cleanup Challenges at Complex Sites. RRM-2, Interstate Technology and Regulatory Council, Washington, D.C. Available at: http://www.itrcweb.org/GuidanceDocuments/ RRM2.pdf.

ITRC. 2013. Environmental Molecular Diagnostics New Site Characterization and Remediation Enhancement Tools. EMD-2, Interstate Technology and Regulatory Council, Washington, D.C. Available at: http://www.itrcweb.org/EMD2/Content/Resources/EMD2.pdf.

ITRC. 2015. "Remediation Management of Complex Sites" (website). Interstate Technology and Regulatory Council, Washington, D.C. Available at: http://www.itrcweb.org/ Team/Public?teamID=64.

Johnson, C.D., M.J. Truex, and T.P. Clement. 2006. Natural and Enhanced Attenuation of Chlorinated Solvents Using RT3D. PNNL-15937, Pacific Northwest National Laboratory, Richland, Washington.

Johnson, C.D. and M.J. Truex. 2006. RT3D Reaction Modules for Natural and Enhanced Attenuation of Chloroethanes, Chloroethenes, Chloromethanes, and Daughter Products. PNNL-15938, Pacific Northwest National Laboratory, Richland, WA.

Looney, B.B., F.H. Chapelle, T.O. Early, K.M. Vangelas, K. Adams, and C.H. Sink. 2006. Mass Balance: A Key to Advancing Monitored and Enhanced Attenuation for Chlorinated Solvents. WSRC-STI-2006-00082, Washington Savannah River Company, Aiken, SC.

Minsker, B., Y. Zhang, R. Greenwald, R. Peralta, C. Zheng, K. Harre, D. Becker, L. Yeh, and K. Yager. 2004. Final Technical Report for the Application of Flow and Transport Optimization Codes to Groundwater Pump and Treat Systems (Three Volumes). ESTCP Project CU-0010, Environmental Security Technology Certification Program, U.S. Department of Defense, Washington, D.C. Available at www.serdp-estcp.org/.

NRC. 2003. Environmental Cleanup at Navy Facilities: Adaptive Site Management. National Research Council, National Academies Press, Washington, D.C.

NRC. 2013. Alternatives for Managing the Nation's Complex Contaminated Groundwater Sites. National Academy of Sciences, Washington, D.C.

Rivett, M.O., S.W. Chapman, R.M. Allen-King, S. Feenstra, and J.A. Cherry. 2006. "Pumpand-Treat Remediation of Chlorinated Solvent Contamination at a Controlled FieldExperiment Site." Environ. Sci. Tech., 40:6770-6781. 
Sale, T., and C. Newell. 2011. A Guide for Selecting Remedies for Subsurface Releases of Chlorinated Solvents. ESTCP ER-200530, Environmental Technology Security Certification Program, Alexandria, Virginia. Available at: https://www.serdpestcp.org/content/download/10883/137620/file/ER-200530-DG.pdf.

Truex, M.J. and C.D. Johnson. 2013. I-5 Pump-and-Treat System Performance Assessment. Public Works, Joint Base Lewis McChord, Washington.

Truex, M.J. and C.D. Johnson. 2013. I-5 Pump-and-Treat System Performance Assessment. Public Works, Joint Base Lewis McChord, Washington.

Truex, M.J., C.D. Johnson, and C.R. Cole. 2006. Numerical Flow and Transport Model for the Fort Lewis Logistics Center. DSERTS NO. FTLE-33, Fort Lewis Public Works, Fort Lewis, Washington.

Truex, M.J., V.R. Vermeul, C.D. Johnson, B.N. Bjornstad, and R.D. Mackley. 2008. Fort Lewis Sea Level Aquifer Pump-and-Treat System: Extraction and Monitoring Well Installation Report. Fort Lewis Public Works, IMNW-LEW-PWE, MS 17 Box 339500, Fort Lewis, Washington.

Truex, M.J., P.V. Brady, C.J. Newell, M. Rysz, M. Denham, and K. Vangelas. 2011. The Scenarios Approach to Attenuation Based Remedies for Inorganic and Radionuclide Contaminants. SRNL-STI-2011-00459, Savannah River National Laboratory, Aiken, SC. Available at: https://clu-in.org/download/techfocus/na/NA-SRNL-STI-201100459.pdf.

USACE. 2000. Operation and Maintenance of Extraction and Injection Wells at HTRW Sites. EP 1110-1-27, U.S. Army Corps of Engineers, Washington, D.C.

USACE. 1999. Ground Water Extraction System Subsurface Performance Checklist. U.S. Army Corps of Engineers, Washington, D.C. Available at: http://www.hnc.usace.army.mil/Portals/65/docs/Directorates/EMCX/Checklists/Grou nd\%20Water\%20Extraction\%20System.pdf.

USGS. 2003. Methodology for Estimating Times of Remediation Associated with Monitored Natural Attenuation. Water Resources Investigations Report 03-4057, U.S. Geological Survey, Reston, Virginia.

White, M.D., D. Appriou, D.H. Bacon, Y. Fang, V. Freedman, M.L. Rockhold, C. Ruprecht, G. Tartakovsky, S.K. White, and F. Zhang. 2015a. STOMP Online User Guide. Pacific Northwest National Laboratory, Richland, Washington. Available at http://stomp.pnnl.gov/user_guide/STOMP_guide.stm. 
White, M.D., D. Appriou, D.H. Bacon, Y. Fang, V. Freedman, M.L. Rockhold, C. Ruprecht, G. Tartakovsky, S.K. White, and F. Zhang. 2015b. eSTOMP Online User Guide. Pacific Northwest National Laboratory, Richland, Washington. Available at http://stomp.pnnl.gov/estomp_guide/eSTOMP_guide.stm.

Widdowson, M.A., E. Mendez III, F.H. Chapelle, and C.C. Casey. 2005. Natural Attenuation Software (NAS) User's Manual, Version 2. Virginia Tech, United States Geological Survey (USGS), and Naval Facilities Engineering Command. Available at: http://www.nas.cee.vt.edu/index.php.

Wiedemeier, T., J. Wilson, D. Kampbell, R. Miller, and J. Hansen. 1999. Technical Protocol for Implementing Intrinsic Remediation with Long-Term Monitoring for Natural Attenuation of Fuel Contaminations Dissolved in Groundwater. Air Force Center for Environmental Excellence, Technology Transfer Division, Brooks Air Force Base, San Antonio, Texas. 
Appendix A

Case Studies 



\section{Appendix A: Case Studies}

\section{- Initiate Remedy Closure}

- Case Study 1: Norton AFB, Riverside, CA

- Dave Becker, U.S. Army Corps of Engineers Environmental and Munitions Center of Expertise

- Transition P\&T to MNA

- Case Study 2A: Tooele Army Depot; Tooele, UT

- Dave Becker, U.S. Army Corps of Engineers Environmental and Munitions Center of Expertise

- Case Study 2B: Idaho National Laboratory Test Area North Site, ID

- Hope Lee, Pacific Northwest National Laboratory

- Continue P\&T

- Case Study 3: Fernald Site, Harrison, OH

- Ken Broberg, Stoller Newport News Nuclear

- Supplement P\&T with Other Treatment Technologies

- Case Study 4: Former Cornhusker Army Ammunition Plant, Grand Island, NE

- Dave Becker, U.S. Army Corps of Engineers Environmental and Munitions Center of Expertise

\section{- Transition to a New Remedy Approach}

- Case Study 5A: Nebraska Superfund Site; Grand Island, NE

- Dave Becker, U.S. Army Corps of Engineers Environmental and Munitions Center of Expertise

- Case Study 5B: Vineland Chemical Superfund; Vineland, NJ

- Dave Becker, U.S. Army Corps of Engineers Environmental and Munitions Center of Expertise

- Case Study 5C: Commencement Bay - South Tacoma Channel Superfund Site, Tacoma, WA

- Tamzen Macbeth, CDM Smith and Kira Lynch EPA Region 10

- Case Study 5D: Del Norte Superfund, Crescent City, CA

- Dave Becker, U.S. Army Corps of Engineers Environmental and Munitions Center of Expertise

Note that these case studies illustrate the type of outcomes described in this document. However, they do not illustrate the specific performance assessment approach because they represent P\&T outcomes determined prior to publication of this document. 
A. 2 


\section{Case Study 1: Norton Air Force Base}

\section{Key Points}

- Transitioned P\&T to remedy closure

- The contaminant source area was addressed with excavation and SVE.

- The plume declined during P\&T application.

- A concentration rebound study (while the P\&T system was shut down) showed concentrations remained below the RAOs with limited exceptions near the former source.

- The P\&T system was terminated based on meeting RAOs with minor areas of exceedance declining and having no risk.

- Monitoring after P\&T system termination verified continued decline of contamination.

\section{Description}

The former Norton Air Force Base (AFB) in San Bernardino, California was placed on the National Priorities List in 1987 because of the Central Base Area (CBA) and Base Boundary (BB) TCE groundwater plumes and the associated source contamination in the vadose zone. The Air Force addressed the contamination in the 1990s with 1) source area excavation, 2) soil vapor extraction, and 3) two P\&T systems. Excavation and off-site disposal of 4200 cubic yards of TCE-contaminated soil was conducted in 1991. The SVE system operated from 1995 to 1997 and removed approximately 7,500 lbs of TCE during that time. The P\&T systems were installed in 1992 and 1995, with both systems using air stripping for the aboveground treatment.

The former Norton AFB is located in the Bunker Hill groundwater basin, and consists of multiple high-permeability aquifers, typically developed for water supply to a maximum depth of 1000 feet. The water-bearing zones were categorized into shallow (as little as 57 feet below the surface), intermediate, and deep zones. The groundwater plumes primarily affected the shallow zone, with some impact to the intermediate zone at locations off-base. The deep zone was not affected. Institutional controls prohibited groundwater extraction on the former base for any purposes other than remediation.

The CBA P\&T system was meant to accomplish mass reduction at concentration hot spots rather than containment. The Base Boundary system was meant to contain and clean up the offsite plume. The presence of cis-1,2-DCE provided evidence that some biodegradation was occurring at the site. A "rebound" test was conducted around year 2000 while the P\&T system was shut down. Essentially no rebound was observed during the one-year period. An independent optimization review conducted under Air Force direction in 2002 found that the CBA system had accomplished its goal of mass reduction and only minor exceedances of standards ( $42 \mu \mathrm{g} / \mathrm{L}$ of TCE versus the MCL of $5 \mu \mathrm{g} / \mathrm{L})$ remained in the immediate vicinity of the source area. Furthermore, the BB system had largely reduced all concentrations below cleanup goals. As a result of the evaluation, the recommendation was to discontinue all P\&T operations. 
The remaining CBA plume was determined to be stable and would not migrate outside of the former base boundary at levels above the applicable cleanup standards.

Per the recommendations, the P\&T systems were shut down and permanently decommissioned in 2005. As of 2011, contamination was not detected at levels above the cleanup goals at any locations within the former plume boundaries.

\section{Case Study Decision Element Summary}

\begin{tabular}{|l|l|}
\hline \multicolumn{1}{|c|}{ Decision Elements } & \multicolumn{1}{c|}{ Site-Specific Assessment } \\
\hline Contaminant concentrations and trends & $\begin{array}{l}\text { Plume declined to meet RAOs, confirmed with a rebound } \\
\text { study }\end{array}$ \\
\hline $\begin{array}{l}\text { Contaminant mass discharge from source } \\
\text { areas or at selected plume locations }\end{array}$ & Not used \\
\hline The attenuation capacity of the aquifer & Not used \\
\hline $\begin{array}{l}\text { Estimated future plume behavior and } \\
\text { time to reach RAOs for the site }\end{array}$ & $\begin{array}{l}\text { At the time of shutdown, the assessment estimated that } \\
\text { the plume would meet RAOs with no action }\end{array}$ \\
\hline $\begin{array}{l}\text { P\&T system design, operational, and } \\
\text { cost information }\end{array}$ & Not used \\
\hline
\end{tabular}

\section{Additional Information:}

The EPA cleanup profile for the site is available at http://yosemite.epa.gov/r9/sfund/r9sfdocw.nsf/ViewByEPAID/CA4570024345\#descr.

Dave Becker, U.S. Army Corps of Engineers Environmental and Munitions Center of Expertise 


\section{Case Study 2A: Tooele Army Depot}

\section{Key Points}

- Transitioned P\&T to MNA

- Chlorinated solvent contaminant source area was initially addressed with capping of former disposal sites and SVE.

- The plume declined during P\&T application.

- The project team anticipated that the plume would be stable without P\&T.

- The P\&T system was shut down and monitoring was initiated to verify natural attenuation performance.

- MNA is underway with some hot-spot treatment being applied (air sparging) to reduce contaminant source flux into parts of the plume.

- MNA is continuing with contingencies identified for use if plume expansion occurs.

\section{Description}

A large groundwater plume of TCE, carbon tetrachloride, and several other chlorinated solvents was discovered at the Tooele Army Depot, Tooele, Utah in the late 1980s. The plume was found to extend outside of the northern Depot boundary. The contamination was related to discharge of industrial wastewater from maintenance of military equipment and munitions at the Depot, which started in 1942. Wastes were discharged until the late 1980s into a sanitary landfill, unlined ditches, and, later, to industrial waste lagoons. Much of the industrial activities were discontinued in the early 1990s. Remediation of the subsurface at the Depot is administered under a RCRA permitting process and several aspects were initiated in the early 1990s. A P\&T system was installed in 1993, becoming fully operational in 1994. Other actions were initiated to control mass flux to the groundwater, including capping of the former ditches, lagoons, and landfill. More recently, soil vapor extraction has also been conducted to address contaminant mass and vapors in the deep vadose zone (more than 300 feet thick in places).

The site is located in the Tooele Valley, part of the Great Salt Lake drainage area, and is generally underlain by coarse-grained alluvial fan deposits shed from surrounding mountains. These coarse materials are inter-bedded in places with finer-grained materials, including lake deposits. Overall, the unconsolidated materials are over 600 feet thick. In areas, fault-bounded bedrock highs of limestone and quartzite extent to near the surface within the boundaries of the plume, thus complicating groundwater flow. Faults appear to act as barriers to groundwater flow; when oriented perpendicular to the direction of groundwater flow, very steep gradients across faults are observed. The plume has affected a significant thickness of saturated unconsolidated materials, as well as bedrock.

The P\&T system had a goal of both containment of the downgradient edge of the plume and the restoration of the aquifer. Hence, extraction wells were placed within the plume, as well at its downgradient end. High pumping rates were applied (approximately 5,500 gpm) and 
extracted water was treated by air stripping prior to downgradient injection back into the aquifer for hydraulic control purposes.

P\&T system operation resulted in a "pull-back" of the plume from off-site locations and some concentration reductions at locations in the plume interior. An Army-sponsored evaluation in the mid-2000s suggested that there was little benefit to the continued operation of the P\&T system. The evaluation concluded that the plume would be relatively stable under non-pumping conditions. As a result of these suggestions, a "non-operations" test was conducted starting in 2004 by turning off the P\&T system and carefully monitoring the plume. The system remains off and plans are being made for the decommissioning the P\&T system because the plume appears to be stable. Contingency actions are identified in case the plume was observed to migrate outside of a defined management area.

Natural attenuation by cometabolic and abiotic processes is being investigated at the site to assess the future fate of the plume. A robust groundwater model for the site has been developed and is routinely updated. The model does not yet include degradation processes, but if the outcome of studies on attenuation process indicates that such processes are important, then the model will be updated accordingly. Hot-spot source-area treatment of groundwater using air sparging is being conducted at select locations to reduce downgradient mass discharge.

Transition to MNA was initiated with contaminant concentrations above the cleanup goals. Steps have been taken for targeted reduction of hot spots and study is underway to verify the attenuation capacity. Contingent actions involving technologies other than P\&T are proposed if the plume migrates outside of the management area.

\section{Case Study Decision Element Summary}

\begin{tabular}{|l|l|}
\hline \multicolumn{1}{|c|}{ Decision Elements } & \multicolumn{1}{c|}{ Site-Specific Assessment } \\
\hline Contaminant concentrations and trends & Plume declined with P\&T. \\
\hline $\begin{array}{l}\text { Contaminant mass discharge from source } \\
\text { areas or at selected plume locations }\end{array}$ & Conducted a rebound test to assess plume stability \\
\hline The attenuation capacity of the aquifer & $\begin{array}{l}\text { Conducted a rebound test to assess plume stability. } \\
\text { Studies underway to verify attenuation processes and } \\
\text { capacity }\end{array}$ \\
\hline $\begin{array}{l}\text { Estimated future plume behavior and } \\
\text { time to reach RAOs for the site }\end{array}$ & $\begin{array}{l}\text { Estimate MNA will control the plume, but have identified } \\
\text { contingency actions such as hot-spot treatment. }\end{array}$ \\
\hline $\begin{array}{l}\text { P\&T system design, operational, and } \\
\text { cost information }\end{array}$ & Not used \\
\hline
\end{tabular}

\section{Additional Information:}

The Installation Action Plan for the site is available at http://www.aec.army.mil/Portals/3/IAP/UT-TEAD.pdf.

Dave Becker, U.S. Army Corps of Engineers Environmental and Munitions Center of Expertise 


\section{Case Study 2B: Idaho National Laboratory Test Area North (TAN) Site}

\section{Key Points}

- Transitioned P\&T to MNA

- A three-component remedy was initiated with bioremediation of the source zone, P\&T of the plume core, and MNA for the distal plume.

- The plume core targeted by P\&T declined during P\&T application.

- A natural attenuation analysis suggested the plume would be stable without P\&T of the plume core.

- The P\&T system was shut down and monitoring has verified natural attenuation performance.

\section{Description}

The Test Area North (TAN) site at the U.S. Department of Energy's Idaho National Laboratory (INL) was used for historical nuclear fuel operations and heavy metal manufacturing. From 1953 to 1972, liquid wastes and sludge from experimental facilities were disposed of to the aquifer via an injection well at the site. The subsurface aquifer at the site is both deep and complex, within fractured basalt. The wastes were primarily industrial and sanitary wastewater, but also included organic, inorganic, and low-level radioactive constituents. In 1987, PCE and TCE were detected in wells used to supply drinking water to workers at TAN and the groundwater contamination was traced to the injection well. In 1989, TAN was included on the National Priorities List and a remedial investigation/feasibility study (RI/FS) was completed in 1995. The RI/FS identified PCE, TCE, DCE, and some radionuclides as contaminants of concern. The chlorinated solvent groundwater plume is nearly $3 \mathrm{~km}$ long and $0.8 \mathrm{~km}$ wide.

Several initial remedial actions were employed to address the contamination at the TAN site, with concurrent investigation and development of a conceptual site model. Early remediation activities included removal of some of the waste sludge from the injection well. An interim pump-and-treat system was installed downgradient from the waste injection well and it was operated from about 1996 to 1998 to create a hydraulic barrier to prevent contaminant migration. The conceptual site model for TAN continued to be refined through an iterative process of identifying the data requirements needed to understand the fate and transport parameters and identifying further (or continuing) data gaps.

The site consists of three separate contamination zones, with different remediation approaches evaluated for each zone. The contamination zones included 1) the source (hot spot) around the waste injection well, with initial TCE concentrations greater than 20,000 $\mu \mathrm{g} / \mathrm{L}, 2$ ) a medial zone of groundwater contamination with TCE concentrations between 20,000 to 1,000 $\mu \mathrm{g} / \mathrm{L}$ extending downgradient from the source zone, and 3) a distal portion of the TCE plume with concentrations less than 1,000 $\mu \mathrm{g} / \mathrm{L}$. Remediation approaches selected for these zones and incorporated in a 2001 ROD Amendment included: 1) in situ bioremediation for the source zone, 2) groundwater P\&T for the medial zone, and 3) monitored natural attenuation for the distal zone. 
The medial zone P\&T system was operated from 2001 to 2005 , resulting in TCE concentrations decreasing to approximately $100 \mu \mathrm{g} / \mathrm{L}$. A rebound test was conducted from 2005 to 2007 and evaluation of that data suggested that operating the P\&T system on a pulsedpumping strategy (i.e., cycles of operation and standby modes) would produce optimal reduction of contaminant concentrations. In addition, a tracer-corrected method was applied to estimate an attenuation half-life for the contaminants. Biological attenuation mechanisms were evaluated using a novel suite of assays, including DNA, enrichment cultures, and enzyme activity probes, to reveal that indigenous microorganisms were significantly contributing to natural attenuation.

Transition to MNA was initiated using rebound data from the medial P\&T area and the attenuation rate data to demonstrate that the plume would not increase beyond an acceptable size after cessation of $P \& T$ operations. The data showed that the plume had been diminished to the point where P\&T operations could be terminated and that MNA would meet the site RAOs. Continued monitoring, as part of the MNA remedy, has been used to verify remedy performance.

\section{Case Study Decision Element Summary}

\begin{tabular}{|l|l|}
\hline \multicolumn{1}{|c|}{ Decision Elements } & \multicolumn{1}{c|}{ Site-Specific Assessment } \\
\hline Contaminant concentrations and trends & Plume declined with P\&T. \\
\hline $\begin{array}{l}\text { Contaminant mass discharge from source } \\
\text { areas or at selected plume locations }\end{array}$ & Conducted a rebound test to assess plume stability \\
\hline The attenuation capacity of the aquifer & $\begin{array}{l}\text { Conducted a rebound test to assess plume stability. A } \\
\text { tracer-corrected contaminant concentration study was } \\
\text { used to develop attenuation rates. Additional studies } \\
\text { verified attenuation processes. }\end{array}$ \\
\hline $\begin{array}{l}\text { Estimated future plume behavior and } \\
\text { time to reach RAOs for the site }\end{array}$ & $\begin{array}{l}\text { Evaluation showed that plume would not increase beyond } \\
\text { an acceptable size with P\&T terminated. }\end{array}$ \\
\hline $\begin{array}{l}\text { P\&T system design, operational, and } \\
\text { cost information }\end{array}$ & P\&T optimized over time during the remedy \\
\hline
\end{tabular}

\section{Additional Information:}

Dettmers, D.L., T.W. Macbeth, K.S. Sorenson Jr., L.O. Nelson, K.L. Harris, L.N. Peterson, G.D. Mecham, and J.S. Rothermel. 2006. "Remediation of a TCE Plume Using a Three-Component Strategy." Practice Periodical of Hazardous, Toxic, and Radioactive Waste Management, 10(2):116-125.

DOE. 2001. Record of Decision Amendment for the Technical Support Facility Injection Well (TSF05) and Surrounding Groundwater Contamination (TSF-23), and Miscellaneous No Action Sites, Final Remedial Action. U.S. Department of Energy, Idaho Operations Office, Idaho Falls, ID.

DOE. 2010. Annual Report for the Final Groundwater Remediation, Test Area North, Operable Unite 1-07B, Fiscal Year 2009. U.S. Department of Energy, Idaho Operations Office: Idaho Falls, ID.

Hope Lee, Pacific Northwest National Laboratory 


\section{Case Study 3: Fernald Preserve Uranium P\&T System}

\section{Key Points}

- Continued with optimized P\&T

- The plume was declining with P\&T, but at a decreasing operational effectiveness, resulting in a longer projected timeframe to reach the RAOs.

- New characterization data showed an area with higher uranium concentrations than initially estimated.

- The groundwater model used for the initial P\&T design was applied to evaluate optimization alternatives for the P\&T system.

- The optimized P\&T system is predicted to accelerate cleanup in key portions of the aquifer and meet site RAOs in a reasonable time, with reduced costs (compared to the original P\&T design).

\section{Description}

The Fernald Preserve, 18 miles northwest of Cincinnati, Ohio, overlies the Great Miami Aquifer (GMA), which the EPA has designated as a sole-source aquifer. A facility at the site operated from 1952 to 1989 to produce more than 226 million kilograms (kg) of uranium metal products. In the process of these production operations, the soil, surface water, sediment, and groundwater on and around the site were contaminated with uranium. In 1991, the site's mission was formally changed from uranium production to environmental remediation and restoration under CERCLA. The cleanup project was divided into Operable Units (OU). OU 5 focused on environmental media and biological receptors, including groundwater, impacted by site activities. With the exception of the GMA, completion of the CERCLA remediation was declared on October 29, 2006, and the site was officially transferred to U.S. DOE Office of Legacy Management. The final ROD for remedial actions at OU 5 defines a P\&T groundwater remedy for Fernald. Uranium is the principal constituent of concern.

P\&T pumping in the GMA began in 1993 from four recovery wells installed in front of the leading edge of the southernmost uranium plume. The P\&T design was updated and expanded using a groundwater model. By 2005, the P\&T system consisted of 23 extraction wells pumping groundwater at a target overall rate of 18,073 Lpm (4,775 gpm). This system was operated from 2005 through June 2014. In 2012, the site groundwater model was used to assess P\&T performance in light of 1) a characterization effort in 2011 that discovered uranium concentrations in a portion of the plume that were greater than estimates based on the initial site data used for the P\&T system design, and 2) decreasing operational effectiveness of the P\&T operation. Following EPA guidance (EPA 1992), the trend determined from uranium concentrations measured at the extraction wells was evaluated each year, along with the 95percent upper confidence limit (UCL) for the concentration data. These uranium concentration trends were compared to the model-predicted trends to evaluate operational effectiveness. 
Because of the observed decline in operational effectiveness, estimates of the cleanup timeframe were longer than initial predictions.

Sixteen different operational alternatives were modeled using the site groundwater model to assess the potential for P\&T optimization to improve operational effectiveness and shorten cleanup timeframes. The selected optimized configuration more efficiently addressed the remaining uranium plume in the aquifer over time, and effectively focuses cleanup on the portion of the uranium plume that has the greatest potential for migrating outside of DOE property boundaries. While the initial P\&T configuration showed declining performance, the model predicts that the optimized P\&T design will accelerate cleanup in key portions of the aquifer and meet site RAOs within a reasonable time frame.

Initial results based on the P\&T operational changes are promising. As the modeling predicted, the optimized P\&T configuration is removing more uranium from the aquifer. Additional monitoring of the optimized system is underway to determine the impact that biofouling and plugging will have on the extraction wells at the higher pumping rates and whether or not continued operation at the higher pumping rates will be cost effective.

\section{Case Study Decision Element Summary}

\begin{tabular}{|l|l|}
\hline \multicolumn{1}{|c|}{ Decision Elements } & \multicolumn{1}{c|}{ Site-Specific Assessment } \\
\hline Contaminant concentrations and trends & $\begin{array}{l}\text { Plume declined, but at less than expected rate, and new } \\
\text { data identified and area with higher concentrations than } \\
\text { initial estimates }\end{array}$ \\
\hline $\begin{array}{l}\text { Contaminant mass discharge from source } \\
\text { areas or at selected plume locations }\end{array}$ & $\begin{array}{l}\text { P\&T performance trends compared to groundwater model } \\
\text { predictions to assess P\&T operational effectiveness }\end{array}$ \\
\hline The attenuation capacity of the aquifer & Not used \\
\hline $\begin{array}{l}\text { Estimated future plume behavior and } \\
\text { time to reach RAOs for the site }\end{array}$ & $\begin{array}{l}\text { Groundwater model used to estimate plume behavior for } \\
\text { P\&T configuration alternatives }\end{array}$ \\
\hline $\begin{array}{l}\text { P\&T system design, operational, and } \\
\text { cost information }\end{array}$ & $\begin{array}{l}\text { Applied optimization evaluation and selected an improved } \\
\text { configuration that is predicted to accelerate cleanup in key } \\
\text { portions of the aquifer and meet RAOs in a reasonable } \\
\text { time, with reduced cost }\end{array}$ \\
\hline
\end{tabular}

\section{Reference}

EPA. 1992. General Methods for Remedial Operation Performance Evaluations. EPA/600/R-92-002, United States Environmental Protection Agency, Ada, Oklahoma.

\section{Additional Information:}

Hooten, G., W. Hertel, and K. Broberg. 2015. "Groundwater Remediation at the Fernald Preserve Cincinnati, Ohio: Modeling and Resulting 2014 Well Field Operational Changes." In: Proceedings, Waste Management Symposia 2015, Phoenix, Arizona.

Ken Broberg, Stoller Newport News Nuclear (SN3) 


\section{Case Study 4: Former Cornhusker Army Ammunition Plant}

\section{Key Points}

- Supplemented P\&T with another treatment technology.

- The site has a long plume of the explosive RDX emanating from different sources.

- The contaminant source in vadose zone was addressed with excavation.

- P\&T was initially applied throughout the plume on site for plume reduction. The off-site plume was allowed to naturally attenuate.

- Injection of a carbon source to bioremediate and diminish the plume has been implemented to supplement the P\&T remedy.

\section{Description}

The site is a former ordnance production facility in central Nebraska that operated during World War II, the Korean War, and the Vietnam War. The Army installation was transitioned to inactive status in 1973, but the property is gradually being transferred to allow commercial redevelopment. The site was listed on the National Priorities List in 1987. Investigations revealed several distinct and overlapping explosives plumes (primarily RDX) emanating from several sources. The plumes were ultimately found to extend over a distance of six miles, including a two-mile-long segment off the Army installation. Soils contaminated with explosives were largely excavated and treated in the mid- to late-1980s.

The site hydrogeology generally consists of surficial silty clay loess overlying sands and gravels that are approximately 50-100 ft thick. The sand and gravel aquifer is a primary drinking water source for the surrounding area. Groundwater is nominally found at depths of approximately 5-10 feet and generally flows east-southeast. The contaminant plume is within the sand and gravel aquifer. A clay unit underlies the sand and gravel aquifer and no contamination has been found below this clay to date.

The final remedy for groundwater, documented in a 1994 Record of Decision (ROD), identified remediation of the contaminant plume using P\&T with extraction wells distributed along the axis of the plume and aboveground treatment by carbon adsorption. The portion of the remedy on the Army installation began operation in late 1998. A ROD amendment, issued in 2001, modified the remedy to include natural attenuation of the off-installation portion of the plume. The treatment plant was initially treating approximately 750 gallons/minute of extracted water. Over time, several optimization efforts have been implemented for the extraction system.

Beginning in 2006, a supplemental technology was voluntarily applied to accelerate the remediation of the on-installation portion of the plume. This supplemental technology is a bioremediation approach involving injection of a carbon source to stimulate anaerobic biodegradation of the explosive compounds. Substrate injections are targeted at the higher contaminant concentration areas. Extraction wells within the plume were incrementally shut 
down as the bioremediation treatment progressed. Extraction is currently being conducted only at the Army installation boundary. The bioremediation supplemental technology is projected to reduce the duration of the remedy by approximately 10 years.

\section{Case Study Decision Element Summary}

\begin{tabular}{|l|l|}
\hline \multicolumn{1}{|c|}{ Decision Elements } & \multicolumn{1}{c|}{ Site-Specific Assessment } \\
\hline Contaminant concentrations and trends & $\begin{array}{l}\text { The plume was contained but did not decline as rapidly as } \\
\text { expected. }\end{array}$ \\
\hline $\begin{array}{l}\text { Contaminant mass discharge from source } \\
\text { areas or at selected plume locations }\end{array}$ & Not used \\
\hline The attenuation capacity of the aquifer & $\begin{array}{l}\text { Assessed empirically to enable use of natural attenuation } \\
\text { for the off-installation portion of the plume. }\end{array}$ \\
\hline $\begin{array}{l}\text { Estimated future plume behavior and } \\
\text { time to reach RAOs for the site }\end{array}$ & $\begin{array}{l}\text { The projected remedial timeframe was significantly } \\
\text { reduced with application of the supplemental technology. }\end{array}$ \\
\hline $\begin{array}{l}\text { P\&T system design, operational, and } \\
\text { cost information }\end{array}$ & $\begin{array}{l}\text { The system was optimized over time. Remedy costs have } \\
\text { been reduced through optimization and with the } \\
\text { supplemental technology. }\end{array}$ \\
\hline
\end{tabular}

\section{Additional Information:}

The EPA Region 7 project web site for the project is available at http://cumulis.epa.gov/supercpad/cursites/csitinfo.cfm?id=0702020.

Project fact sheet available at http://www.epa.gov/region07/cleanup/npl_files/ne2213820234.pdf.

Dave Becker, U.S. Army Corps of Engineers Environmental and Munitions Center of Expertise 


\section{Case Study 5A: Superfund Site in Nebraska}

\section{Key Points}

- Transitioned from P\&T to another treatment remedy

- The PCE contaminant source in the vadose zone was addressed with SVE.

- P\&T was applied at the source area to control contaminant mass discharge, but the plume did not decline as much as anticipated.

- The ROD was amended to a remedy with in situ thermal remediation (ISTR) for the source area and in situ chemical oxidation (ISCO) or enhanced bioremediation for the dissolved-phase plume.

- The P\&T system was terminated and ISCO has been implemented. ISTR planning is underway for addressing hot spots.

- Following ISTR treatment of the source area, other polishing technologies, including bioremediation or thermally activated persulfate ISCO, may be needed.

\section{Description}

The site is a PCE groundwater plume that was identified in 1986 as affecting a municipal water supply well for a medium-sized city in Nebraska. After additional investigation by EPA, the primary source of contamination was found to be a former dry cleaner located in the downtown area, approximately two blocks upgradient of the municipal well. Additional sources in the area were identified as having had a limited contribution to the groundwater contamination. The site was listed on the National Priorities List in 1991.

The initial remedy, documented in a 1996 Record of Decision, included application of SVE (with vapor-phase carbon treatment) for the soils above the water table and P\&T for the groundwater remediation (with ex situ groundwater treatment by air stripping). A new well was installed just downgradient of the source area to implement the P\&T remedy. Until the implementation of the remedy in 1998, the municipal well was pumped to contain the plume and the extracted water was directed to either storm drains or the sanitary waste treatment plant.

The site geology generally consists of sands and gravels to a depth of $28 \mathrm{ft}$ below ground surface (bgs), a silt/silty sand unit from approximately $28 \mathrm{ft}$ down to as deep as $35 \mathrm{ft}$ bgs, and sands and gravels below to a depth of approximately $90 \mathrm{ft}$ bgs. Within the sands and gravels are deposits of silty sands and occasional thin clayey sand layers and sandy clay layers. Groundwater is generally found at depths of approximately 20 feet. The silt/silty sand layer appears to have had a significant impact on contaminant distribution. The extraction well at the source was primarily screened below the silt. High contaminant concentrations are still found above, within, and below the silt/silty sand layer.

The P\&T system was operated until 2009 and the SVE system was operated until 2012. A ROD amendment issued in 2012 changed the remedy to include in situ thermal remediation for the source area and in situ chemical oxidation or enhanced bioremediation for the dissolved- 
phase plume. The initial injection of permanganate for ISCO treatment of the plume occurred in 2009. Residual oxidant remains at the site. Recent sampling has confirmed that SVE has successfully removed contaminants in the vadose zone to levels that are not a threat. Design of in situ thermal remediation for high groundwater concentrations under and immediately downgradient of the dry cleaners is underway.

The transition to an alternate set of technologies was spurred by various optimization analyses and the recognition that the P\&T system was not achieving progress in diminishing the plume at the expected rate.

\section{Case Study Decision Element Summary}

\begin{tabular}{|l|l|}
\hline \multicolumn{1}{|c|}{ Decision Elements } & \multicolumn{1}{c|}{ Site-Specific Assessment } \\
\hline Contaminant concentrations and trends & Plume did not decline significantly \\
\hline $\begin{array}{l}\text { Contaminant mass discharge from source } \\
\text { areas or at selected plume locations }\end{array}$ & Not used \\
\hline The attenuation capacity of the aquifer & Not used \\
\hline $\begin{array}{l}\text { Estimated future plume behavior and } \\
\text { time to reach RAOs for the site }\end{array}$ & Estimated P\&T would not meet goals in a reasonable time \\
\hline $\begin{array}{l}\text { P\&T system design, operational, and } \\
\text { cost information }\end{array}$ & $\begin{array}{l}\text { Evaluated optimization and determined other treatment } \\
\text { processes would be more effective. }\end{array}$ \\
\hline
\end{tabular}

\section{Additional Information:}

The most recent five-year review for the site is available at http://www.nwk.usace.army.mil/Missions/Environmental/EnvironmentalProjects/NOP.aspx.

Dave Becker, U.S. Army Corps of Engineers Environmental and Munitions Center of Expertise 


\section{Case Study 5B: Vineland Chemical Superfund Site}

\section{Key Points}

- Transitioning P\&T to another treatment remedy

- Arsenic contamination from herbicide/fungicide manufacturing was addressed through soil excavation/washing and groundwater P\&T.

- An optimization study in 2010 suggested evaluation of arsenic immobilization in lieu of continued P\&T.

- Subsequent detailed characterization of the site geochemistry led to an improved conceptual site model and bench testing of multiple approaches to arsenic immobilization was conducted.

- A pilot test of air sparging to cause arsenic immobilization is in progress.

- Sparging may replace or supplement P\&T. There is the potential for significant cost savings while having comparable performance.

\section{Description}

The site is a former arsenical herbicide/fungicide manufacturing facility that was added to the National Priority List in 1984. Arsenic contamination affected site soils, groundwater, and offsite sediments associated with the adjacent Blackwater Branch stream and the Maurice River downstream of its confluence with the Blackwater Branch stream.

The initial remedy specified in the 1989 Record of Decision included building demolition, soil flushing (later changed to excavation and soil washing), sediment removal (some sediment also underwent soil washing), and P\&T. Building demolition was ultimately completed in 2004. Soil washing for treatment of on-site soils and work on the Blackwater Branch adjacent to the site was completed by 2010 . The P\&T system was installed largely as a containment system to prevent migration of arsenic-contaminated groundwater to the Blackwater Branch stream and has operated since construction was completed in 2000. The P\&T system includes multiple extraction wells and a large treatment system that is capable of treating about $1400 \mathrm{gpm}$.

The site geology consists largely of sands and gravels of the Cohansey Sand. Hydraulic conductivity values are very high (ranging to over $700 \mathrm{ft} / \mathrm{day}$ ). A low-permeability interval, 1025 feet thick and informally termed the "Banded Zone," separates a shallow aquifer from an intermediate aquifer. The geochemistry of the two aquifers is different and an important geochemical boundary exists within the Banded Zone. Arsenic contamination has been confined to the shallow aquifer since 2006. Groundwater tends to flow toward the Blackwater Branch stream; however, the flow directions are strongly affected by active extraction operations. Groundwater is generally encountered within 15 feet of the surface in most locations near the extraction system.

An early study, including a field pilot test, was conducted to assess the potential to enhance the mobility of arsenic in the saturated zone. The pilot test results were ambiguous and the 
concept has not been pursued since then. A 2010 optimization study conducted at the request of EPA evaluated the remedy and suggested the P\&T system could be replaced by in situ stabilization of the arsenic and still protect the Blackwater Branch stream. Subsequent studies have greatly elucidated the site geochemical conditions, stream/groundwater interaction, and possible approaches to arsenic immobilization. As a part of the transition evaluation, current pilot testing is being conducted to evaluate air sparging as a means to sequester arsenic, with promising results.

The transition to an immobilization remedy, driven by air sparging, would allow termination of $\mathrm{P} \& \mathrm{~T}$ operations and would result in a large cost reduction. At a minimum, it would allow a substantial reduction in pumping, with a lesser, but still significant, savings for treatment system operations.

\section{Case Study Decision Element Summary}

\begin{tabular}{|l|l|}
\hline \multicolumn{1}{|c|}{ Decision Elements } & \multicolumn{1}{c|}{ Site-Specific Assessment } \\
\hline Contaminant concentrations and trends & Plume was contained with P\&T, but was not declining \\
\hline $\begin{array}{l}\text { Contaminant mass discharge from source } \\
\text { areas or at selected plume locations }\end{array}$ & Not used \\
\hline The attenuation capacity of the aquifer & Not used \\
\hline $\begin{array}{l}\text { Estimated future plume behavior and } \\
\text { time to reach RAOs for the site }\end{array}$ & $\begin{array}{l}\text { Evaluated impact of geochemistry on plume behavior to } \\
\text { identify an alternative treatment approach. }\end{array}$ \\
\hline $\begin{array}{l}\text { P\&T system design, operational, and } \\
\text { cost information }\end{array}$ & $\begin{array}{l}\text { Cost/benefit of alternative treatment technology better } \\
\text { than P\&T }\end{array}$ \\
\hline
\end{tabular}

\section{Additional Information:}

The Remediation System Evaluation report for the site is available at http://epa.gov/tio/download/remed/rse/vineland-rse-final.pdf.

Dave Becker, U.S. Army Corps of Engineers Environmental and Munitions Center of Expertise 


\section{Case Study 5C: Commencement Bay - South Tacoma Channel Superfund Site}

\section{Key Points}

- Supplementing P\&T to enable transition to MNA

- P\&T was selected as a remedy for groundwater contamination by chlorinated solvents.

- P\&T has partially contained the source area plume, but the plume has not declined.

- A combination of excavation, thermal treatment, and bioremediation is being applied to reduce the source and plume to meet revised remedial action objectives (RAOs) that include a specified contaminant mass discharge (CMD) goal that will enable transition to MNA.

- Evaluated CMD coming into different extraction wells within the P\&T system as a means of quantifying significance of source strength and selecting thermal and bioremediation treatment areas.

- Modified operation of the P\&T system to monitor CMD of the source remedy and determine compliance with the CMD goal.

\section{Description}

The Well 12A site is located in Tacoma, Washington approximately 4 miles southwest of the southernmost tip of Commencement Bay. Contamination was introduced to an aquifer from former oil recycling operations that include releases of petroleum hydrocarbons and chlorinated solvents as non-aqueous-phase liquids (NAPLs). The site encompasses the source of contamination at the property of the former Time Oil Company and the dissolved phase plume impacts the City of Tacoma's production Well 12A. The contaminants of concern at the site are tetrachloroethene (PCE), trichloroethene (TCE), cis-1,2-dichloroethene (DCE), trans-1,2-DCE, vinyl chloride (VC), and 1,1,2,2-tetrachloroethane (PCA). TCE is considered to be the most prevalent compound. Dense non-aqueous-phase liquid (DNAPL) has been identified in some portions of the aquifer. These zones and a silt layer within the glacial outwash/till hydrogeology of the subsurface act as a continuing source to a plume traveling downgradient in the graveldominated zones of the aquifer. These persistent sources are spread over an area of about 16,500 $\mathrm{m}^{2}$.

The original 1983 Record of Decision (ROD) involved the installation of an air stripping system to treat contaminated groundwater for Well 12A. A ROD amendment in 1985 included excavation of contaminated soils at the site, installation of a P\&T system near the source area, excavation of about 5,000 cubic yards of filter cake, and installation of a SVE system for a portion of the source zone that removed approximately 54,100 pounds of VOCs. Over a P\&T operational period of over 20 years, the system extracted approximately 860 million gallons and removed approximately 19,000 pounds of VOCs, partially contained the source area plume, but did not significantly diminish the extent of the plume. Source depletion, while occurring, was slow and would likely not meet RAOs. 
A 2009 ROD Amendment selected an amended remedy and developed additional RAOs. The amended remedy includes soil contamination reduction and use of thermal treatment and bioremediation to diminish the source of contaminants in the groundwater with the goal of reducing CMD sufficiently to allow for transition of the active remedy (including the P\&T system) to passive long-term monitoring. A source-reduction target expressed as a CMD objective was included in the ROD. An attenuation evaluation estimated contaminant degradation along the flowpath from the source area to the Well 12A receptor. Based on the estimated natural attenuation capacity of the system, it was determined that a $90 \%$ reduction in CMD from the source would be sufficient to allow for attenuation to reduce concentrations to MCLs before impacting the Well 12A receptor. This also would trigger when the source P\&T containment system would no longer be needed to protect the receptor and operations could be shut down. Monitoring during and after the source reduction effort will be used to quantify CMD and verify assumptions of the aquifer attenuation capacity as input to a decision to transition to long-term monitoring.

The source reduction effort is being implemented using targeted actions selected as appropriate for the different source conditions present at the site. For more saturated DNAPL zones, responsible for the majority of contaminant discharged to the P\&T system, in situ thermal treatment was applied to volatilize and extract the DNAPL. For the discrete residual DNAPL hotspots and diffused and sorbed contaminant mass in an extensive silt zone acting as a secondary source of aquifer contamination, , bioremediation using a substrate combining vegetable oil, ethyl lactate, and sodium bicarbonate is being applied. Shear-thinning fluid is also being used to promote improved distribution of the substrate to the silt zone. At two localized DNAPL hot spots within the bioremediation treatment area, a low-energy thermal system is being used to accelerate the DNAPL treatment rates.

Detailed hydraulic and capture zone assessment of the P\&T system led to modifications to its operation such that it could be used to measure CMD for evaluating compliance of the RODspecified interim objectives. Once the interim objectives are achieved, the active treatment phase (including P\&T system) will be shut down and the source area of the site transitioned to longterm monitoring. 


\section{Case Study Decision Element Summary}

\begin{tabular}{|l|l|}
\hline \multicolumn{1}{|c|}{ Decision Elements } & \multicolumn{1}{c|}{ Site-Specific Assessment } \\
\hline Contaminant concentrations and trends & Plume was partially contained but did not decline with P\&T \\
\hline $\begin{array}{l}\text { Contaminant mass discharge from source } \\
\text { areas or at selected plume locations }\end{array}$ & $\begin{array}{l}\text { Analyses determined a CMD value that would enable } \\
\text { transition for P\&T to MNA and was used as a remediation } \\
\text { objective for source reduction in the site ROD. Used CMD } \\
\text { at individual P\&T system wells in conjunction with other } \\
\text { site data to evaluate strength of multiple sources for } \\
\text { mapping treatment technologies. }\end{array}$ \\
\hline The attenuation capacity of the aquifer & $\begin{array}{l}\text { An estimate of natural attenuation was coupled with the } \\
\text { CMD evaluation to define the target CMD for transition to } \\
\text { MNA. }\end{array}$ \\
\hline $\begin{array}{l}\text { Estimated future plume behavior and } \\
\text { time to reach RAOs for the site }\end{array}$ & $\begin{array}{l}\text { If the target CMD is reached, MNA may be sufficient to } \\
\text { contain the plume and meet RAOs. Additional monitoring } \\
\text { will be applied to support a future decision to transition } \\
\text { from P\&T to MNA after source reduction has been } \\
\text { implemented. }\end{array}$ \\
\hline $\begin{array}{l}\text { im } \& \text { system design, operational, and } \\
\text { cost information }\end{array}$ & $\begin{array}{l}\text { The ROD considered a comparison of cost/benefit for } \\
\text { continued P\&T to the cost/benefit for source reduction } \\
\text { combined with P\&T and later transition to MNA. }\end{array}$ \\
\hline
\end{tabular}

\section{Additional Information:}

The ROD Amendment for the site is available at http://www.epa.gov/region10/pdf/sites/cb-stc/well12a_rod_amend_oct2009.pdf.

Tamzen Macbeth (CDM Smith) and Kira Lynch (EPA Region 10) 
A. 20 


\section{Case Study 5D: Del Norte County Pesticide Storage Area Superfund Project}

\section{Key Points}

- Transitioned P\&T to a TI waiver and MNA

- P\&T was selected as a remedy for groundwater contamination by chlorinated pesticides, most notably 1,2-dichloropropane.

- After source removal and seven years of P\&T, the plume has declined.

- A TI waiver waived the ARAR associated with reaching the MCLs for 1,2-dichloropropane, enabling a containment approach with MNA.

- A natural attenuation analysis suggested the plume would be stable without P\&T.

- The P\&T system was shut down and monitoring was initiated to verify natural attenuation performance.

- MNA was implemented with institutional controls to prevent use of the contaminated ground water.

\section{Description}

A County-owned property near the airport at Crescent City, CA was operated as a collection point for pesticides for Del Norte County from 1970 to 1981. In 1981, the site was discovered to have contaminated soil and groundwater, and was added to the National Priorities List in 1984. Contamination by 1,2-dichloropropane (1,2-DCP) and 2,4-dichlorophenoxyacetic acid (2,4-D) was likely caused by rinsing pesticide containers on-site and then disposing of the residues and rinsates in a bermed, unlined sump area. A relatively small plume of pesticide-contaminated groundwater was found to extend off the site. Elevated chromium concentrations were also found, but were ultimately determined to be from naturally occurring sources. Pesticide containers, both rinsed and unrinsed, were removed from the site for proper disposal in 1982. Approximately 300 cubic yards of contaminated soils were excavated at the site and sent off-site for disposal.

The site lies on a marine terrace shelf on the edge of the Pacific Ocean. The marine terrace represents an approximately 1.5-mile-wide and relatively flat zone that is parallel to the Pacific coastline and which once lay below sea level near the shore. The terrace is bound to the east by the Coast Range mountains. The aquifer beneath the site lies in the Quaternary-aged Battery Formation. The Battery Formation consists of moderately well-sorted fine sands, silts, and clays with generally moderate groundwater permeability. The presence of clays and fines likely contributes to continuing releases of 1,2-DCP into the groundwater. Groundwater flow velocities are estimated to be on the order of 10 feet per day.

In accordance with a Record of Decision issued in 1985, a P\&T system was installed in 1989 and began operations in 1990. Following soil excavation, groundwater concentrations dropped significantly even before P\&T system operations began. The P\&T system had a goal of both containment of the downgradient edge of the plume and the restoration of the aquifer. Thus, 
extraction wells were placed within the plume, as well at its downgradient end. Pumping rates were high, approximately 5,500 gpm and extracted groundwater was treated by air stripping before being injected back into the aquifer at a downgradient location.

The P\&T system was operated for seven years, after which time the system was shut down because it was believed the plume was stable and that dispersion, sorption, and other processes would hold the 1,2-DCP plume boundary in check. Concentrations of other contaminants had been reduced to levels below their respective standards. A 2000 ROD amendment was issued that changed the remedy to MNA. A technical impracticability (TI) waiver was issued waiving the need to attain the 1,2-DCP drinking water standard (MCL) of $5 \mu \mathrm{g} / \mathrm{L}$ everywhere at the site. Hence, the 2000 ROD amendment also called for the implementation of institutional controls to prevent the use of groundwater at the site, with MNA containing and slowly diminishing the plume. The site was delisted from the NPL in 2002, but monitoring is on-going because 1,2-DCP concentrations remain above the MCL.

The P\&T system diminished the plume, but reaching MCL for 1,2-DCP was not expected in a reasonable time. However, with a TI waiver that waived the drinking water standard ARAR to allow for long-term containment, transition to MNA was possible to control the plume. Transition to MNA was initiated with contaminant concentrations above the cleanup goals. Institutional controls were used to prevent exposures.

\section{Case Study Decision Element Summary}

\begin{tabular}{|l|l|}
\hline \multicolumn{1}{|c|}{ Decision Elements } & \multicolumn{1}{c|}{ Site-Specific Assessment } \\
\hline Contaminant concentrations and trends & $\begin{array}{l}\text { Plume declined with P\&T, but expect it will be difficult to } \\
\text { reach the MCL for 1,2-DCP }\end{array}$ \\
\hline $\begin{array}{l}\text { Contaminant mass discharge from source } \\
\text { areas or at selected plume locations }\end{array}$ & Not used \\
\hline The attenuation capacity of the aquifer & Not used \\
\hline $\begin{array}{l}\text { Estimated future plume behavior and } \\
\text { time to reach RAOs for the site }\end{array}$ & $\begin{array}{l}\text { MNA is predicted to control the plume, but with 1,2- DCP } \\
\text { above the MCL - Used a combination of TI waiver, ICs, } \\
\text { and MNA. }\end{array}$ \\
\hline $\begin{array}{l}\text { P\&T system design, operational, and } \\
\text { cost information }\end{array}$ & Not used \\
\hline
\end{tabular}

\section{Additional Information:}

The ROD amendment for the site is available at http://cumulis.epa.gov/superrods/index.cfm?fuseaction=data.rodinfo\&mRod=09009232000AMD113.

Dave Becker, U.S. Army Corps of Engineers Environmental and Munitions Center of Expertise 
PNNL-24696

\section{Distribution}

No. of

$\underline{\text { Copies }}$

\# Electronic Distribution

Department of Energy Richland Operations Office

JG Morse

(PDF)

US Army Corps of Engineers

DJ Becker
No. of

Copies

\# Electronic Distribution

Pacific Northwest National

Laboratory

MJ Truex

(PDF)

CD Johnson

(PDF)

MH Lee

(PDF)

DM Wellman

(PDF) 




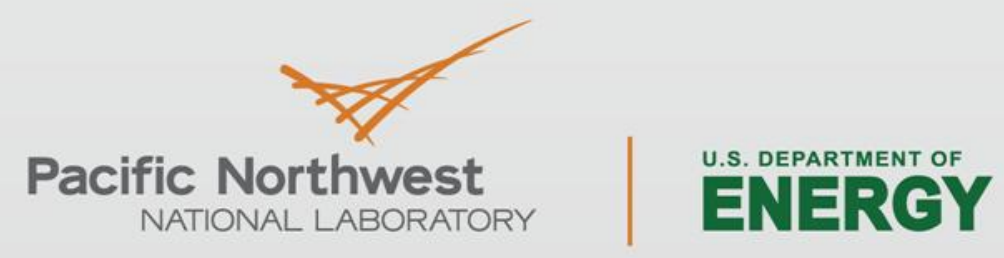

Proudly Operated by Battelle Since 1965

902 Battelle Boulevard

P.O. Box 999

Richland, WA 99352

1-888-375-PNNL (7665)

www.pnnl.gov 